\title{
Targeted Nanoparticles for the Treatment of Alzheimer's Disease
}

\author{
Rafael Martín-Rapún ${ }^{* a}$, Laura De Matteis ${ }^{\mathrm{a}}$, Alfredo Ambrosone ${ }^{\mathrm{b}}$, Sonia García-Embid ${ }^{\mathrm{b}}$, Lucía \\ Gutiérrez $z^{\mathrm{a}}$, Jesús M. de la Fuente ${ }^{*} \mathrm{bc}$
}

${ }^{a}$ Instituto de Nanociencia de Aragón (INA), Universidad de Zaragoza, 50018-Zaragoza, Spain. ${ }^{b}$ Instituto de Ciencia de Materiales de Aragón-CSIC/Universidad de Zaragoza, Zaragoza, Spain; 'Institute NanoBiomedicine and Engineering, Shanghai Jiao Tong University, Shanghai, P. R. China

\begin{abstract}
Research in Alzheimer's disease is increasing worldwide because of its dramatic impact on society and the healthcare costs it causes. Although many potential formulations are continuously evaluated, at present most of the available therapies are only symptomatic treatments. However, a number of therapeutic targets have been defined mainly related to two pathological hallmarks of Alzheimer's disease: first, the accumulation of amyloid $\beta$ peptide aggregates in the central nervous system (CNS) and, second, the presence of neurofibrillary tangles inside the neuronal cells. The therapeutic targets are located in the CNS, which limits the efficacy of drugs systemically administered: the blood brain barrier (BBB) selectively allows the permeation of just a few kinds of molecules from the systemic circulation to the CNS. On the other hand, local administration routes to CNS are highly invasive.

In recent years nanoparticles have been used as drug carriers to enhance the solubility, circulation time and bioavailability of all kind of drugs, also applied to Alzheimer's disease treatment. Moreover, nanoparticles have also been designed to cross the $\mathrm{BBB}$ or to use alternative administration routes to overcome it (i.e. intranasal administration), thus allowing the release of the drug cargo in CNS.

Herein the application of nanoparticles to enhance the targeting of drugs to the brain for Alzheimer treatment is reviewed. In most cases, the multivalency of nanoparticles in terms of the functionalization of their surface is reported to be crucial for the successful delivery of the drug. The carrier should be grafted with specific moieties to overpass the BBB and to direct an active molecule to a particular molecular target in the brain. In this sense nanotechnology-based approaches would help to avoid invasive administration and to increase the efficacy of less invasive treatments.
\end{abstract}

Keywords: Alzheimer's disease, nanoparticles, blood-brain barrier (BBB), central nervous system (CNS), drug delivery, targeted medicine, neurodegeneration

\section{INTRODUCTION}

Alzheimer's disease (AD) has been gaining more and more attention in the last decade due to the registered increase of dementia cases and the lack of success in finding effective treatments. No successful prevention strategy or therapy has been found up to now leading to AD ranking as 6 th cause of death in the United States $[1,2]$.

Dementia has recently been called 'twenty- first century plague' and considered as public health priority. World Health Organization 2012 report on dementia estimated that there were 35.6 million people living with dementia worldwide that year [3], while according to World Alzheimer Report (Alzheimer's Disease International) the estimation in 2015 had increased to 46.8 million people [4].

*Address correspondence to these authors at the Instituto de Nanociencia de Aragón (INA) Universidad de Zaragoza, Edificio I+D, 50018 Zaragoza (Spain); email: rmartin@unizar.es

Instituto de Ciencia de Materiales de Aragón-CSIC/Universidad de Zaragoza, Zaragoza, Spain; jmfuente@unizar.es
$\mathrm{AD}$ is the most common cause of dementia. It affects prevalently people older than 65 years, since younger onset dementia is a rare condition accounting for approximately $5 \%$ of all cases. In the world there are currently nearly 900 million people over 65 years old and due to the increase of the world population the frequency of dementia cases is expected to almost double by 2030 . Neither healthcare nor financial systems are prepared to face the magnitude of the situation [4].

Alzheimer's disease also affects familiar and social relationships with a devastating impact for caregivers, since they often suffer high emotional stress and depression that supposes significant additional health care costs [5].

About the geographic distribution of $\mathrm{AD}$, in World Alzheimer Report (ADI) for 2015 it was estimated that 80\% of all people with dementia live in the world's 20 richest countries [4]. According to statistics, in 2015, East Asia is the world region with the largest amount of people living with dementia ( 9.8 million), followed by Western Europe (7.4 million). These regions are closely followed by South Asia with 5.1 million and North America with 4.8 million. Taking into account the number of the statistics addressed, the need for effective therapies is dramatically evident. 
$\mathrm{AD}$ is a heterogenic, complex disorder characterized by a multiple impairment of physiological and cellular functions caused by genetic, epigenetic, and environmental factors. In 1906, Alois Alzheimer described for the first time distinctive plaques and neurofibrillary tangles in the brain of a 50-yearold woman presenting severe cognitive dysfunctions [6]. A more in-depth description of Alzheimer's disease and the distinction from dementia deriving from cerebrovascular anomalies was reported by Roth later in 1955 [7]. Aalten and coworkers identified four different sub-syndromes of neuropsychiatric symptoms of AD: hyperactivity (aggression, disinhibition, irritability, aberrant motor behavior and euphoria), psychosis (delusion, hallucination and sleep disorder), affectivity (depression and anxiety) and apathy (apathy and appetite disorder) [8]. The variability of neuropsychiatric symptoms has been also revised by Zhao and colleagues in a very recent statistical analysis [9].

Alzheimer's diagnosis is currently dependent in a large part on cognitive and functional assessments. In the first phase of the illness, mild cognitive impairment and shortterm and spatial memory deficits are the only symptoms, therefore most of the time they can be underestimated and an early diagnosis is not possible. AD diagnosis is especially difficult in the case of early-onset AD (EOAD), when the disease develops at an age under 65 years old. In this case $\mathrm{AD}$ is very often overlooked by health professionals due to its rare condition, about $5 \%$ of all $\mathrm{AD}$ cases. Symptoms may be incorrectly attributed to stress or there may be conflicting diagnoses from different health care professionals.

EOAD is also referred as familial $\mathrm{AD}$ as it is caused by very rare, penetrant and deterministic mutations in genes coding for amyloid precursor protein (APP); for presenilins 1 and 2 (PSN1 and PSN2), which are basic components of the amyloid beta $(\mathrm{A} \beta)$ cleaving $\gamma$-secretases; and, for alpha- 2 macroglobulin $[10,11]$. On the other hand, late-onset $A D$ (LOAD) is age-related ( $\geq 65$ years) and associated to diverse risk factors including epigenetic alterations, environment, ageing and genetics $[12,13]$. In this respect, one of the best established risk factors in LOAD is the presence of $\varepsilon 4$ isoform of $\mathrm{A} \beta$ transporter apolipoprotein $\mathrm{E}$ (ApoE) [14]. Individuals carrying both alleles of APOE $\varepsilon 4$ gene have a $50 \%$ greater probability of developing the disease.

Interestingly the deterministic and risk genes involved in $\mathrm{AD}$ are mostly related to the production and transport of $\mathrm{A} \beta$ peptides. Consistently, one of the two major pathological hallmarks of $\mathrm{AD}$ is the accumulation of $\mathrm{A} \beta$ peptides in the brain parenchyma forming amyloid plaques outside and around neurons, and in the walls of small brain arteries. The other is the formation of intracellular neurofibrillary tangles, pathological aggregates of hyperphosphorylated microtubule-associated tau protein [15-18]. Besides these lesions, a strong oxidative stress and a pathological dysfunction associated to brain blood barrier (BBB) permeability often concur to generate synaptic damages and neuronal loss.

The complete molecular network contributing to the neuronal and synaptic loss behind the clinical features of $\mathrm{AD}$ appears intricate and has not been elucidated yet [19]. Long standing amyloid cascade hypothesis $[20,21]$ situates the accumulation of $\mathrm{A} \beta$ peptides as the initial factor for $\mathrm{AD}$ which would unleash the hyperphosphorylation of tau proteins and finally, neuronal dysfunction and death. That hypothesis is currently under question, but clearly those two pathological lesions play an important role in $\mathrm{AD}$ along with other alterations [19, 22]. Following we will separately describe the main issues related to $\mathrm{AD}$ along with the potential targets for $\mathrm{AD}$ therapies.

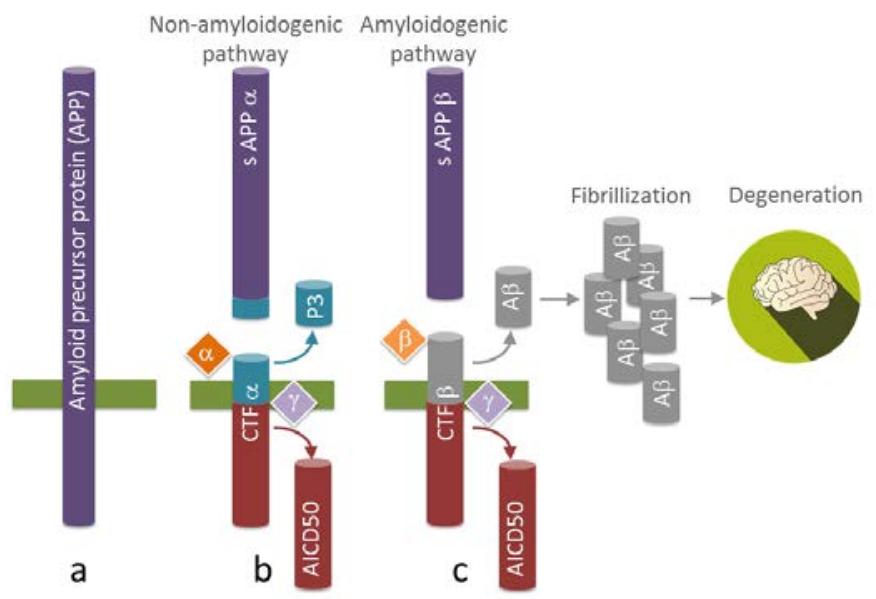

Figure 1. APP (a) can be cleaved by $\alpha$-secretase within the amyloid sequences (blue) (b), or by $\beta$-site APP cleaving enzyme (BACE), which cleaves APP in the extracellular space at the $\beta$-site (c). Overall, these enzymatic reactions generate two large soluble ectodomains, termed sAPP $\alpha$ and sAPP $\beta$, respectively. sAPP $\alpha$ is considered the precursor of the so-called nonamyloidogenic pathway, while the sAPP $\beta$ concurs to initiate the amyloidogenic one (pathogenic). In particular, subsequent processing of the carboxy-terminal fragments (CTFs) of sAPP $\beta$ by $\gamma$-secretase results in the production of $A \beta$ and the APP intracellular domain (AICD). $\gamma$-secretase-mediated cleavage is slightly imprecise and generates $\mathrm{C}$-terminal heterogeneity of $\mathrm{A} \beta$ peptide lengths [23].

\section{PATHOLOGICAL HALLMARKS OF AD}

\subsection{Deposition of the $A \beta$ peptides}

$A \beta$ peptides are highly fibrillogenic peptides, which give rise to oligomeric species and plaques that accumulate in the brain of patients of $\mathrm{AD}$ and of other cognitive disorders such as Down's syndrome. From all the forms of aggregation of $\mathrm{A} \beta$ peptides, the soluble oligomers seem to be the most toxic ones due to their ability for triggering pathological responses in cells by interacting with their membranes.

Physiologically speaking, $A \beta$ are secreted peptides, prevalently anabolized and catabolized in the brain at relatively low levels. They originate from a sequential cleavage of amyloid precursor protein (APP) mediated by membrane-bound endoproteases, namely $\beta$ - and $\gamma$-secretases [23-25]. APP is a member of a single-pass transmembrane protein family, presenting a large extracellular domain and a short cytoplasmic tail (Figure 1). APP biological function is still object of debate and remains largely undefined. However, the most likely hypotheses suggest that APP may 
play a role in cell and synaptic adhesion, synaptic pruning, cell signaling and apoptosis [26]. Conversely, the APP metabolism mediated by secretases, the fate of APP-derived fragments and the deposition of $A \beta$ peptides are much better understood. Basically two distinct pathways (amyloidogenic and non-amyloidogenic) have been described as schematically reported in Figure 1 [23-25].

The amyloidogenic pathway originates from the consecutive action of beta-site APP cleaving enzyme ( $\beta$ secretase, BACE) and $\gamma$-secretase. $\gamma$-secretase catalyses last cleavages and generates the $C$-terminus of $A \beta$ peptides. Its action produces a large repertoire of fragments with diverse tendency to form deposits [23]. Among the $\mathrm{A} \beta$ species, the 40-residue (A $\beta 40)$ is the most abundant peptide ( $~ 80-90 \%)$, followed by 42 -residue fragment (A $\beta 42, \sim 5-10 \%)$ and even longer variants, less abundant, but still pathogenic. The A $\beta 42$ species is more hydrophobic and fibrillogenic than A $\beta 40$, thus contributing prominently to extracellular plaque formation. From the structural point of view, $\gamma$-secretase is a multiprotein complex with a catalytic core consisting of presenilin 1 (PS1) or presenilin 2 (PS2), whose coding genes are involved in EOAD.

On the basis of current knowledge, it appears clear that both $\beta$ - and $\gamma$-secretases are key players in $A \beta$ production and deposition, suggesting that regulating their enzymatic activities in the brain may be beneficial against AD. Not surprisingly, BACE and $\gamma$-secretases have become object of an intense research aimed at reducing $A \beta$ production [27].

$\mathrm{A} \beta$ peptides accumulation and subsequent aggregation are consequences of an imbalance between their production, and their clearance from the brain [28]. Production of $A \beta$ peptides has been treated above. Their clearance occurs through BBB and also by cellular mechanisms. Influx and efflux of $A \beta$ are receptor-mediated and their dynamics are described below, in the frame of the dysfunctions of $\mathrm{BBB}$ associated to $\mathrm{AD}$.

Likewise receptor dynamics, $A \beta$ transport and removal matter. Apolipoprotein E (ApoE) is a key protein involved in $\mathrm{A} \beta$ clearance [29]. ApoE mediates the transport of lipids, cholesterol and other hydrophobic molecules, including amyloid $\beta(\mathrm{A} \beta)$. In 1991, Namba and colleagues reported the first evidences that ApoE was co-deposited in senile plaques in the brains of $\mathrm{AD}$ patients [30]. Genetic findings confirmed that the highly polymorphic ApoE gene is an important risk factor in $\mathrm{AD}[14,31]$.

How and to what extent ApoE isoforms differentially contribute to $A \beta$ aggregation, transport and clearance in the brain is still debated. In fact, data from in vitro and in vivo studies as well as those coming from clinical observations are tremendously conflicting. Recent findings show that ApoE4 is less efficient in $A \beta$ clearance than is ApoE3 in transgenic mouse models of $A \beta$-amyloidosis [32]. ApoE might control, in an isoform-specific way, $A \beta$ removal from the brain to the systemic circulation through the blood-brain barrier [29]. All these scientific evidences suggest that developing treatments directed toward ApoE could represent an interesting therapeutic strategy against $\mathrm{AD}$ [33].

Finally, increasing evidences strongly support the hypothesis that $A \beta$ accumulation may be also debited to dysfunction in the cellular mechanisms for $A \beta$ clearance. In ' 90 s many scientific findings demonstrated the relationship between lysosomal dysfunction and morphology in $\mathrm{AD}$, suggesting that lysosomal defects may be the earliest histological change in this pathology [34].

The role of transcription factor TFEB in AD has been recently investigated as well. TFEB is the master regulator of lysosomal biogenesis [35]. Viral gene transfer of TFEB in neurons of APP/PS1 mouse model of AD accelerated lysosomal degradation of endocytosed APP, which reduced the steady-state levels of APP and in turn decreased both the interstitial fluid $A \beta$ levels and amyloid deposits [36].

\subsection{Neurofibrillary tangle formation}

The second pathological abnormality in $\mathrm{AD}$ brain is the presence of intracellular neurofibrillary tangles (NFTs) formed by filaments of hyperphosphorylated microtubuleassociated protein tau (MAPT), which impair severely the microtubule functions and lead to the collapse of cytoskeleton. Interestingly, tau behaves as a natively unfolded protein or intrinsically disordered protein, lacking significant amounts of secondary structure in the longest isoform. This means that this protein is highly flexible and may have variable conformations [37]. Tau protein consists of an N-terminal acidic region followed by a proline-rich region and a $\mathrm{C}$-terminal basic portion. Tau anchors to the microtubule through a repeated domain at $\mathrm{C}$-terminal, while the N-terminal part projects from the microtubule surface creating an active interface for further interactions with other cytoskeletal elements and neuronal plasma membrane components (Figure 2) [38].

Genetic evidences show that mutations in tau gene in familial frontotemporal dementia and Parkinson linked to chromosome 17 (FTDP-17) cause neurodegeneration and dementia [39]. Interestingly, the FTDP-17 mutations appear to alter conformation of tau protein making it more prone for subsequent phosphorylation mediated by brain protein kinases [40].

The abnormal hyperphosphorylation of tau is recurrent in $\mathrm{AD}$ and other related neurodegenerative disorders (taupathies). When tau becomes hyperphosphorylated dissociates from the microtubules and accumulates as insoluble fibrils, finally forming NFTs (Figure 2).

The presence of aberrant tau proteins could affect the function of microtubules [41]. In neurons, microtubules are involved in cell architecture and form dynamic structures along which organelles and functional information are shuttled. Therefore, cytoskeleton dysfunction in neuronal cells definitely prejudices their normal functions. At the onset of $\mathrm{AD}$, intraneuronal NFTs are confined to distinct brain districts. Afterwards, spreading effects have been largely correlated to disease progression, suggesting that NFTs contribute to synaptic deficits and irreversible neuronal loss in AD. As tau cytoplasmic levels notably increase after hyperphosphorylation, it occurs that tau also aberrantly interacts with a plethora of cellular proteins, further perturbing cell homeostasis. Aberrant hyperphosphorylation can be debited to abnormal activity of tau kinases and phosphatases as well. Glycogen synthase 
kinase $3 \beta$ (GSK-3 $\beta$ or Tau kinase 1) cyclin-dependent kinase 5 (cdk5), cAMP-dependent protein kinase (PKA), and calcium/calmodulin-dependent kinase II (CaMK-II) are the most important kinases involved in tau phosphorylation [42, 43].

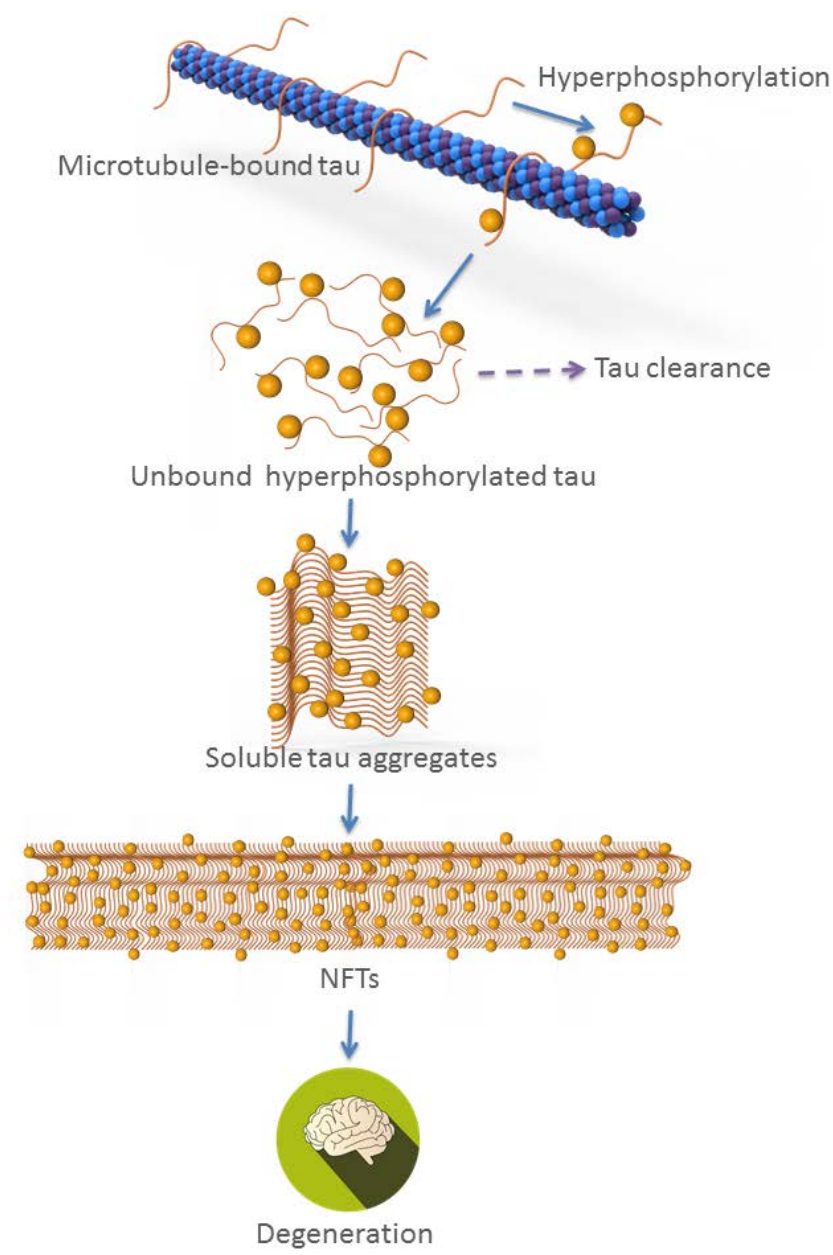

Figure 2. Tau is a microtubule-associated protein able to bind the interface between tubulin hetero-dimers promoting microtubule assembly and stabilization in the brain. Hyperphosphorilation of Tau inhibits its binding to microtubules and induces self-aggregation of tau into filaments. Neurofibrillary tangles (NFTs) are widely associated to neurodegeneration.

\subsection{Dysfunction of the blood brain barrier}

A rich network of blood vessels nourishes the brain. Therein, the circulating blood is separated from the extracellular fluid in the central nervous system (CNS) by a highly selectively permeable barrier, the blood brain barrier (BBB), which is formed by brain endothelial cells connected by tight junctions. The main function of $\mathrm{BBB}$ is the selective control of fluid and biomolecule exchange between the CNS and the systemic circulation. The tight packing of brain endothelial cells restricts the diffusion of large and/or hydrophilic entities into the CNS while allowing the diffusion of small and/or lipophilic substances. Other substances that are needed by CNS are allowed through the BBB by active receptor-mediated transport [44].

Many evidences relate neurodegenerative diseases with alterations of the normal functionality of the BBB or its integrity. Changes in a number of transport pathways could be involved, including transcellular transport (receptormediated and adsorptive transcytosis) [45]. In particular, in the case of transcytosis transport, only the transport through the basal or apical membrane could be affected, determining a condition of imbalance. In Alzheimer's disease affected brains, some important transport carriers or receptors show physiopathological changes. In particular, the neurovascular hypothesis has been proposed as a mechanism of pathogenic cascades for $\mathrm{AD}[17,46]$. Up to now, it is still unclear whether the neurovascular alterations reported in $\mathrm{AD}$ patients are the cause or the effect in the disease process. However it is proven that there is a relationship between neurovascular changes and disease progression associated with neuronal dysfunction [17].

Impaired vascular clearance of $\mathrm{A} \beta$ across the $\mathrm{BBB}$ increases its capillary deposition and the formation of amyloid lesions [15, 47]. Overall, influx of $A \beta$ peptides into the brain across the BBB occurs prevalently through the receptor for advanced glycation end products (RAGE), while their clearance across the BBB is mediated mainly by the low-density lipoprotein receptor related protein-1 (LRP1) $[47,48]$. RAGE receptor is significantly overexpressed in hippocampus and inferior frontal cortex of AD patients with respect to non-demented controls. Not least, RAGE proteins levels positively correlated with the severity of the $\mathrm{AD}$ pathology [49].

Concerning the clearance of $A \beta$ from the brain, lipoprotein receptor has been reported to serve as a receptor for $A \beta$ precursor protein (APP) and apolipoprotein $E$ (ApoE). Also soluble $\mathrm{A} \beta$ can be transferred by $\mathrm{BBB}$ endothelial cells from the brain to the blood, by LRP1 binding to $A \beta$ at the ablumenal (brain) side of the BBB followed by transcytosis. $[15,50]$. Soluble oligomers and intermediate amyloids of $\mathrm{A} \beta$ are reported to be more neurotoxic than monomers and fibrils since they can interact with cell membrane, thus creating serious neuronal damages [17]. Levels of LRP are strictly related with age so it is considered a major risk factor for non-familial AD [45, 47].

Permeability glycoprotein (P-gp) transporters are efflux transporters in the $\mathrm{BBB}$ that are responsible for the expulsion of toxins from brain to blood. Changes in the expression of this transporter have been described for different neuropathologies. In the case of Alzheimer's disease the decrease in P-gp expression has been found to be associated with the increase in the deposition of $A \beta$ neurofibrils $[45,51$, 52].

Receptor-mediated transcytosis (RMT) is also highly affected in patients suffering from Alzheimer's disease. Among the receptors involved in the case of $\mathrm{AD}$, there are transferrin-receptor (TfR), insulin-receptor and lipoproteinreceptor. The role of TfR is the movement of transferrinbound iron through the brain capillary endothelial cells by transcytosis. In $\mathrm{AD}$ affected brains, an alteration of the expression of the receptor is reported in the hippocampus. $[45,53]$. It has been also reported that $A \beta$ neurofibrils can 
compete with insulin for the receptor causing severe imbalances in glucose metabolism in neuropathologic condition [45].

Talking about pathological changes registered in BBB functionality in Alzheimer's disease, some issues should be considered, as the possibility to take advantage of this particular condition to deliver drugs that would not be allowed through the barrier in a normal condition, which could represent a chance to find possibly more effective therapies. However in patients suffering from $\mathrm{AD}$, the more severe are the changes in $\mathrm{BBB}$, the higher the neurodegenerative level is from a cognitive point of view. So it becomes difficult to evaluate if the possibility of drug delivery offered by BBB alterations could be considered an advantage to treat the disease or if trying first to restore BBB integrity should be a priority to avoid any increase in the rate of degeneration [45].

\subsection{Oxidative stress and inflammatory processes}

There is overwhelming evidence that oxidative stress, inflammation and metal accumulation contribute to $\mathrm{AD}$ etiology and progression.

During the age-related neurodegeneration and cognitive decline, brain tissue is constantly exposed to oxidative stress characterized by an imbalance in reactive oxygen species (ROS) production and antioxidative defense. Detrimental effects of oxygen radicals have been widely reported in neurons of $\mathrm{AD}$ brains including DNA damages, lipid peroxidation, protein oxidation, formation of advanced glycation end products (AGEs), carbonyl-modified neurofilament proteins and free carbonyls. As clinically proved, markers of oxidative stress are significantly higher in $\mathrm{AD}$ patients and oxidative DNA damage of neurons and glia is now accepted as one of the earliest observable events in Alzheimer's pathogenesis [54, 55]. Zawia and coworkers proposed in 2009 that the formation of stretches of methylated and oxidized cytosine-guanine sites can represent signals potentially relevant in Alzheimer's disease physiopathology [56]. Oxidized guanosine form 8-oxo-G, which is one of the most common oxidative DNA damage biomarkers, can be found often associated with cytosine methylation. Moreover the authors proposed that the accumulation of $A \beta$-precursor-proteins and $A \beta$ peptides can increase in response to early life exposure to specific stimuli, such as xenobiotic metals [56, 57].

High levels of poly-unsaturated fatty acids and elevated consume of oxygen make the brain an ideal site of lipid peroxidation. Indeed, lipid peroxidation is one of the major sources of free radical-mediated injury of neuronal membranes. A significant number of oxidative breakdown products including 4-hydroxy-2,3-nonenal (HNE), acrolein, malondialdehyde and F2-isoprostanes have been observed in AD brains compared to age-matched controls [58]. These cytotoxic metabolites of lipid peroxidation can modify the redox state and the function of proteins involved in energy metabolism, cellular signaling, $\mathrm{pH}$ regulation, neuronal communication, neurotransmitter regulation, tau hyperphosphorylation, and APP processing, thus producing severe changes in neuronal homeostasis [59].
Although a direct role for mitochondria in $\mathrm{AD}$ pathogenesis is still controversial, some evidences indicate that mitochondrial dysfunctions may be a trigger for $\mathrm{AD}$. For instance, observed reduction in brain energy metabolism [60] and mitochondrial metabolic enzyme deficiency [61, 62] have been related with $\mathrm{AD}$. In particular, $\mathrm{A} \beta 42$ has been identified in mitochondria where it binds to $17-\beta-$ hydroxysteroid dehydrogenase, a mitochondrial matrix protein involved in fatty acid metabolism. Moreover it was observed that it inhibits respiratory chain function in isolated rat brain mitochondria [63]. Morphometric and ultrastuctural analysis of $\mathrm{AD}$ brains showed drastic alterations in mitochondrial dynamics and morphology such as reduced number, increased size and broken internal membrane cristae, which were found accompanied by an oxidative damage marked by 8 -hydroxyguanosine and nitrotyrosine $[64,65]$.

Alzheimer disease pathophysiology seems to be linked also to inflammatory processes in the brain. Neuroinflammation elicited by environmental and genetic factors might cause microglial activation, astrogliosis, as well as the production of inflammatory cytokines, reactive oxygen species, nitric oxide, glutamate and by-products of COX-2 reactions [66].

Interestingly, activated microglia (the brain-resident immune cells) was found surrounding lesions in Alzheimer's disease and also massive production of pro-inflammatory cytokines has been associated to neurodegenerative condition [67]. It has been hypothesized that a switch in the microglia cells phenotype could accelerate at some point the progression of the disease. In the earliest phases of the disease the anti-inflammatory M2 phenotype (characterised by secretion of the anti- inflammatory cytokines interleukin 4 , interleukin 10 , interleukin 13 , and TGF- $\beta$, and increased phagocytic capacity without production of toxic nitric oxide) is activated trying to clear amyloid and protect neurons. When M2 microglia is not quick enough to compensate the excessive expression of $A \beta$ in the illness, a switch to the proinflammatory M1 phenotype, promoted by the uncontrolled $\mathrm{A} \beta$ accumulation, would lead to fatal neuron damage. [6871].

Also pathologic astrocytes can be recognized in $\mathrm{AD}$ and other neurodegenerative diseases. Like M2 microglia phenotype, astrocytes are involved in $\mathrm{A} \beta$ clearance and degradation. In $\mathrm{AD}$ patients it has been observed $\mathrm{A} \beta 1-42$ accumulation in astrocytes in the enthorinal cortex [68-72].

Several studies have also associated Alzheimer disease to a dysregulation of metal homeostasis leading to their abnormal accumulation into the brain of patients [73-75]. Besides the redox toxicity associated with the metal imbalance in the brain, it seems that their presence in the $\mathrm{AD}$ brain may contribute to $A \beta$ plaque formation $[76,77]$. In 1994, Bush and co-workers reported that $\mathrm{A} \beta$ becomes amyloidogenic upon reaction with stoichiometric amounts of $\mathrm{Zn}^{2+}$ and $\mathrm{Cu}^{2+}[78,79]$.). Metal ions dysregulation in $\mathrm{AD}$ is also an important aspect since it seems to directly affect oxidative stress, mitochondrial dysfunction, neuroinflammation, $A \beta$ plaque formation and tau aggregation [80]. 


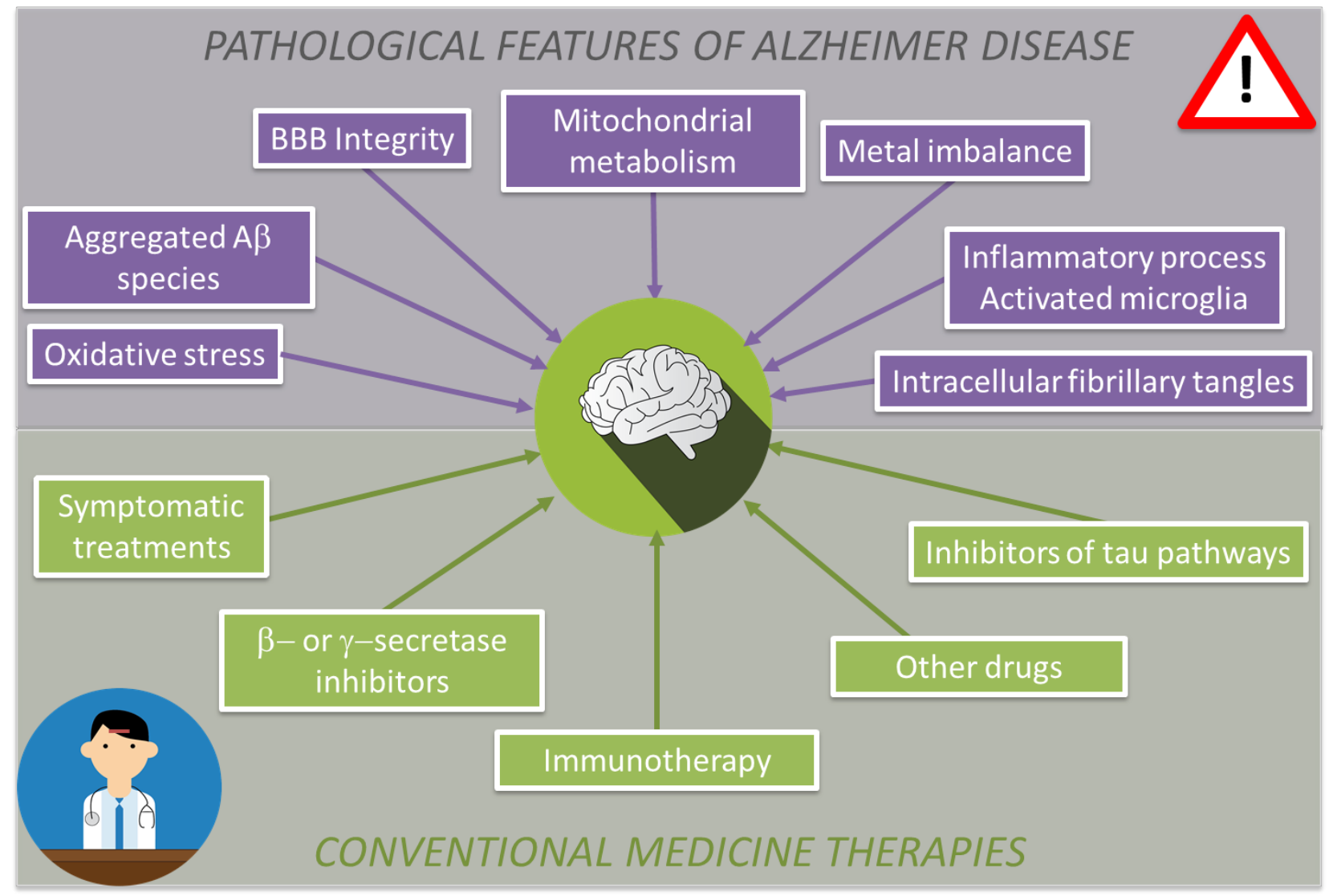

Figure 3. Overview of the main pathological features of Alzheimer's disease and the major groups of therapeutics explored to date

It has been reported by Urrutia and co-workers that the three hallmarks of neurodegeneration just described (mitochondrial dysfunction, metal accumulation and neuroinflammation) could be involved together in a synergistic self-feeding cycle ending in apoptotic cell death [67].

\section{THERAPEUTICS AGAINST AD}

Although many drugs are continuously in the testing phases for $\mathrm{AD}$, no new drugs have been approved in EU and USA for the healing or prevention treatment in almost 15 years (Figure 3). Up to now, only symptomatic treatments exist for AD. Unfortunately they act only for a limited time, mainly in the first phases of the illness, to delay as much as possible the loss of cognitive abilities of the patients. These treatments in the market consist mostly of cholinesterase inhibitors such as donepezil (Aricept; Eisai/Pfizer), rivastigmine (Exelon; Novartis), galantamine (Razadyne; Johnson \& Johnson) and tacrine (Cognex; First Horizon Pharmaceuticals), and the N-methyl-D-aspartate (NMDA)receptor modulator memantine (Namenda; Forest/Lundbeck) $[13,81]$.
Last research frontiers, hopes and major issues on $\mathrm{AD}$ pharmacologic treatments are described in some very recent reviews $[13,82]$.

Up to now, most of the industry's research efforts have been focused on the 'amyloid hypothesis' and associated targets. Several novel strategies have begun to target directly/indirectly the accumulation of $\mathrm{A} \beta$ deposits through the use of monoclonal antibodies, antigens, beta and gamma secretase inhibitors [83], and anti-amyloid aggregation compounds. The inhibition of $\gamma$-secretase or BACE1 is one of the most important fronts for $\mathrm{AD}$ treatment and/or prevention. The secretase inhibition represents an upstream interference with the amyloid cascade, regardless of $A \beta$ species or aggregation states exerting neurotoxicity.

Among the new BACE1 inhibitors under active development are the small molecules MK-8931 (Merck), AZD3293 (AstraZeneca/Lilly), E2609 (Eisai/Biogen), and JNJ 54869111 (Janssen). These new compounds are aiming at finding the answers that their predecessors could not, since several gamma secretase inhibitors such as semagacestat (Lilly), begacestat (Pfizer), and avagacestat (Bristol-Myers Squibb) all failed in clinical studies and were consequently 
discontinued. These drugs exhibited a great potential in reducing $\mathrm{A} \beta$ in vitro and in vivo, but also leaded to a harmful crosstalk with Notch pathway (semagacestat) [84, 85], or to a progress to dementia at similar rates as patients on placebo in clinical studies (avagacestat).

More recently monoclonal antibodies, such as bapineuzumab and solanezumab, were developed for the prevention of sporadic $\mathrm{AD}$ by targeting $\mathrm{A} \beta$ peptide species $[13,86]$. In contrast to bapineuzumab, solanezumab recognizes soluble monomeric $A \beta$, not fibrillary. It might sequester soluble $A \beta$, shifting equilibrium between different species of $A \beta$, and removing small soluble species of $A \beta$ that are directly toxic to synaptic function.

Another front for the development of new therapies for AD treatment takes into account the possibility of inhibiting the tau pathways, in particular kinases responsible for tau phosphorylation. Such novel studies showed promising starts, in particular with compounds such as valproate, lithium [87, 88] and Methylene blue. Other innovative efforts have also begun in the development of anti-tau vaccines [13].Worth of mention is the study on Methylene Blue due to its promising perspectives until very recently. The compound was shown to reduce tau aggression in transgenic mice. TauRx Pharmaceuticals finished phase II clinical trials [89]. Unfortunately the results of phase III clinical trials disclosed in July 2016 showed that it failed to slow the cognitive and functional decline of Alzheimer's patients compared with a control.

Immunotherapeutic strategies for $\mathrm{AD}$ have been proposed also in the case of tau dysfunction. In particular, successful in vivo approaches have been exploited to target selectively phosphorylated tau species such as phosphoSer396/phospho-Ser404 [90, 91], or abnormally phosphorylated tau species such as phospho-Ser422 [92]. Overall, tau immunotherapy reduced brain pathology and prevented cognitive decline in mouse models.

Clearance of aberrant tau appears to be a valid defence system to prevent neurotoxicity in tauopathies. To this aim, the involvement of the ubiquitin proteosomal system (UPS) in the degradation of hyperphosphorylated tau has been documented [93]. Very recently, Polito and colleagues have reported promising results in tau clearance in AD [94]. They demonstrated that TFEB overexpression considerably reduces neurofibrillary tangle pathology and rescues behavioral and synaptic deficits and neurodegeneration in AD mouse model of tauopathy.

Due to the lack of a standard treatment for Alzheimer's disease, also various drugs of common use have been proposed for its prevention, taking into account the illness physiopathology and the risk factors currently considered for AD. Among them there are antihypertensive drugs, hormone replacement therapy (HRT), non-steroidal anti-inflammatory drugs (NSAIDs), HMG-CoA reductase inhibitors (statins), and antidiabetic drugs. Unfortunately, up to now, the effectiveness of these drugs on prevention of AD still has to be demonstrated [82]. However, it has been experimentally proved that non-steroidal anti-inflammatory drugs (NSAIDs) significantly lower the $A \beta$ levels. Worth of note, a recent meta-analysis, aiming to unravel the significant correlations between the anti-inflammatory drugs consumes and the risk of Alzheimer's disease, supports the medically-assisted use of NSAIDs for prevention of AD [95].

It is also interesting to note that for most of the considered targets of the illness, intervening at the dementia stage may be too late. The treatment, particularly antiamyloid therapies, could possibly lead to better results if initiated earlier in the disease process. The study of such possibility has been hampered in last years due to the lack of diagnostic techniques sensitive enough. With recent advances in biomarker and imaging techniques it is now possible to identify cognitively normal individuals with evidence of brain amyloid, for example, often considered to have 'preclinical' or 'asymptomatic' AD [96]. These techniques open the way to test early intervention strategies in the very early stages of the illness (pre-dementia).

Finally, prevention is also an issue of major importance in the case of $\mathrm{AD}$ since most of the physiologic modifications due to the illness seem to be very difficult to reverse.

\section{BBB AND ADMINISTRATION ROUTES TO CNS}

One of the main difficulties that lead to unsuccessful treatments is the complicated drug delivery to the brain, mostly because of the presence of the blood brain barrier [97]. In spite of the efforts on research in the last decades, crossing the BBB still remains a challenge in the development of efficient systems (based on nanotechnology or not) to deliver drugs for neurodegenerative diseases treatment.

BBB is formed by a complex system of different cell types (endothelial cells, astroglia, pericytes, perivascular macrophages, and a basal lamina). One of the major functions of the barrier, together with the blood cerebrospinal fluid barrier, is to prevent the contact between the brain and toxic substances. In fact, $98 \%$ of all small molecules do not cross the BBB [98].

This function of limiting the entrance of substances into the brain is possible thanks to tight junctions, very intimate cell-to-cell connections forming the so called zonula occludens, especially diffused in brain endothelia [50].

Only small liposoluble molecules $(<400 \mathrm{Da}$, with less than nine hydrogen bonds) can cross the BBB unassisted, via lipid-mediated diffusion. Such passive transport of small molecules through biological membranes requires their movement through the lipid bilayer. On the contrary, hydrophilic molecules can only cross the endothelial wall transcellularly. Transcellular bidirectional transport across the BBB can be classified into five main categories: carriermediated transport, ion transport, active efflux transport, receptor-mediated transport, and caveolae-mediated transport $[50,98]$.

At present, the efficacy of treatments directed to the brain is strictly dependent on the administration route. Due to the previously mentioned limitations related to the presence of the blood brain barrier, usually the intra-venous and oral administration routes are not effective. By using invasive methods of administration like the temporal disruption of the BBB integrity [99], intracerebroventricular infusion [100] or intracerebral implants, the drug can be administered directly 
into the brain tissue, overcoming the BBB. Nevertheless these methods are not convenient for use in humans for several reasons, including safety and costs [101, 102].

Among the invasive administration routes, brain infusion is one of the most commonly used in the case of brain illnesses [103]. This method consists in the local administration of the drug through direct injection into the brain using a catheter that could be stereotactically targeted to precise anatomical locations. The application of such methods is obviously limited, but still remains as the ultimate option in the case where physiological barriers substantially impair the effectiveness of any other delivery route [103].

A non-invasive route for brain drug delivery is the intranasal administration via the olfactory and trigeminal neural pathways $[104,105]$. The intranasal administration allows delivering therapeutic agents preferentially to the brain since both the olfactory and trigeminal nerves innervate the nasal cavity, providing a direct connection with the CNS. This route of administration has been shown to present a safe and acceptable alternative to parenteral administration of various drugs [106, 107].

\section{NANOTECHNOLOGY: A VALUABLE TOOL FOR FUTURE MEDICINE}

Nanotechnology is a very modern science that is devoted to the study and understanding of matter at the scale between 1 and $100 \mathrm{~nm}$. The general properties of a material at the nanoscale could be very different from the properties of the same bulk material. This concept has been widely proven in the case of inorganic nanoparticles, as for example iron oxide nanoparticles [108].

At present, most of the applications based on nanosized materials in biomedicine can be addressed to nanoparticles. The importance of nanoparticles in medicine lies in the fact that most biochemical and biological mechanisms in the human body occur at the nanoscale and the same macrobiomolecules involved in such processes possess a nanoscaled size. From this point of view, nanoparticles can be a solid support for the delivery of different molecules and macromolecules for therapies or diagnosis (almost all of them) or, depending on the properties of the material, can be themselves the therapeutic or diagnostic agent (mostly magnetic and plasmonic nanoparticles) $[109,110]$. In this review we will take into consideration the application of nanoparticles for therapy, especially drug delivery systems with specific targeting.

The use of nanometric-sized particles as carriers seems very promising because of the protection and stabilizing effect that they can offer to the associated drug, and also for improving drug efficacy through enhanced delivery or residence time. The association of the drug with a nanocarrier can help reducing potential side-effects by decreasing the dose of the drug in other tissues and increasing the amount of drug at the desired target site.

\subsection{Nanoparticles and Alzheimer' disease}

Innovative drug delivery systems able to pass the BBB have been considered during the last 10 years as a strategic alternative approach for the development of treatments for neurodegenerative diseases, such as AD. As previously described, in the frame of Alzheimer's disease, finding an effective therapy could be strictly related to increase the solubility of already tested molecules or to improve their ability to cross the BBB. An appropriate nanocarrier could help in achieving both goals. Nanoparticles of different nature, size and shape have already been tested as drug delivery systems, most of them being already proved as able to cross BBB [111].

Generally speaking, nanoparticles are usually classified as inorganic (metallic, metal oxide and ceramic particles) and organic (lipidic and polymeric particles) (Figure 4).

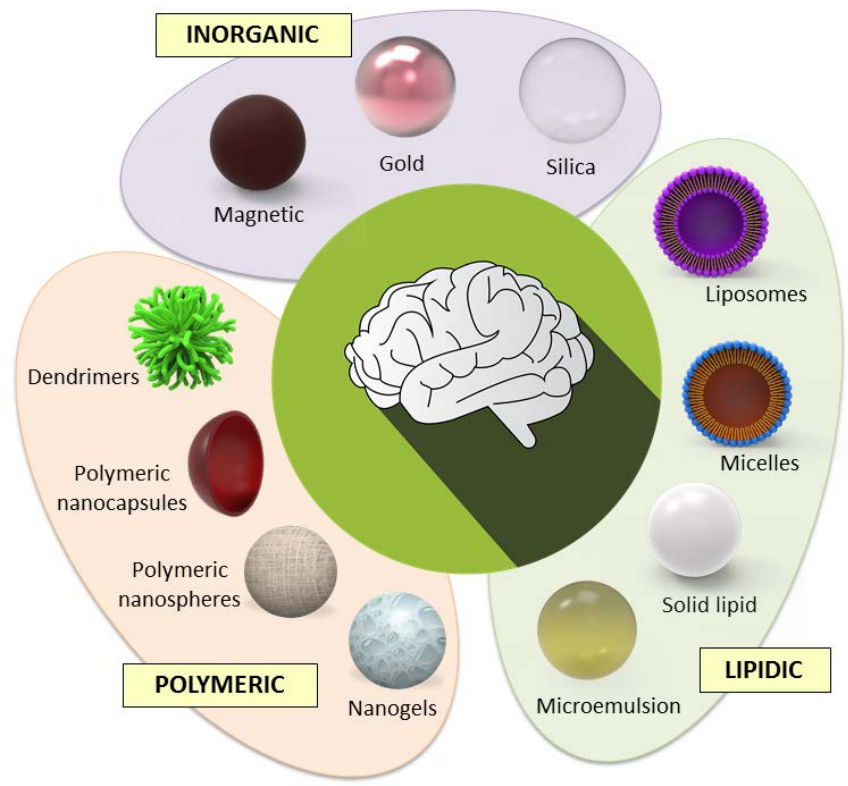

Figure 4. Main kinds of nanoparticles used in research of new therapies for Alzheimer's disease.

Among the inorganic particles, especially magnetic and gold nanoparticles are widely used in nanomedicine, both for diagnosis and treatment. In the case of magnetic nanoparticles, they offer the opportunity for magnetic delivery of drugs, which would be ideally directed straight to the affected tissue under the action of a magnetic field. Both magnetic and gold nanoparticles can be used as therapeutic agents in (magnetic and optical) hyperthermia-based treatments.

Among magnetic materials, iron oxide is the most commonly used in biomedical applications because of its biodegradable nature, biocompatibility, and its superparamagnetic properties. At present a variety of iron oxide nanoparticles of different size are used for biomedical purposes [112-116].

The use of iron oxide nanoparticles as novel carriers for drug delivery for neurodegenerative diseases has been reported in the literature [117]. They have been also tested for the destruction of amyloid plaques using an alternate magnetic field (magnetic hyperthermia) and up to now very promising results have been obtained in vitro [118]. Moreover a recent work reviewed their use as contrast agents for magnetic resonance imaging (MRI) to detect amyloid $\beta$ peptide inside the brain [119]. In some cases it has been reported that magnetic nanoparticles were not able to cross 
the $\mathrm{BBB}$ to reach their target in the brain. However this limitation can be bypassed modifying their surface with appropriate compatible molecules [119].

Gold nanoparticles have possibly reached even a wider application thanks to the reproducibility and easiness of their synthesis and also due to the possibility to tune their size and shape to obtain different optical properties [120]. Nearinfrared light is known to penetrate deep into biological tissues without causing ionizing damage. If gold nanoparticles with appropriate properties have penetrated into a tumor or other target tissue and a near infrared laser is applied on them, the particles will heat up and destroy surrounding cells in a process known as "photothermal ablation" $[120,121]$. This therapy is raising attention as a promising strategy for light-induced destruction of $A \beta$ fibrils. However, also the ability of gold nanoparticles themselves to cross the BBB seems to be not completely clear. It is reported that gold nanospheres can be used successfully as BBB-crossing vehicles [122]. On the contrary, another recent study by Yin and co-workers showed that the BBB crossing of gold nanostars was only possible through their association with a cell penetrating peptide [123]. Finally gold nanoparticles have been used also as a detection tool for $\mathrm{A} \beta$ peptide detection based on their aggregation in presence of copper ions [124].

Worth of mention are also silica particles that have been widely studied in the nanotechnology research for diverse applications due to their versatile and flexible fabrication methods. Silica particles properties can be tuned to obtain different porosity of the material at the nanoscale, which allows their use as potential reservoirs for therapeutics or diagnostic agents to effectively operate as drug delivery systems [121]. Silica-based nanoparticles have been also tested for the treatment of neurodegenerative diseases [125, 126].

Most organic nanoparticles are at present widely tested for biomedical application due to their high biocompatibility and biodegradability. Lipidic nanoparticles include micellebased systems, liposomes, nanoemulsions and solid-lipid nanoparticles. To date, liposomes and micelles have achieved the most significant clinical success of all nanoparticles. Apart from the already mentioned advantages related to the nanoscale size of these particles, in the case of lipid-based particles it should be noted that they could enhance the solubility of hydrophobic compounds and improve their availability by different administration routes.

Liposomes are nanosized vesicles, which consist of a lipid bilayer enclosing an aqueous core. Structurally, liposomes mimic the composition of the cellular bilayer. They are capable of carrying hydrophilic pay-loads in their interior, as well as trapping hydrophobic drugs within their lipid membranes. Liposomes are generally divided into the "classical" and the "stealth" ones [127]. The classical liposomes present several limitations. First, they are rapidly uptaken by the cells of the mononuclear phagocyte system and they are subsequently cleared from circulation. Second, the retention properties of drugs inside them are strictly dependent on the drug nature. These aspects were solved with the development of Stealth liposomes, whose rigidity was increased with the addition of monosialoglyprotein
GM1 and were sterically stabilized by grafting their surface with polyethylene glycol [127-130]. Liposomes have been widely used for encapsulating active molecules towards AD treatment. The most promising results have been reported with the intranasal administration of these carriers [131, 132].

Contrary to liposomes, micelles offer a reservoir for hydrophobic drugs in their interior. They consist of a 10-100 $\mathrm{nm}$ spherical monolayer of lipids. The limitation of micelles consists in their need to be sterically stabilized. For this reason they are usually combined with PEG or other polymers to obtain a more rigid outer shell and afford the socalled "polymeric micelles". Multiple chemotherapeutics have been incorporated in these lipid based NPs, some reaching clinical use in humans [129, 133]. Moreover micelle-based carriers have been successfully used to target the brain $[134,135]$.

Solid lipid nanoparticles consist of highly pure lipid crystals. The use of these systems is limited by a low drug loading capacity and difficult release once the lipid crystallization occurred. Nanostructured lipid carriers are mixtures of solid and liquid lipids and their imperfect crystal structure provides more space for accommodating the encapsulated drugs, thus offering better performances for drug delivery [128]. Solid lipid nanoparticles have been also used successfully for the delivery of drugs for neurodegenerative diseases [136].

Finally microemulsion based systems are gaining interest in the field of biomedicine. Microemulsion is a thermodynamically stable colloidal system that can be spontaneously formed by mixing different components (lipid, water, surfactant and cosurfactant) together in an appropriate proportion. It is a very versatile system since the components can be varied in order to allow or improve the encapsulation of drugs of different nature. In the case of these systems, considerable amounts of drug can be encapsulated inside the carrier [128].

Polymeric nanoparticles are being studied for drug delivery for the treatment of a wide range of diseases, including cancer, viral infections, cardiovascular diseases and recently also neurodegenerative diseases [137-139].

They can be prepared following two approaches: (i) the dispersion of preformed polymers and (ii) the polymerization of monomers. Drug loading can be obtained either by drug entrapment within the polymer matrix or by drug adsorption on the nanoparticle surface [140]. Both methods are considered mild processes apart from the eventual contact of the drug of interest with not compatible solvents.

The efficacy of polymeric nanoparticles-based therapies depends on their careful design since the selection of the chemistry of the building blocks of these nanocarriers can drastically affect their size, payload, safety, pharmacokinetics and intracellular fate [140].

Among polymeric nanoparticles special attention should be paid to nanogels [141]. They are also referred as hydrogel nanoparticles and the most common synthesis method used for nanomedicine purposes is through the formation of noncovalent interactions between a polyion and the chains of the polymer (ionotropic gelation method). Also covalent binding 
can be used to form nanogels or to increase their rigidity. The result is a highly hydrated three-dimensional network, in which drugs can be easily entrapped. Due to their polymeric nature, a broad range of chemical modifications is possible on the polymer structure before the production of the nanogel to control the material properties. Nanogels exhibit high stability in vivo, tunable size, biodegradability and surface functionality [141]. Nanogels have been reported as good candidates for drug delivery for $\mathrm{AD}$, especially in the case of intranasal administration [142, 143].

Among polymers used to obtain nanogels, polysaccharides as chitosan and alginate are widely used for biomedical purposes. Chitosan is a positively-charged natural polymer, able to interact electrostatically with negatively-charged sites on a cell surface. Chitosan nanoparticles hold an important place in protein and nucleic acid delivery strategy. The cationic surface of chitosan nanoparticles is responsible for the mucoadhesive properties of the chitosan-based nanocarriers that facilitate the retention in the site of interest, thus providing a sustained release of the encapsulated drug. For this reason chitosan nanoparticles are considered very promising candidates for the Alzheimer treatments through intra-nasal administration [144, 145].

Sodium alginate is a biocompatible and biodegradable natural polymer that has been extensively used in hydrogelbased particles formation. Alginate presents a considerable potential for hydrophilic drug entrapment [140, 146].

Polymeric nanocapsules can be also fabricated through the layer-by-layer self-assembly of polymers onto (sacrificial) spherical substrates, such as polymeric beads or inorganic templates, followed by the decomposition of this substrate. For drug delivery purposes, the most elegant way to encapsulate drug molecules inside these nanosized structures is via either drug-loaded templates or drugconjugated polymers as shell components [147].

Finally, dendrimers and dendritic polymers are polymers based in a branching repeating unit providing highly functionalized and compartmentalized structures. Due to their structure they can carry different drugs in the core [148]. Dendrimers behavior has been analyzed in mouse microglial cells and mouse neuroblastoma cells in sight of their more in-depth study for Alzheimer applications [149].

\subsection{Nanoparticle targeting}

The reported examples about drug delivery based on the use of nanocarriers show that nanotechnology could represent an important ally of medicine. The strategy of using specifically designed nanoparticles as carriers is interesting especially in the case of neurodegenerative diseases that are being partially handled or not handled at all.

Taking into account the reported difficulties currently hampering an efficient approach to AD treatment, there is an urgent need to develop more efficient strategies for drug delivery. An advantage of having a nanocarrier consists in the possibility of engineering its surface to expose proper ligands to drive the delivery of an active drug to a specific target. Generally speaking, targeting aims to improve the success of delivery of the compound of interest to a specific site of action, possibly bypassing the barriers retaining the therapeutic activity. By doing this, the local concentration and the residence time of the drug would be increased in the right site of action and consequently undesired effects on surrounding cells and tissues would be diminished.

There are two complementary strategies for targeting, passive and active, each of them relying on the functionalization of the nanocarrier surface with different kinds of molecules [150].

The passive approach consists in the coating of the carrier surface with an inert material (organic or inorganic) to prevent the formation of the protein corona [151], which is the layer(s) of proteins and of other biomolecules that rapidly adsorb onto a nanoparticle as soon as it enters in a physiological environment [152]. A lack of control on the protein corona formation strongly limits the use of nanomaterials in medicine since the protein corona leads to the activation of the complement and coagulation cascades, opsonization and rapid accumulation in macrophages. So the uncontrolled nanoparticle-protein interactions can mark a nanoparticle for uptake in off-target cell populations and accumulation in determined organs [153, 154]. Using the strategy of passive coating the circulation time is increased favoring the delivery of the drug to the desired tissue [155]. Although passive targeting is most commonly devoted to render the nanocarrier surface inert to avoid any non-specific interaction, it can be used also to tune the physico-chemical properties of nanoparticle surface for controlling the level of cellular uptake [156]. For this purpose, most used coatings are charge-neutral, highly hydrophilic 'anti-fouling' polymers. In presence of these coatings, protein adsorption is thermodynamically unfavorable. High molecular-weight polymers are particularly attractive due to the high conformational freedom of their chains in water, which creates an additional entropic barrier to protein adsorption [152].

Both cellular uptake and delivery to a target site can be controlled by using an active targeting on the nanocarrier surface. This strategy consists in linking on the particle surface a selection of moieties or biomolecules that are recognized by molecular interaction at specific sites (biological membranes among them). The added functionality of the nanocarrier can increase its affinity for specific cells or tissues: The most common molecular interactions involved are antigen-antibody or ligandreceptor binding. In this case molecules like peptides, sugars, antibodies, proteins and oligonucleotides are immobilized on nanocarriers surface and are used as molecular Trojan horses [157].

The presence of a molecule conjugated to the carrier is necessary to specifically recognize the target or carry out a defined activity in a biological environment. Nevertheless the efficiency of this recognition and/or activity strongly depends on the appropriate choice of the conjugation process [158]. There are several aspects to be taken into account when a functionalization protocol is going to be optimized for grafting an active molecule on the surface of a nanoparticle. The ratio between biomolecule and nanocarrier is one of the characteristics that should be controlled to correctly analyse any biological result of the targeted delivery [159]. Another key aspect is the functional orientation of the biomolecule on the surface. In fact, 
especially when a molecular recognition is involved, the proper orientation of a biomolecule is necessary to have the "active face" of the molecule available for the interaction with its counterpart in the biological environment (Figure 5). If the biomolecule is randomly attached on the nanocarrier surface, through non-specific chemistry or electrostatic interactions, only some of the molecules will eventually expose the active site $[160,161]$. The correct orientation of the targeting biomolecule mostly depends on the strategy chosen to link it on nanocarrier surface [162]. The previously mentioned electrostatic interaction together with hydrophobic ones are usually multi-punctual weak bonds that lead to a strong attachment and keeps the desired molecule fixed on nanocarrier surface. Nevertheless, as they can involve practically any part of the biomolecule (apart from those cases in which particularly charged or hydrophobic chains of the biomolecule are present in a defined area), the result is the global random orientation on the surface.

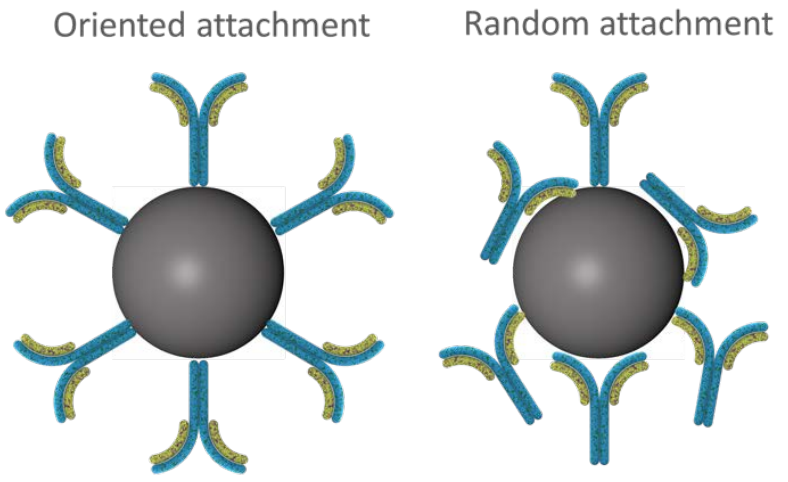

Figure 5. Schematic representation of the oriented and random attachment of an antibody on a nanoparticle. In an appropriate oriented attachment the recognition region is always available for interaction while not all the recognition elements are available in the case of a random attachment.

Biomolecules can be conjugated to nanocarrier surface also through covalent linking if the surface provides functional groups that can react with the molecule, both directly to the surface of some NPs or to surface-bound stabilizing ligands and coatings. This immobilization strategy can involve also a spacer to physically separate the biomolecule from the surface thus avoiding steric hindrance. The control over this separation distance could represent an important issue for some kind of applications. The use of a covalent strategy allows also reducing significantly the leaching of the molecule from the surface that represents an important advantage with respect to strategies based on weak interactions.

The choice of the conjugation strategy finally depends on the combination of nanocarrier properties and the nature of ligand molecule. For both factors the presence of suitable (and compatible) functional groups should be evaluated $[160,163]$. All the mentioned aspects are better highlighted in the reported works from the literature and some have been also explored in systems applied to $\mathrm{AD}$ treatment $[164,165]$.

The anatomical route of delivery plays an important role on the fate of the nanocarrier and its biodistribution. These two aspects can be controlled by modifying the surface of the nanocarrier using passive grafting or active targeting. This is especially important in the case of brain delivery and BBB limitations, since crossing the BBB remains a major challenge in the development of drugs and their delivery systems for treatment of brain diseases even after decades of research.

In the case of Alzheimer disease, the targeting on nanoparticle surface has been used mainly to direct a drug to a specific site of interest and to overcome the BBB hindrance or to reach both objectives at the same time.

\section{TARGETED NANOPARTICLES IN THE TREATMENT OF AD}

Below we have gathered a collection of the most representative works using targeting nanotechnological approaches for the treatment of AD. Interestingly inorganic nanoparticles have only been seldom used, for targeting or therapeutics using controlled local heating. Most often organic nanoparticles have been used as drug carriers taking benefit of the multivalency on their surface for targeting and crossing biological barriers. Among organic nanoparticles, liposomes are by far the most commonly used, probably because of their biocompatibility and the likeness of BBB for lipidic substances. Nanoparticles based on dendritic polyamines are preferred for carrying RNA or DNA. Nevertheless a number of excellent reviews on nanomedicine in the treatment of $\mathrm{AD}$ have already approached the topic after the nature of the used nanoparticles $[17,166]$. Herein we will primarily classify the existing literature according to the $\mathrm{AD}$ feature that is addressed by the reported technology.

\subsection{Targeted nanoparticles to mitigate neuronal transmission dysfunctions}

Behavioral and cognitive impairments caused by AD are consequence of neuronal and synaptic loss. However, most currently available treatments for $\mathrm{AD}$ aim at counteracting synaptic loss by using acetylcholinesterase inhibitors to delay as long as possible the loss of cognitive abilities of the patients. Being only symptomatic treatments, the effort from the nanotechnological point of view has been done in developing brain-targeted nanocarriers for already commercially available drugs [132, 167-169]. Table 1 offers an overview of reports on the use of carriers for acetylcholinesterase inhibitors via intranasal or targeted intravenous administration. 
Table 1. Use of carriers for acetylcholinesterase inhibitors via intranasal or targeted intravenous administration.

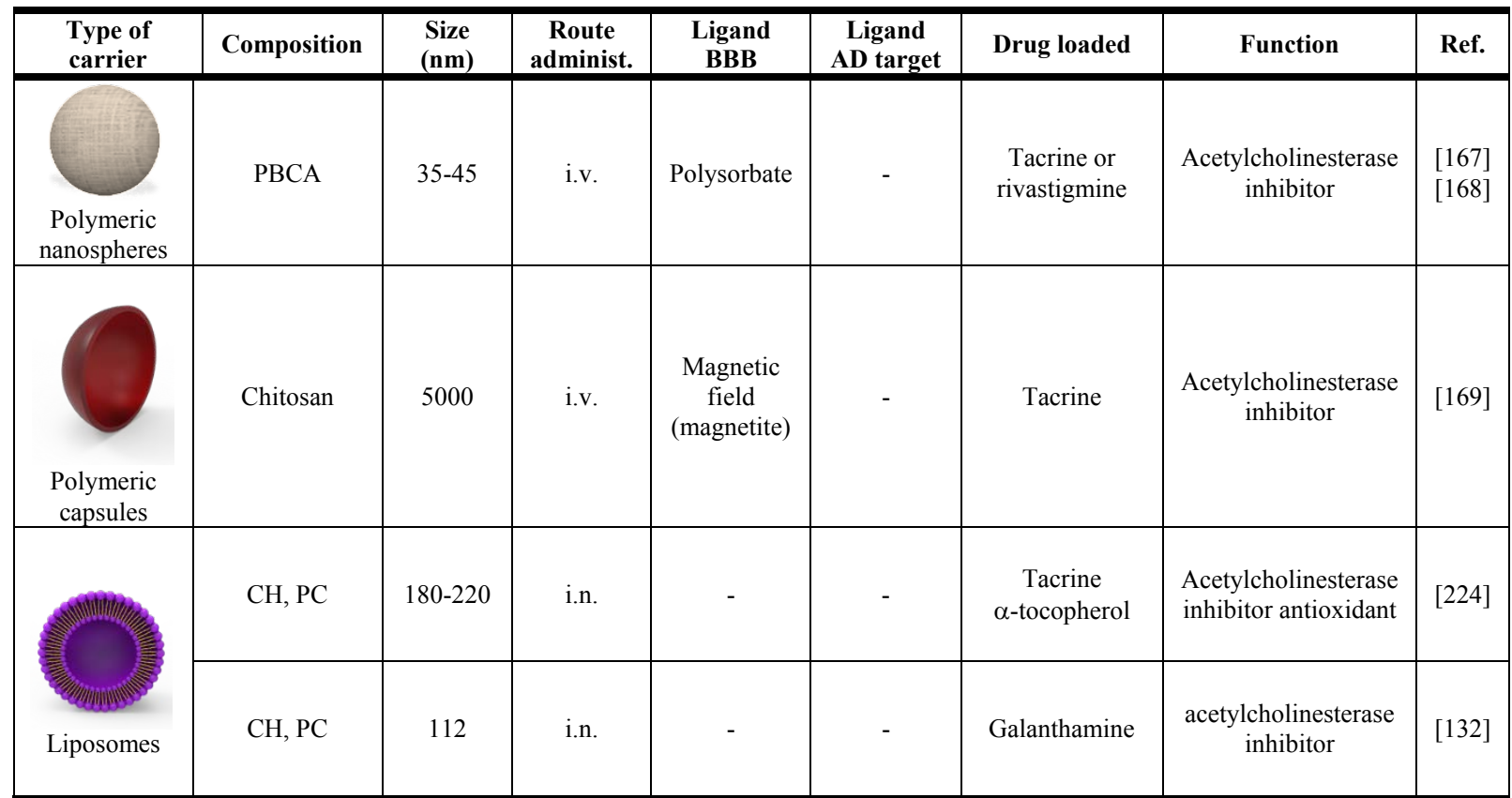

LEGEND. Composition. PBCA: poly-n-butyl-cyanoacrylate. CH: cholesterol. PC: phosphatidylcholine. Routes of administration. i.n.:intranasal. i.v.: intravenous injection.

As an example Wilson et al. have developed a system of biodegradable poly(n-butylcyanoacrylate) nanoparticles to encapsulate tacrine [167] and rivastigmine [168]. For both drugs the encapsulation yield was nearly $90 \%$ with a drug load of $17-18 \%(\mathrm{w} / \mathrm{w})$. Coating the loaded nanoparticles with polysorbate $80(1 \%)$ leaded to a small decrease in the drug load. The approach proved to be successful after tests with animals. The drug was administered to healthy male Wistar rats intravenously as a free drug, bound to nanoparticles and also bound to nanoparticles coated with polysorbate $80(1 \%)$. One hour after administration the concentration of rivastigmine in the brain for the loaded nanoparticles with polysorbate 80 group was 3.82 fold and 3.12 fold those of the free drug rivastigmine and of the drug bound to nanoparticles without polysorbate 80 coating. In consequence, targeting ability of the nanoparticles could be attributed to the coating. The hypothesis is that apolipoprotein E and/or B adsorb on the polysorbate coating in the blood stream, resulting in apolipoprotein-overcoated nanoparticles that would mimic lipoprotein particles and could be taken up by the brain capillary endothelial cells via receptor-mediated endocytosis.

The same group prepared a formulation of magnetic chitosan microparticles loaded with tacrine for its magnetic targeting to the brain [169], where a suitable magnet would be placed. Tests in Wistar rats resulted in the magnetic chitosan microparticles increasing the concentrations of tacrine in the brain by 5.38 fold when compared to the free drug.

A more recent work takes advantage of the fast progress of nanocarriers suitable for non-invasive intranasal administration, which allows for bypassing BBB and therefore has been increasingly investigated for therapies for neurodegenerative disorders such as AD. Li et al. 2012 loaded flexible liposomes with galanthamine hydrobromide
(GH) and studied its pharmacokinetic behavior and efficiency in acetylcholinesterase inhibition in rats [132]. Both were greatly enhanced compared with oral administration. The peak concentration $\left(\mathrm{C}_{\max }\right)$ and the area under the time-concentration curve from 0 to 10 hours $(\mathrm{AUC} 0 \rightarrow 10)$ for intranasal administration were 3.52 and 3.36 times higher than those of orally administered GH. Consistently also the peak time was greatly shortened from $1.5 \mathrm{~h}$ for oral administration to $0.75 \mathrm{~h}$ for intranasal administration of GH loaded flexible liposomes. There are not any data for comparison with an analogous targeted system for intra-venous administration.

These works succeeded in improving the bioavailability of the drugs in the brain, by using nanocarriers and a targeting strategy. Unfortunately, contrasting neuronal transmission dysfunctions cannot stop or reverse the development of $\mathrm{AD}$, although it can ameliorate the cognitive abilities of the patients.

\subsection{Targeted nanoparticles to block the amyloid pathway}

Amyloid cascade hypothesis identified the accumulation of $\mathrm{A} \beta$-peptides, either as soluble oligomers or as insoluble plaques, as the primary cause of $\mathrm{AD}[20,21]$. This hypothesis has prompted the researchers to focus in the fight against the accumulation of $A \beta$ peptide species for years. In this issue several but not all the possible strategies have been followed using nanotechnology, first disaggregation of the existing aggregates, and second, the inhibition of the production of $A \beta$ by silencing the corresponding gene. Also important are the development of vaccines or the use of $A \beta$ targeting for localized drug delivery. The examples are reported in the following paragraphs. 
Table 2. Nanoparticles targeted to $A \beta$ species.

\begin{tabular}{|c|c|c|c|c|c|c|c|c|}
\hline $\begin{array}{l}\text { Type of } \\
\text { carrier }\end{array}$ & Composition & $\begin{array}{l}\text { Size } \\
(\mathrm{nm})\end{array}$ & $\begin{array}{c}\begin{array}{c}\text { Route } \\
\text { administ. }\end{array} \\
\text { ad }\end{array}$ & Ligand BBB & $\begin{array}{c}\text { Ligand AD } \\
\text { target }\end{array}$ & Drug loaded & Function & Ref. \\
\hline \multirow{8}{*}{ Liposome } & $\begin{array}{l}\text { DPPC, CH, } \\
\text { DPS- } \\
\text { curcumin. }\end{array}$ & 200 & i.c.v. & - & curcumin & - & Targeting & [172] \\
\hline & $\begin{array}{l}\text { DPPC, } \mathrm{CH} \text {, } \\
\text { DSPE-PEG }\end{array}$ & 150 & i.v. & $\begin{array}{l}\text { Passive } \\
\text { targeting }\end{array}$ & $\begin{array}{c}\text { Methoxy } \\
\text { XO4 }\end{array}$ & - & Targeting & [187] \\
\hline & $\begin{array}{c}\text { PC or DSPC, } \\
\text { CH, DSPE- } \\
\text { PEG }\end{array}$ & $140-170$ & In vitro & $\begin{array}{l}\text { Antibody } \\
\text { (OX26Mab) }\end{array}$ & $\begin{array}{l}\text { Antibody } \\
\text { (A } \beta \text { Mab) }\end{array}$ & - & Targeting & [181] \\
\hline & $\begin{array}{c}\text { SM, CH, } \\
\text { DMPA, DSPE- } \\
\text { PEG }\end{array}$ & 130 & In vitro & $\begin{array}{l}\text { Antibody } \\
\text { (RI7217) }\end{array}$ & PA & - & Targeting & [164] \\
\hline & $\begin{array}{l}\text { DSPC, CH, } \\
\text { DSPE-PEG }\end{array}$ & $90-120$ & i.v. & $\begin{array}{c}\text { Antibody } \\
\text { (OX26Mab) }\end{array}$ & $\begin{array}{l}\text { Antibody } \\
\text { (19B8MAb) }\end{array}$ & - & Targeting & [165] \\
\hline & $\begin{array}{l}\text { SM, CH, } \\
\text { DMPA }\end{array}$ & $100-150$ & i.p. & $\begin{array}{l}\text { Peptide } \\
(\mathrm{mApoE})\end{array}$ & PA & - & $\begin{array}{l}\text { Destabilize brain } \\
\mathrm{A} \beta \text { aggregates } \\
\text { and promote } \\
\text { peptide removal } \\
\text { across the BBB }\end{array}$ & [178] \\
\hline & DMPC & $20-35$ & i.v. & $\begin{array}{l}\text { Protein } \\
\text { (ApoE3) }\end{array}$ & $\begin{array}{l}\text { Protein } \\
\text { (ApoE3) }\end{array}$ & - & $\begin{array}{l}\text { Decreased } \\
\text { amyloid } \\
\text { deposition }\end{array}$ & [186] \\
\hline & $\begin{array}{l}\text { PC, DSPE- } \\
\text { PEG }\end{array}$ & $80-300$ & i.v. & $\begin{array}{c}\text { Protein } \\
\text { (lactoferrin) }\end{array}$ & - & $\begin{array}{c}\text { Peptide } \\
\text { (KLVFF) and } \\
\text { curcumin }\end{array}$ & $\begin{array}{c}\beta \text {-sheet breaker } \\
\text { antioxidant }\end{array}$ & [189] \\
\hline $\begin{array}{c}\text { Polymeric } \\
\text { nanospheres }\end{array}$ & PEG-PLA & $90-110$ & i.v. & $\begin{array}{l}\text { Peptide } \\
\text { (TGN) }\end{array}$ & $\begin{array}{l}\text { D-Peptide } \\
\text { (D-QSH) }\end{array}$ & $\begin{array}{l}\text { Peptide } \\
\text { (H102) }\end{array}$ & & {$[182]$} \\
\hline$\theta$ & $\mathrm{Au}$ & $20-25$ & i.v. & passive & $\begin{array}{l}\text { Peptide } \\
\text { (LPFFD) }\end{array}$ & POMD** & $\begin{array}{c}\text { Inhibition of } \\
\text { aggregation } \\
\text { Dissociation } \\
\text { antioxidant }\end{array}$ & {$[122]$} \\
\hline $\begin{array}{c}\text { Gold } \\
\text { nanoparticle } \\
\text { S }\end{array}$ & $\mathrm{Au}$ & 15 & i.v. & $\begin{array}{l}\text { Peptide } \\
\text { (THR)* }\end{array}$ & $\begin{array}{c}\text { Peptide } \\
\text { (LPFFD)* }\end{array}$ & - & $\begin{array}{l}\text { Inhibition of } \\
\text { aggregation }\end{array}$ & [185] \\
\hline
\end{tabular}

* both aminoacid sequences are grafted in a single linear peptide THRPPMWSPVWPCLPFFD attached to the gold nanoparticle through the cysteine. **Actually grafted onto the gold nanoparticle. LEGEND. Composition. DPPC: 1,2-dipalmitoyl-sn-glycero-3-phosphocholine. CH: cholesterol. DPScurcumin: phospholipid - curcumin conjugate. DSPE-PEG: 1,2-distearoyl-sn-glycero-3-phosphoethanolamine-N-[methoxy(polyethylene glycol)-2000] ammonium salt. PC: phosphatidylcholine. DSPC: Distearoylphosphatidylcholine. SM: sphingomyelin. DMPA: 1,2-Dimyristoyl-sn-glycero-3-phosphatidic acid. DMPC: 1,2-Dimyristoyl-sn-glycero-3-phosphocholine. PEG-PLA: poly(ethylene glycol)-block-poly(lactic acid. Routes of administration. i.n.: intranasal; i.p.: intraperitoneal injection. i.v.: intravenous injection. i.c.v.: intracerebroventricular injection. Ligands: Methoxy XO4: 4-((E)-4-((E)-4hydroxystyryl)-2-methoxystyryl)phenoxy. OX26Mab: mouse monoclonal transferrin receptor antibody. A $\beta$ Mab: anti-A $\beta 1-42$ monoclonal antibody. RI7217: anti-transferrin receptor antibody. PA: Phosphatidic acid. 19B8Mab:anti-amyloid $\beta$ peptide antibody. mApoE: peptide derived from the receptor binding domain of apolipoprotein E (CWG-LRKLRKRLLR). ApoE3: apolipoprotein E3. TGN: Brain penetrating peptide (TGNYKALHPHNG). D-QSH: D-peptide sequence with binding affinity for $A \beta$ (QSHYRHISPAQVC). THR: peptide sequence targeting transferrin receptor (THRPPMWSPVWP). LPFFD: $\beta$-sheet breaker peptide (LPFFD). Drug loaded. H102: $\beta$-sheet breaker peptide (HKQLPFFEED). POMD: polyoxometalate with Wells-Dawson structure. 


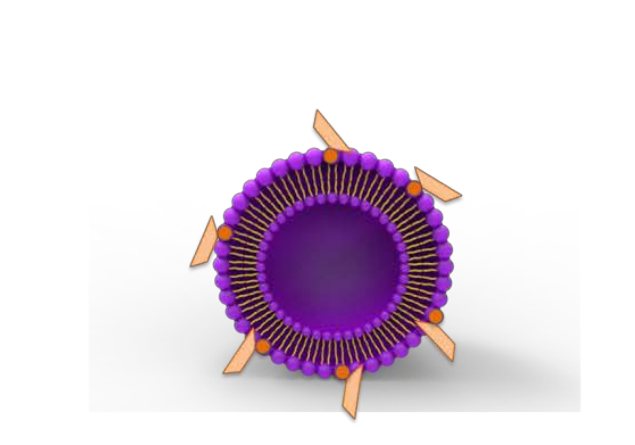

Lipid-S-curcumin liposomes

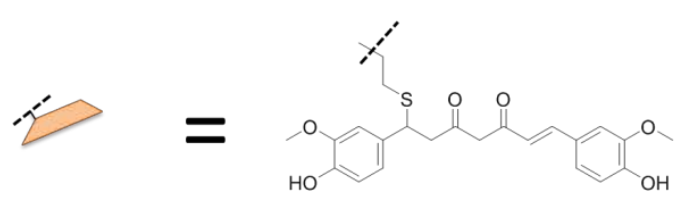

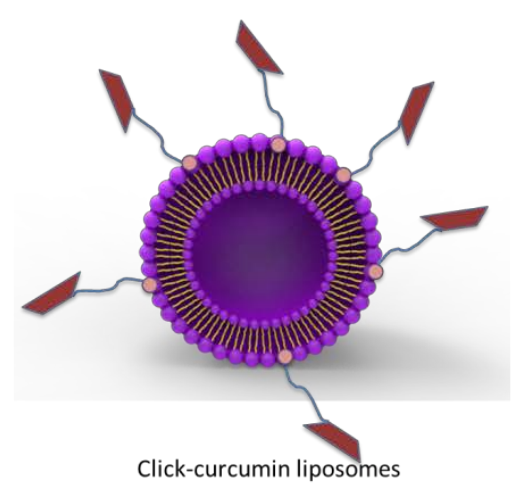

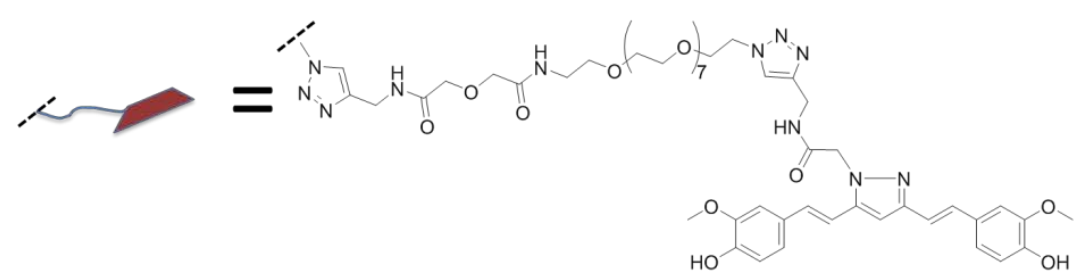

Figure 6. Nanoliposomes (NLs) functionalized with curcumin through thiol-Michael addition (left) and click chemistry (right) [171].

\section{aggregates \\ 6.2.1. Recognition and disruption of the}

$\mathrm{A} \beta$ peptides are recognized as one of the main pathophysiological hallmarks of $\mathrm{AD}$ and have become one of the main objectives for therapeutic and/or diagnostic purposes. A selection of references of nanoparticles targeted to $\mathrm{A} \beta$ species is given in Table 2 .

There is a relatively broad variety of fragments which have been used on the surface of nanocarriers to target $A \beta$ peptides: curcumin [170-173], lipidic fragments (e.g. cardiolipin, and phosphatidic acid) [164, 174-179], antibodies [165, 180, 181], peptides [122, 159, 182-185], and apolipoprotein [186]. Although some groups have focused their work on the development of targeted nanotools with potential for drug delivery or diagnosis [164, 165, 187, 188], some other examples have already gone beyond and reported not only the targeting but also the delivery of therapeutics aiming at disaggregating $\mathrm{A} \beta$ plaques and oligomers [178, 182, 186, 189]. Nanotechnological targeted therapeutics under research have consisted of small drugs [170-173, 189], designed peptides [122, 182, 189, 190], and localized heating [185]. In some cases the targeting and therapeutic functions are exerted by the same fragment.

Among the small molecular drugs reported for AD, curcumin has been by far the most used by research groups. Curcumin is a polyphenolic compound derived from the dietary spice turmeric [191, 192]. Interestingly it shows affinity for $A \beta$ peptides, and activity in disrupting the aggregates and in inhibiting their formation, which makes of it both a potential targeting agent and drug for $\mathrm{AD}$ treatment [193]. Curcumin was tested as targeting agent covalently linked on the surface of liposomes (130-200 nm), via either click-chemistry conserving the planarity of the molecule or through thiol-Michael addition (Figure 6) [170-173]. All nanoliposomes (NLs) with curcumin showed high affinity for fibrillar and/or oligomeric $A \beta$ species in thioflavin $T$ (ThT) and immune assays (endogenous amyloids) although click-curcumin NLs displayed higher affinity. Surprisingly, curcumin decorated NLs showed different affinity for $A \beta$ peptides depending on the origin, endogenous or synthetic, of the peptides. Whereas, click-curcumin NLs also showed extremely high affinity for $\mathrm{A} \beta 1-42$ fibrils $\left(10^{5} \mathrm{nM}\right)$ in surface plasmon resonance (SPR) experiments (synthetic amyloids), lipid-S-curcumin NLs did not bind to A $\beta 1-42$ monomers and oligomers in these experiments [171, 173].

Interestingly, even though the curcumin was covalently linked on the surface of the NLs, it was able to downregulate the secretion of $A \beta$ peptide in cells overexpressing human APP [172]. When injected in the brain of transgenic mouse model (APPxPS1) lipid-S-curcumin NLs could specifically stain $\mathrm{A} \beta$ deposits in vivo. Unfortunately these differences cannot be unarguably attributed to the linking functional group since a flexible oligoethyleneglycol spacer was used in the click-curcumin NLs and not in the lipid-Scurcumin NLs. The NLs diffused locally along the injection tract and, on a longer distance, along the fibers of the corpus callosum. This diffusion could be attributed to the NL carrier, since fluorescent NLs, devoid of curcumin, showed the same diffusion properties [172].

Despite the high affinity for $A \beta$ with which curcumin imparted the nanocarrier, intracranial administration was required in the absence of a targeting agent for crossing the BBB [172]. For this reason most of the groups follow approaches that include strategies to go across the blood brain barrier and target the $A \beta$.

Methoxy-XO4 is another low molecular weight compound that is currently used as a fluorescent $A \beta$ probe for the detection and quantification of plaques, tangles and cerebrovascular amyloid. Tanifum et al. used this fragment to prepare an $\mathrm{A} \beta$-targeting fluorescent lipid conjugate 
[DSPE-PEG-3400-XO4] that was included in the formulation of pegylated liposomal nanocarriers [187]. A $\beta$ plaque deposits were bound in vivo after intravenous injection in an $\mathrm{AD}$ mouse model (APP/PSEN1 transgenic mice) labeling parenchymal $A \beta$ deposits and vascular $A \beta$ peptide characteristic of cerebral amyloid angiopathy. The delivery across the $\mathrm{BBB}$ relied on the long circulating time of the liposomes as a result of the PEG coating (passive targeting) and also on the brain penetrating capacity of the XO4 fragment. The system was the first successful design for intravenous delivery of $A \beta$-targeted liposomal nanocarriers [187].

Anionic phospholipids cardiolipin (CL) and phosphatidic acid (PA) also showed very high affinity to A $\beta 1-42$ and its aggregated forms when decorating NLs and solid lipid nanoparticles [174]. The affinity for $A \beta 1-42$ fibrils was studied by SPR and ultracentrifugation on a discontinuous density gradient. Low binding of NLs incorporating PA or $\mathrm{CL}$ was detected on immobilized $\mathrm{A} \beta 1-42$ monomers. In contrast, the affinity of liposomal PA or CL for A $\beta 1-42$ fibrils and oligomers was very high, with values in the nanomolar range for the fibrils. Multivalence likely plays a key role in such a high affinity. The selectivity was qualitatively shown by the absence of binding to bovine serum albumin.

After having shown the applicability of the system for A $\beta$ targeting, Re et al. provided the sphingomyelincholesterol-CL (or PA) NLs with the ability of crossing the BBB by functionalizing them with ApoE-derived peptides (141-150 monomer and its tandem dimer) [175, 176. Fluorescence and radiochemical assays showed that the functionalization of the NLs with ApoE-derived peptides allowed their uptake by a rat brain endothelial cell line (RBE4) in contrast to non-functionalized NLs. Increasing the density of functionalization increased the uptake of the NLs and also the transendothelial permeability. Although the monomer functionalized NLs were better internalized by cells, the dimer delivered significantly higher transendothelial permeability values [175, 176]. The presence of the ApoE-derived peptides on the surface did not affect the ability of the NLs to bind A $\beta 1-42$ peptide in vitro.

Subsequently the system was tested in in vivo experiments in 2013. Similar bifunctionalized NLs with a modified ApoE-derived peptide to cross the BBB and phosphatidic acid to target amiloyd $\beta$ peptides, exhibited much higher permeability across the BBB either in vitro (5fold) or in vivo in healthy mice with respect to the NLs functionalized only with phosphatidic acid [177]. Biodistribution studies of radiolabeled mApoE-PA-NL after intravenous injection in healthy mice showed just $0.30 \%$ of the total dose was located in the brain compared to $0.17 \%$ of PA-NL [177]. Intraperitoneal administration (three injections per week, for 3 weeks) in 10 month-old APP/presenilin 1 transgenic mice leaded to a $33 \%$ of brain insoluble $A \beta 1-42$ peptides. Brain $\mathrm{A} \beta$ oligomer were also drastically reduced. Meaningfully, A $\beta$ peptide amount increased $20 \%$ and $18 \%$ in spleen and liver respectively [178]. More recently fundamental fluorimetric studies have been conducted on the interaction of $A \beta$ oligomers with this class of liposomes [179].

Full-length recombinant ApoE3 was used by Song et al. in combination with 1,2-dimyristoyl-sn-glycero-3phosphocholine (DMPC) based liposomes [186]. In contrast to other reports of ApoE3 decorated liposomes, in this case there was a direct interaction of ApoE3 with the lipids in the liposome. The novel nanostructure, which the authors named as apolipoprotein E3 reconstituted high density lipoprotein (ApoE3-rHDL), displayed a relatively small size (20-30 nm). Surface plasmon resonance, transmission electron microscopy, and co-immunoprecipitation studies demonstrated the high binding affinity of ApoE3-rHDL to both $\mathrm{A} \beta$ monomer and oligomer, similar to natural ApoE3rHDL and higher than ApoE3 alone. The clearance of $A \beta$ was emphasized. In vitro studies showed accelerated microglial, astroglial and liver cell degradation of $\mathrm{A} \beta$ by facilitating the lysosomal transport. One hour after intravenous administration in mice the amount of 125IApoE3-rHDL accumulated in the cerebral cortex and hippocampus were $0.41-0.43 \%$ of the administered dose, comparable to well-acknowledged nanocarriers for brain targeting drug delivery. Studies using senescence-accelerated prone mouse (SAMP8) showed that intravenous administration of ApoE3 rHDL succeeded in decreasing $A \beta$ deposition, attenuating microgliosis, ameliorating neurologic changes, and rescuing memory deficits. A four week daily administration proved to be safe although it is obviously a short-term treatment taking into account the nature of $\mathrm{AD}$ [186].

The utilization of monoclonal antibodies or synthetic peptides may be preferable over the actual substrate of the receptors, as they do not need to compete with endogenous molecules but still grant the capability to enter brain capillary endothelial cells (BCECs) by receptor mediated endocytosis [44]. ApoE derived peptide was substituted by the anti-transferrin receptor antibody RI7217 in phosphatidic acid functionalized nanoliposomes (RI-PA-NLs) [164]. RI7217 was conjugated to the tip of polyethylene glycol molecules at the surface of the liposomes, through a biotinstreptadivin linkage or through thiol-maleimide covalent ligation. Conjugation with RI7217 leaded to higher values of uptake and permeability across the barrier model in comparison with non-functionalized ones, although a superior performance was reported for the direct covalent coupling of RI7217 compared to biotin-streptadivin linkage [164]. Confocal microscopy experiments illustrated that RIPA-NLs were not transported via the endosome-lysosome pathway, suggesting receptor-mediated transcytosis as a possible transport mechanism across the BBB model. Although the results of permeation in vitro were slightly worse than using ApoE derived peptide [164, 175], this work shows the importance of the nature of the chemical binding of the targeting ligand. 


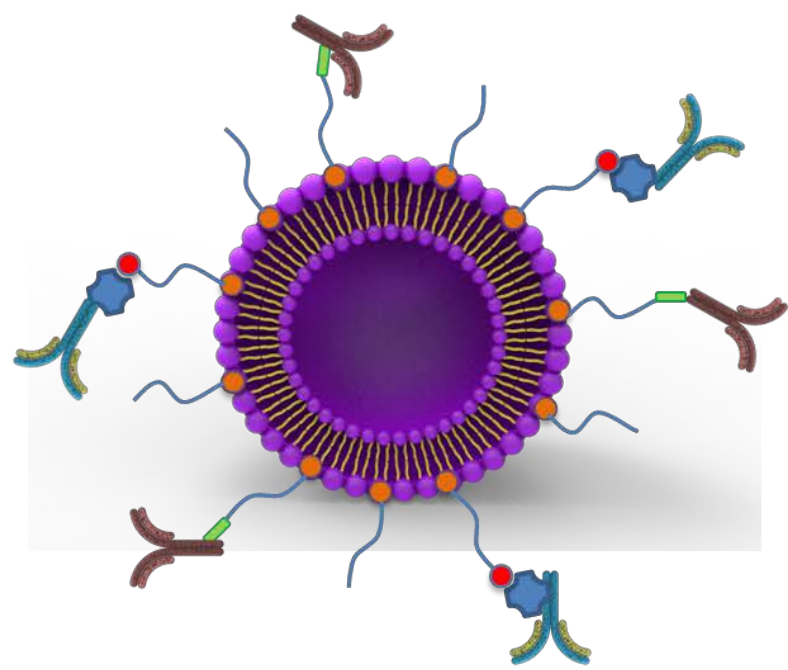

mAb OX26

mAb $19 B 8$

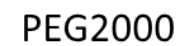

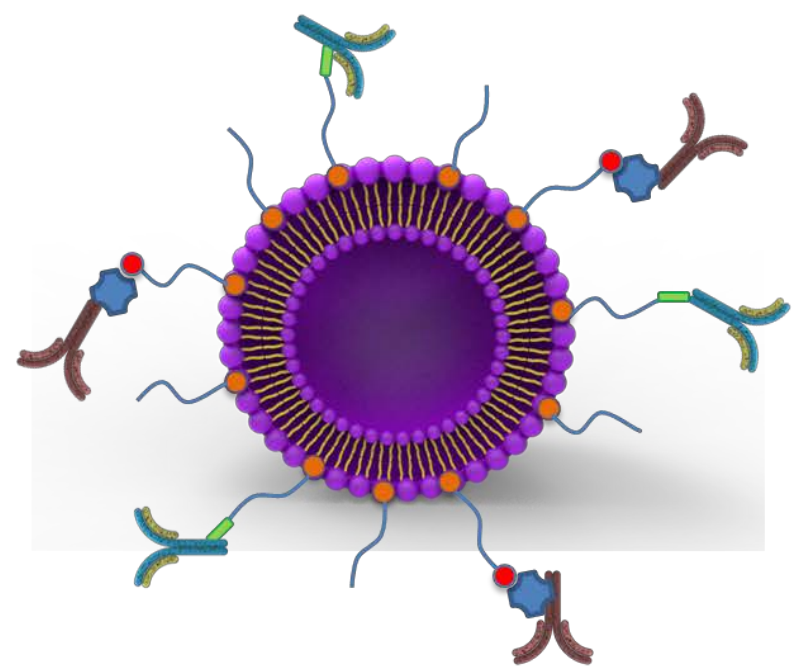

Streptavidin-Biotin complex<smiles>CCN1C(=O)CC(SCCC(=O)NC(C)C)C1=O</smiles>

Figure 7. Schematic representation of two of the liposome series studied by Loureiro et al. for the effect of the chemical linkage on the performance of dually functionalized liposomes [165]. Left, liposomes functionalized with OX26MAb and 19B8Mab respectively through streptavidin-biotin complex and thiol-maleimide chemistry. Right, the second series of liposomes functionalized with OX26MAb and 19B8Mab respectively through thiol-maleimide chemistry and streptavidinbiotin.

Dual targeting for $\mathrm{A} \beta$ peptides and $\mathrm{BBB}$, and the importance of the chemical binding nature of the targeting fragments to the liposomes were also explored by Loureiro et al. using DSPC (1,2-distearoyl-sn-glycero-3phosphocholine), Chol (cholesterol ovine wool), DSPEPEG2000 pegylated liposomes [165]. The anti-transferrin receptor monoclonal antibody (OX26MAb) was used to address the $\mathrm{BBB}$ and an anti-A $\beta$ peptide antibody (19B8MAb) was used to recognize the $A \beta$ aggregates. Different kind of liposomes were tested, with just one of the ligands, or with both, each one attached to the liposomes via biotin-streptavidin complex or through maleimide (Figure 7). In contrast to other reports the cellular uptake of the liposomes was much more efficient when OX26MAb was conjugated through streptavidin-biotin complex instead of the maleimide group [165]. The authors hypothesized that the presence of two antibodies, one of them bound to biotinstreptavidin, could generate the formation of different layers to minimize lateral repulsions between the proteins: OX26MAb would be more available in the system with two antibodies if linked through the streptavidin-biotin system instead of the maleimide group. Additionally, the results in vitro indicated that the transport across the $\mathrm{BBB}$ could also be assisted by the 19B8MAb since it has been suggested that anti-A $\beta$ antibodies cross slowly the BBB by extracellular pathways [194].

In this line Markoutsa et al. have also reported on the apparent interaction between targeting ligands in dually targeted liposomes [180, 181]. In this case, similar permeability values were observed for liposomes decorated through the biotin-streptavidin complex with OX26MAb and anti-A $\beta-M A b$ and liposomes functionalized only with OX26MAb. Since the detrimental effect of a second antibody on the same vesicle for the uptake of OX26MAb functionalized liposomes had already been reported, the authors decided to explore the occurrence of independent additional interactions induced by the second antibody [ 180 , 181]. Indeed, liposomes functionalized only with anti-A $\beta$ $\mathrm{MAb}$ also showed higher uptake by hCMEC/D3 cells than the control liposomes. The uptake values also increased by 2-2.5 times, when incubations were carried out in the 
presence of A $\beta 1-42$ peptides. Finally, experiments blocking the RAGE receptors, which is the receptor primarily responsible for the $A \beta 1-42$, proved that RAGE receptor was involved in the transcytosis of the anti-A $\beta-\mathrm{MAb}$ functionalized liposomes. The authors suggested that higher differences would be observed if the orientation of the antibody on the liposome was controlled [181].

There are some arguments against the use of monoclonal antibodies for targeting: they can give rise to immunogenic response and it is difficult to develop protocols for the appropriate orientation of the antibody on the nanoparticle. Some of these issues can be addressed with the use of engineered peptides. Zhang et al. proposed a system using pegylated polylactic acid nanoparticles which were targeted for $\mathrm{BBB}$ and $\mathrm{A} \beta 1-42$ by using two peptides, TGNYKALHPHNG (shortened as TGN) and QSHYRHISPAQV (shortened as QSH), which had been screened by phage display for penetrating the BBB and recognizing $A \beta 1-42$ respectively [159]. Both peptides were covalently attached to the nanoparticles by thiol-maleimide chemistry, with a degree of functionalization that was optimized to obtain the maximal targeting effect. Monofunctionalized nanoparticles with TGN (TNP) or QSH (QNP) respectively showed high uptake by immortalized mouse brain endothelial cells (bEnd.3 cells), and high affinity for A $\beta 1-42$ in thioflavin $\mathrm{T}$ (ThT) binding assay and SPR measurements. Biodistribution experiments after intravenous injection in mice with coumarin-loaded dually targeted nanoparticles (TQNP) afforded a drug targeting index (DTI) of 2.05, 2.11 and 3.77 for cerebrum, cerebellum and hippocampus respectively [159]. This system was later studied for the encapsulation of a $\beta$-sheet breaker peptide, HKQLPFFEED (shortened as H102) [182]. The loading capacities of the H102-loaded nanoparticles were approximately $0.54-0.61 \%$ with an encapsulation efficiency of $58 \%$ for the nanoparticles functionalized with TGN and QSH at the same time (TQNP/H102). Tests in the AD model mice showed an increased accumulation of $\mathrm{H} 102$ at brain A $\beta 1-42$ which leaded to better and neuroprotective effects with dually targeted nanoparticles (TQNP/H102) compared to non-modified (NP/H102) or TGN-modified nanoparticles (TNP/H102). Beyond the ability of this system for penetrating into the $\mathrm{CNS}$ and for targeting the $\mathrm{AD}$ brain lesions [159], this study confirms the suitability of the system as carrier for peptide drugs which otherwise would lack of stability, circulation time and/or permeation through the BBB [182].

Kumaraswamy et al. used another kind of peptide, a $\beta$ sheet breaker peptide KLVFF, in combination with curcumin to fight the cytotoxicity caused by $A \beta$ peptides [189]. In this approach curcumin and KLVFF were encapsulated in liposomes formed by phosphatidylcholine and 1,2distearoyl-sn-glycero- 3-phosphoethanolamine-N[amino(polyethylene glycol)-2000] ammonium salt (DSPEPEG(2000)). Targeting was achieved by functionalization of the surface with lactoferrin via thiol-maleimide linkage. Rather low encapsulation yield for KLVFF of $35 \%$ was observed which further diminished to $22 \%$ when curcumin was also encapsulated. The peptide was proved to intercalate between the phospholipid acyl chains of the lipid carrier. Release kinetics of curcumin and peptide from the liposomal carrier followed the matrix type system. The efficacy of the formulation was tested by cell viability assays using IMR-32 neuroblastoma cells incubated with A $\beta 1-42$ peptide [189].

BBB crossing can be achieved, not only by receptor mediated mechanisms, but based on the size of the nanocarrier. Gao et al. developed a system consisting of gold nanoparticles grafted with polyoxometalates with WellsDawson structure, AuNPs@POMD, with a total $22 \mathrm{~nm}$ size [122]. POMDs had been previously reported to inhibit $A \beta$ aggregation by binding a cationic cluster from His 13 to Lys 16. $\beta$-sheet breaker LPFFD peptide was derived from the A $\beta$ central hydrophobic region from Leu17 to Phe20, right next to the cationic cluster. The authors rationalized that decorating AuNPs@POMD with LPFFD peptide should lead to a larger binding site on $\mathrm{A} \beta$ and thus to exhibit greater anti$A \beta$ toxicity for the therapy of Alzheimer's disease. LPFFD peptide was incorporated as CLPFFD (pep) using the cysteine at $\mathrm{N}$-terminus to bind the gold nanoparticles via $\mathrm{Au}-$ $\mathrm{S}$ chemistry. The authors evaluated the half maximal inhibitory concentrations (IC50) for the quantification of the inhibitory effects of AuNPs@POMD, NAc-CLPFFD and AuNPs@POMD-pep. The IC50 value of AuNPs@POMDpep was approximately 6.14 and 4.31 times lower than those of N-Ac-CLPFFD and AuNPs@POMD, respectively, which suggests that the inhibitory efficiency of AuNPs@POMDpep was markedly increased due to the synergistic effects of AuNPs@POMD and the peptide. Interestingly a synergistic effect was also found in the decrease of $A \beta$-mediated peroxidase activity and of $A \beta$-induced cytotoxicity. Finally inductively coupled plasma mass spectrometry (ICP-MS) studies after intravenous administration in mice showed AuNPs@POMD-pep could cross the BBB [122].

Gold nanoparticles, also linked to CLPFFD peptide for $\mathrm{A} \beta$ recognition, were used in combination with microwave irradiation to inhibit irreversibly the normal aggregation of $\mathrm{A} \beta$ peptides in solution. The resulting irradiated products were not amyloidogenic [183, 184], thus the peptides were probably denatured by the optothermal effect. The system was later designed to cross $\mathrm{BBB}$ in in vivo experiments. By conjugating a V shaped peptide to the AuNP through a cysteine residue in the lower part of the V. One of the upper parts contained a directing portion (THR) to vectorize the peptide to the transferrin receptor and lead the system across the blood-brain barrier, and the other a recognition/attachment portion (LPFFD) for the $A \beta$ aggregates. In vitro, AuNP-THR-LPFFD constructs were able to cross the model of BBB, with a noticeable synergistic effect between the two peptidic fragments. However biodistribution analysis after intraperitoneal injection and transcardial perfusion with PBS in rats, showed only small amounts of conjugates in the brain parenchyma compared to the administered doses $(0.07 \%)$ [185]. The fact that both targeting functions are contained in one V-shaped peptide could originate detrimental interactions.

The utilization of an external radiation source was also envisaged in a drug delivery system developed by $\mathrm{Xu}$ et al. [188]. Instead of implementing a targeted system, the researchers designed a nanocarrier that would only release its cargo in the presence of $\mathrm{A} \beta$ oligomers. The drug carrier design consisted of a graphene-mesoporous silica hybrid (GMS)-supported lipid bilayer, inspired from $A \beta$ oligomermediated cell membrane disruption in the pathogenesis of 
amyloidosis. A $\beta$ peptides are not specifically targeted, but drug release would only take place in their presence, as they trigger the disruption of the lipid bilayer. As a second mechanism to ensure drug release, the use of a near-infrared laser was also introduced taking advantage of the photothermal effect of GMS and thermal sensitivity of lipid bilayers, which also implied the use of a fluorescent dye assess when the laser had to be turned on. Unfortunately the system lacks the capacity to cross the BBB [188].

Intranasal administration was chosen for the delivery of a $\beta$-sheet breaker peptide H102 [190]. Despite affording promising results after intraventricular administration, the peptide drug showed low penetration through BBB and very low stability in vivo, being cleared rapidly after intravenous injection with a plasma half-time less than $2 \mathrm{~min}$. the encapsulation of the peptide drug in phospholipid-based liposomes clearly improved its nasal mucosa permeation of the drug and extended its stability in plasma. In experiments with rats the AUC of the encapsulated drug after intranasal administration was 2.69 times higher than that of a $\mathrm{H} 102$ solution using a $1 \%$ chitosan to favor the absorption. The transport to the brain was also improved: The drug amount in the hippocampus of groups that received liposomes was 2.92 times higher than that of the given solution of peptide and chitosan. The efficacy of the system in AD treatment was assessed based on behavioral experiments, on the detection of acetylcholinesterase (AchE), choline acetyltransferase (ChAT) and insulin degrading enzyme (IDE) activity, and on histological assays for the plaque deposition [190].

Very recently the encapsulation of tarenflurbil in poly (lactide-co-glycolide) nanoparticles (TFB-NPs) and solid lipid nanoparticles (TFB-SLNs) has been reported [195]. Tarenflurbil is a A $1-42$ selective lowering agent and $\gamma$ secretase modulator, which failed in phase III trials in 2008. Its failure is generally attributed to an insufficient ability to penetrate the brain [196]. A series of surfactants were tested to obtain a good encapsulation efficiency and nanoparticle size both for polymeric and solid lipid nanoparticles. Plasma and brain pharmacokinetics were studied after single dose and multiple-dose intranasal administration in Sprague Dawley (SD) rats. Compared to intravenous, intranasal and oral administration of the free drug, concentration of tarenflurbil in the brain was improved when the drug was loaded in nanoparticles and administered following the intranasal route [195].

\subsubsection{Prevention of $A \beta$ peptides production}

Although most $\mathrm{AD}$ therapies in research are based in $\mathrm{A} \beta$ peptides recognition and disruption of their oligomers and plaques, another approach under investigation aims at the down-regulation of their production [197-200]. A $\beta$ peptides originate from the proteolytic cleavage of the amyloid precursor protein APP, performed by a series of secretase proteins. $\beta$-site APP cleaving enzyme 1 (BACE1, $\beta$ secretase) cleaves APP to a 99 amino acid fragment, initiating the sequence that eventually leads to the formation of the amyloid peptides with 40-42 aminoacids which are the major components of amyloid plaques and oligomers [201]. Although up-regulation of BACE1 has been associated to $\mathrm{AD}$ cases, down-regulation of this protein has also been reported to lead to behavioral and physiological deficits
[197]. The development of several low molecular weight BACE inhibitors is currently in course but to our knowledge the nanotechnological approach to this $\mathrm{AD}$ aspect has been centered in the regulation of BACE by targeted gene therapy. A smart nanocarrier designed for this job requires of targeting agents able to facilitate the internalization across BBB and by the neurons (Table 3). That is the case of rabies virus glycoprotein (RVG29) peptide, a 29-amino-acid peptide, which can bind to the acetylcholine receptor, present not only in the vascular endothelium of BBB but also in the membrane of neurons.

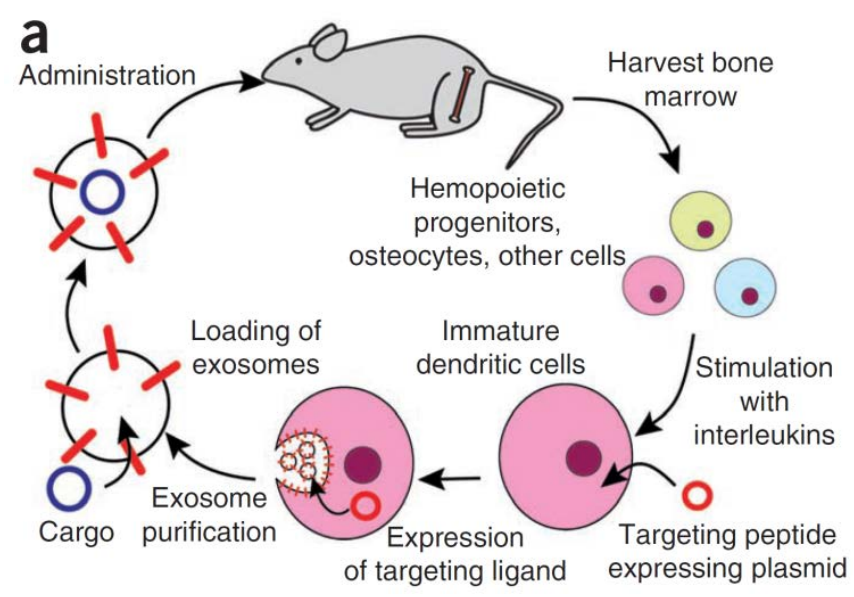

Figure 8. Schematic representation of production, harvest and re-administration of targeted self-exosomes for gene delivery as reported by Alvarez-Erviti et al. Reprinted by permission from Macmillan Publishers Ltd: [Nature Biotechnology] [198], copyright (2007).

In a pioneering work, Alvarez-Erviti et al. used transfected dendritic cells to produce exosomes expressing RVG29 on their external surface (Figure 8) [198]. Appropriate siRNA was introduced in the purified exosomes by electroporation. Due to RVG29 action intravenously targeted exosomes delivered siRNA specifically to neurons, microglia and oligodendrocytes in the brain, resulting in a specific gene knockdown. When exosomes were administered intravenously to normal $\mathrm{C} 57 \mathrm{BL} / 6$ mice a significant protein knockdown $(62 \%, \mathrm{P}<0.01)$ was observed in BACE siRNA-RVG exosome-treated mice resulting from a significant decrease in BACE1 mRNA levels $(61 \% \pm 13 \%$, $\mathrm{P}<0.01)$, which leaded to a significant decrease $(55 \%, \mathrm{P}<$ 0.05 ) in the total $A \beta 1-42$ levels. BACE1 knockout did not have an overt effect on the mouse phenotype suggesting BACE1 inhibition might be free of side effects. 
Table 3. Targeting nanoparticles aiming at treating $\mathrm{AD}$ through the reduction of $\mathrm{A} \beta$ production or through immunotherapy against $A \beta$ (vaccine).

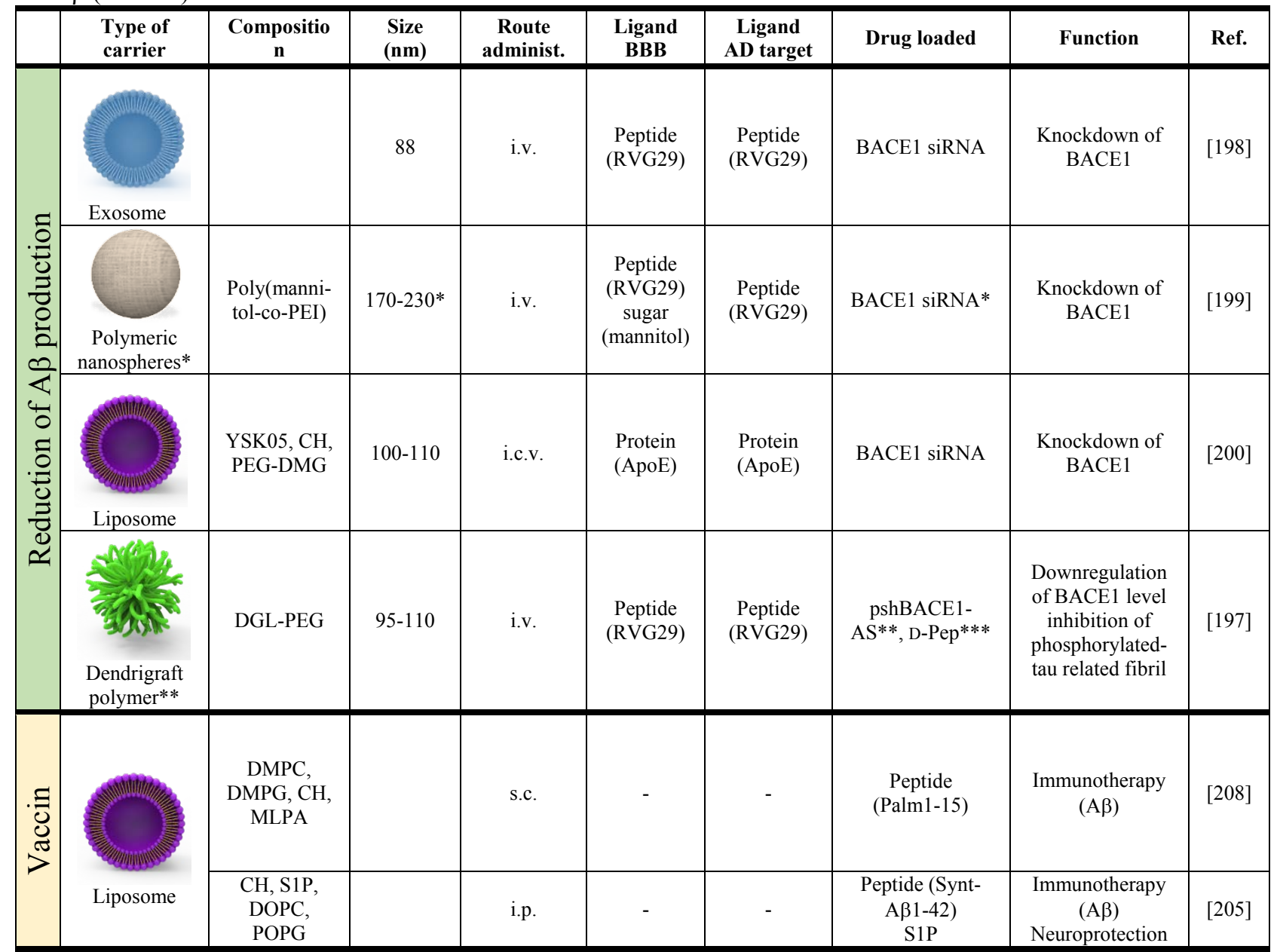

* The drug carrier was formed by several polymer particles surrounding the siRNA by electrostatic interactions. ** The drug carrier was formed by several DGL-PEG particles surrounding the pshBACE1-AS by electrostatic interactions. *** D-Pep is actually grafted onto DGL-PEG. LEGEND. Composition. Poly(mannitol-co-PEI): branched polyethylenimine crosslinked with mannitol diacrylate. CH: cholesterol. YSK05: 1-methyl-4,4-bis(((9Z,12Z)-octadeca9,12-dien-1-yl)oxy)piperidine. PEG-DMG: 1-(monomethoxy polyethyleneglycol 2000)-2,3-dimyristoylglycerol. DGL-PEG: PEGylated dendrigraft poly-Llysine. DMPC: Dimyristoylphosphatidylcholine. DMPG: dimyristoylphosphatidyl glycerol. MLPA: Monophosphoryl lipid A. S1P: D-erythro-sphingosine-1phosphate. DOPC: 1,2-dioleoyl-sn-glycero-3-phosphocholine. POPG: 1-Palmitoyl-2-oleoyl-sn-glycero-3-phosphoglycerol, sodium salt. Routes of administration. i.v.: intravenous injection. i.c.v.: intracerebroventricular injection. s.c.: subcutaneous injection. Ligands. RVG29: rabies virus glycoprotein peptide (sequence: YTIWMPENPRPGTPCDIFTNSRGKRASNG). ApoE: apolipoprotein. Drug loaded. BACE1 siRNA: small interfering RNA for BACE1. pshBACE1-AS: Plasmid encoding a short hairpin RNA against BACE1 antisense, a natural antisense transcript non-coding RNA that regulates BACE1 expression. D-Pep: all D amino-acid peptide inhibitor of tau fibril formation (sequence: D-TLKIVW). Synt-A $\beta 1-42$ : synthetic amyloid $\beta$ peptide formed by 42 residues.

Recently, the same strategy has been applied using polyamines for targeted gene delivery [197, 199]. Heterobifunctionalized linear PEG fragments were coupled on one tip to the polyamine via an amide bond, whereas RVG29 was coupled on the other tip through thiolmaleimide covalent ligation. RNA or DNA were complexed via electrostatic interaction with the polyamine. Further functionalization or targeting to other aspects of $\mathrm{AD}$ could be incorporated covalently conjugated [197]. Employment of RVG peptide on the surfaces of complexes largely increased the silencing efficiency more than two folds using Neuro2a and SH-sy5y cell lines which are originated from neuronal cells while there was no evident increase of silencing effect using HepG2, A549, C2C12 and HeLa cells [199]. In vivo studies showed the BACE1 silencing efficiency of this kind of complexes both for in hippocampus and cortex parts in $\mathrm{AD}$, reaching 2.32-fold and 3.03-fold reduction in in vivo gene silencing of BACE1 expression respectively in cortex and hippocampus [199].

In a closely related approach Tamaru et al. used a liposomal nanoparticle containing a proton-ionizable amino lipid (YSK-MEND). The encapsulation of the nucleic acids 
was driven by ionic interactions whereas the liposomal external surface was functionalized with recombinant ApoE. Although the studies showed the capacity of the system to knock gene expression down, the way of administration for the in vivo experiments was intraventricular injection, thus limiting the applicability of the system [200].

\subsubsection{Anti- $A \beta$ Vaccine}

Active immunization strategies have also been tested against $\mathrm{AD}$, normally by the controlled administration of $\mathrm{A} \beta$ peptides or fragments of them. There are several promising reports in the literature which use nanoliposomes for a better administration (Table 3).

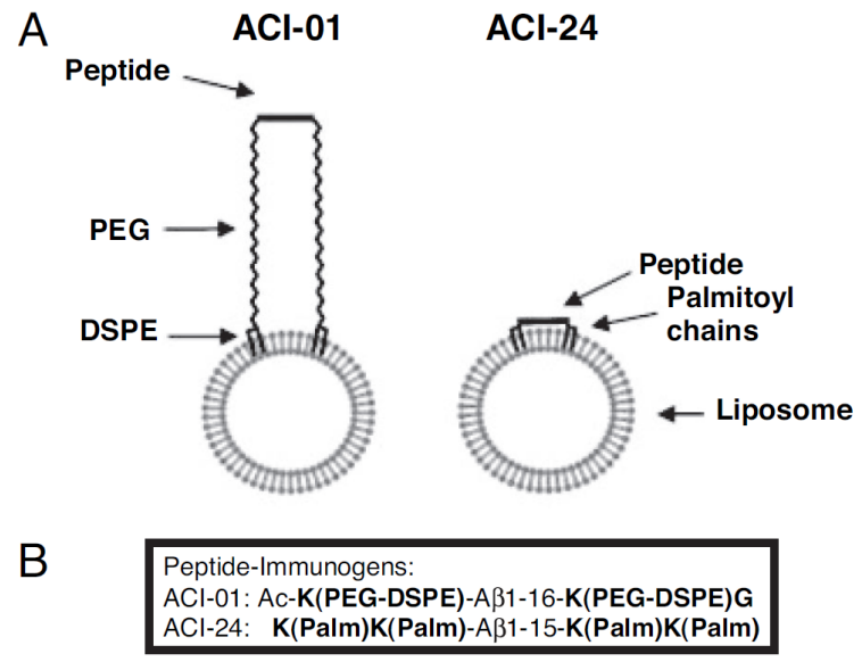

Figure 9. Design of the two liposomal vaccines containing peptide immunogens with the first 16 (ACI-01, A $\beta 1-16)$ and 15 (ACI-24, A $\beta 1-15$ ) amino acids of the full length $A \beta 1-42$ peptide. (A) In ACI-01 two PEGylated lysine residues act as covalently linked spacers between the antigen, $A \beta 1-16$, and the liposome. For ACI-24, the antigen was anchored to the liposome through a terminal palmitoylated lysine residue covalently linked at each end of $A \beta 1-15$. (B) Sequence of the peptides integrated into the liposomal vaccines ACI-01 and ACI-24. Reproduced by permission from [207]

First attempts for vaccines against AD leaded to a clinical trial of active immunization with aggregated synthetic $\mathrm{A} \beta 1-42$ peptide/QS2 1 adjuvant against $\mathrm{A} \beta$ in patients with $\mathrm{AD}$ in 2001 [202]. The immunization was successful in patients with an abbreviated immunization protocol, by generating anti-A $\beta$ antibodies, reducing cerebrospinal levels of tau, and reporting a slower cognitive decline. However, the clinical trial had to be interrupted because of a significant number of meningoencephalitis among the immunized subjects probably induced by an extensive T-cell-mediated immune response [202]. In order to overcome this problem, Carrera et al. developed a system (EB101) consisting of A $\beta 1-42$ and sphingosine-1-phosphate emulsified in a phospholipid liposome complex [203-205]. Monthly intraperitoneal administration (9 injections, 7 months) of EB101 to APP/PS1 mice before the onset of $\mathrm{A} \beta$ deposition and/or at an older age was effective in halting the progression and reducing the AD-like neuropathological hallmarks: $\mathrm{A} \beta$ plaques, neurofibrillary tangle-like structures, activated astrocytes, and neuroinflammation. The success of the formulation compared to the non nanotechnological approach would reside in the codelivery of sphingosine-1phosphate to stimulate an anti-inflammatory reaction and act as a neuronal regenerating agent in in vitro and in vivo studies. In spite of the promising results to our knowledge the vaccine is not under clinical trials yet.

This kind of inflammatory reaction was not addressed by Songjiang et al., who used chitosan nanocarriers for delivering $A \beta$ antigen to the brain [206].

ACI-24 is another liposome vaccine that was also designed to elicit an antibody response against aggregated A $\beta$ peptides [207-209]. This vaccine consists of tetrapalmitoylated preparations of $\mathrm{N}$-terminal $\mathrm{A} \beta$ fragments, which rapidly stimulate anti-A $\beta$ antibodies that dissolve $\mathrm{A} \beta$ fibers in vitro and in vivo (Figure 9). Pro-inflammatory $\mathrm{T}$ cell activation is prevented by using the truncated $A \beta-15$ sequence, thus lacking $\mathrm{T}$-cell epitopes located closer to the peptide's C-terminus. Each A $\beta 1-15$ sequence was functionalized with palmitoylated lysines at either end, so that it was anchored into the surface of liposomes in such a way that the peptides adopted an aggregated $\beta$-sheet structure, forming a conformational epitope. When PEG fragments were used as spacers between the liposome and the $A \beta 1-15$ sequence, its conformation was changed and the efficacy of the vaccine was compromised (ACI-01 in Figure 9). For preclinical studies ACI-24 was repeatedly subcutaneously injected together with the adjuvant monophosphoryl lipid A (MPLA) into APPxPS-1 transgenic mice and into cynomolgus monkeys. The treatment generated high titers, which involve a non-inflammatory Th2 helper cell response. The concentration of insoluble A $\beta 40$ and 42 and of soluble A $\beta 42$ decreased after a three-month treatment study in APPxPS-1 mice. Interestingly it also improved novel object recognition while causing neither gliosis nor increases in measures of pro-inflammatory cytokines. ACI-24 is being currently evaluated for the treatment of Alzheimer's disease in Down's syndrome, a genetic condition that leads to brain $\mathrm{A} \beta$ deposition and dementia in mid-life [210]. 
Table 4. Targeted nanoparticles aiming at neurofibrillary tangles reduction as a treatment against AD.

\begin{tabular}{|c|c|c|c|c|c|c|c|c|c|}
\hline & $\begin{array}{l}\text { Type of } \\
\text { carrier }\end{array}$ & Composition & $\begin{array}{l}\text { Size } \\
(\mathbf{n m})\end{array}$ & $\begin{array}{c}\text { Route } \\
\text { administ. }\end{array}$ & $\begin{array}{c}\text { Ligand } \\
\text { BBB }\end{array}$ & $\begin{array}{c}\text { Ligand } \\
\text { AD target }\end{array}$ & Drug loaded & Function & Ref. \\
\hline 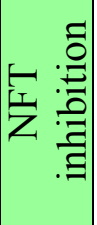 & $\begin{array}{c}\text { Alas } \\
\text { Dendrigraf } \\
\text { polymer* }\end{array}$ & DGL-PEG & $95-110$ & i.v. & $\begin{array}{c}\text { Peptide } \\
\text { (RVG29) }\end{array}$ & $\begin{array}{l}\text { Peptide } \\
\text { (RVG29) }\end{array}$ & $\begin{array}{c}\text { pshBACE1-AS*, } \\
\text { Peptide } \\
\text { (D-Pep)** }\end{array}$ & $\begin{array}{l}\text { Downregulation } \\
\text { of BACE1 level } \\
\text { inhibition of } \\
\text { phosphorylated- } \\
\text { tau related fibril }\end{array}$ & [197] \\
\hline 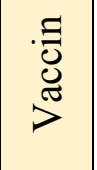 & Liposome & $\begin{array}{l}\text { DMPC, } \\
\text { DMPG, CH, } \\
\text { MLPA }\end{array}$ & & s.c. & - & - & $\begin{array}{c}\text { Peptide } \\
\text { (tau-fragment) }\end{array}$ & $\begin{array}{l}\text { Immunotherapy } \\
\text { (Tau) }\end{array}$ & [213] \\
\hline
\end{tabular}

* The drug carrier was formed by several DGL-PEG particles surrounding the pshBACE1-AS by electrostatic interactions. ** D-Pep was actually grafted onto DGL-PEG. LEGEND. Composition. DGL-PEG: PEGylated dendrigraft poly-L-lysine. DMPC: Dimyristoylphosphatidylcholine. DMPG: dimyristoylphosphatidyl glycerol. CH: cholesterol. MLPA: Monophosphoryl lipid A. S1P: D-erythro-sphingosine-1-phosphate. Routes of administration. i.v.: intravenous injection. s.c.: subcutaneous injection. Drug loaded: pshBACE1-AS: Plasmid encoding a short hairpin RNA against BACE1 antisense, a natural antisense transcript non-coding RNA that regulates BACE1 expression. D-Pep: all D amino-acid peptide inhibitor of tau fibril formation (sequence: DTLKIVW). Tau-fragment: tetrapalmitoylated 16-mer synthetic peptide corresponding to human protein Tau sequence 393-408, with phosphorylated residues S396 and S404.

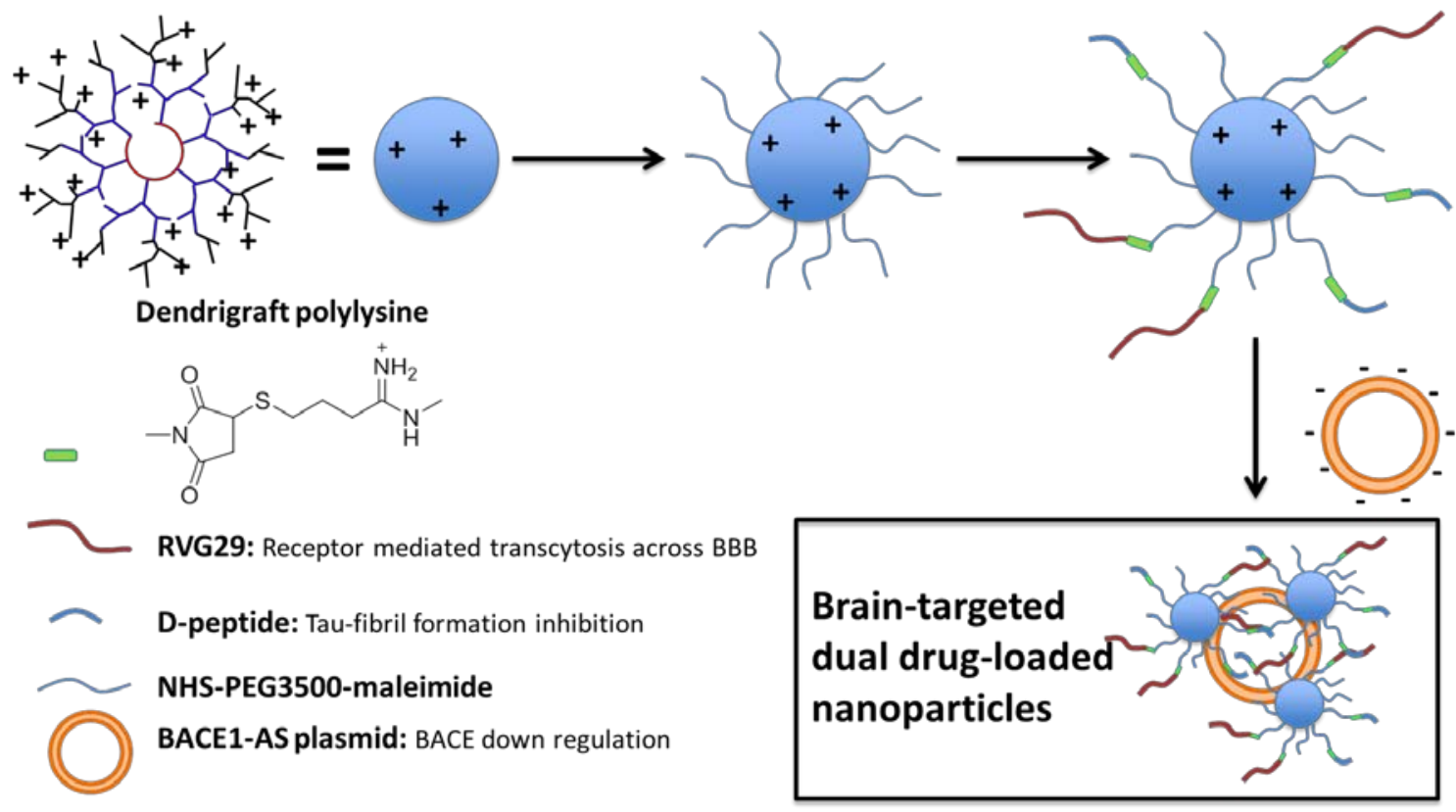

Figure 10. Dual drug -loaded nanoparticles reported by Liu et al. Polyamine, dendrigraft polylysine, is first reacted with NHSPEG3500-maleimide chains. The maleimide groups are then used for further functionalization with two functional peptides RVG29 and a D-peptide. Finally, the polycationic nature of polylysine at physiological $\mathrm{pH}$ is used for the electrostatic interaction with a plasmid [197].

\subsection{Inhibition of tau protein aggregation}

In spite of being another major lesion in $\mathrm{AD}$, less therapeutic attention has been paid to intracellular fibrillary tangles, which also holds for nanotechnological approaches. Intracellular fibrillary tangles appear to be downstream to $\mathrm{A} \beta$ lesions [22], which has leaded to give more importance to $\mathrm{A} \beta$ aggregates. There are few reports on targeted nanoparticles against tau aggregation as shown in Table 4.
In an outstanding work of 2016, Liu et al. reported a multifunctional nanocarrier for therapeutic gene and peptide co-delivery treating the two main hallmarks of $\mathrm{AD}$ [197]: $\mathrm{A} \beta$ plaque deposition and inhibition of tau-related fibril formation. Dendrigraft polylysine was chosen as the vehicle for the double therapy. Part of the amine groups could be used for pegylation and covalent functionalization with thiol maleimide chemistry with RVG29 and a D-peptide (Figure 
10). The former was used to interact with acetylcholine receptor in the $\mathrm{BBB}$ and neurons for receptor mediated endocytosis. The latter is a peptide computer-designed to interact with tau-protein and break its oligomers [211]. The strategy against $\mathrm{A} \beta$ plaque deposition consisted of the down regulation of BACE by delivering a non-coding RNA plasmid already treated above. The plasmid interacts with the rest of amino groups of the dendrigraft polylysine via electrostatic interactions. Double fluorescence experiments with labeling of the plasmid and the D-peptide demonstrated that both therapeutic agents were internalized simultaneously by cells. There was some dissociation between the plasmid and the rest of the carrier after cellular uptake, which is a desired feature as the plasmid therapeutic action has to be exerted in the nucleus whereas the D-peptide has to work in the cytoplasm. In vivo experiments also with double labeling demonstrated that this system is able to deliver DNA and Dpeptide to the brain after intravenous administration, thanks to the targeting ability of RVG29 peptide. Administration to AD model mice (APP/PS1 transgenic mice) succeeded in downregulating BACE to levels comparable to nontransgenic mice. Tau-positive immunostaining experiments showed that nanoparticles with D-peptide modification produced a decrease in the tau positive signals, demonstrating that D-peptide played a role in disrupting the fibril formation in hippocampus [197].

\subsubsection{Anti-tau Vaccine}

Similar to amyloid related vaccine ACI-24, tau-related vaccine ACI-35 is a liposome-based vaccine that uses monophosphoryl lipid A (MPLA) as adjuvant. In this case the immune response is directed to pathological conformers of phosphorylated tau proteins. The vaccine consists of liposomes displaying 16 copies of a synthetic tau fragment that is phosphorylated at the protein's pathological phosphorylation residues S396 and S404. The design prevents autoimmune $\mathrm{B}$ cell or $\mathrm{T}$ cell responses against physiological forms of this important intracellular protein [208, 212].

The vaccine was successful in generating high titers of polyclonal IgG antibodies specifically directed against phosphorylated tau, rather than non-phosphorylated tau after a three-month regimen of subcutaneous ACI-35 injection in both wild-type C57BL/6 and P301L mutant tau transgenic mice. ACI-35 treatment increased retention of body weight, delayed onset of a clasping motor phenotype, and extended lifespan, but it did not improve endurance on a rotarod test. Inflammatory markers resulted negative in this preclinical study [213]. Phase 1b study was completed in 2015 and ACI-35 was licensed to Janssen the same year.

\subsection{Treatment of inflammation or oxidative stress}

As a result of the multifactorial and heterogeneous nature of $\mathrm{AD}$, compounds with multiple properties are very good candidates for the treatment. Curcumin is a molecule with diverse properties including antiinflammatory, antioxidant, antiproliferative, and antiangiogenic activities [191, 192], some of which can be very helpful for the treatment of AD patients. It is known to have anti-A $\beta$ and anti-tau hyperphosphorylation properties, as well as to regulate the secondary changes such as oxidative and inflammatory stress and cholesterol regulation [191-193]. Several approaches have been developed for the encapsulation of this drug, as it is hydrophobic and insoluble in water, which limits its bioavailability and its application.

Jaruszewski et al. synthesized nanovehicles carrying curcumin or dexamethasone complexed hydroxypropyl-betacyclodextran [214]. This complex was then encapsulated into chitosan modified with Magnevist $\AA$, a gadolinium-based MRI contrast agent, to obtain theragnosis agents. Thanks to the anti-A $\beta$ antibody grafted on the surface, these nanoparticles are capable of targeting the cerebrovascular amyloid deposit, and there, they were able to provide MRI and SPECT (single photon emission computed tomography) contrast and carry specific drugs to reduce de inflammation. The ability of the grafted nanovehicles to migrate towards the $\mathrm{BBB}$ endothelium was evaluated in vitro using a using quartz crystal microbalance with dissipation monitoring (QCM-D) technology, showing a 3-fold increase in comparison to the same nanoparticles without the antibody. Besides, they showed a higher binding and internalization to cells treated with $A \beta$, which is an indicative of their specificity. It was shown as well, that the antibody conjugated to the nanovehicles surface was important for the recognition and targeting of the particle, but the protonated chitosan chains were responsible for the internalization, as the antibody itself was not internalized in a high amount.

In a similar study conducted by Agyare et al., chitosan nanoparticles carrying the immunosupresant cyclosphosphamide, were modified with an anti-A $\beta$ antibody and Magnevist ${ }^{\circledR}$ [215]. In this specific case, the antibody was modified with putrescine, which has been shown to enhance the BBB permeability of nanoparticles. These nanoparticles were effective in targeting cerebrovascular amyloid in both in vivo and in vitro studies, using human microvascular endothelial cell monolayer (hCMEC/D3) and mice respectively, and providing contrast for imaging using MRI and single photon emission computed tomography. The nanovehicles reduced the production of pro-inflammatory cytokines by the $A \beta$ challenged $B B B$ endothelium in a more efficient way than the drug alone, which proved their efficacy. It was shown that model cells where able to uptake in a more efficient way the antibody linked to the nanoparticle than the antibody itself, which shows that the nanovehicle, and not the antibody, plays a major role in the internalization.

It can be concluded that these nanoparticles are able to detect amyloid accumulation, showing good contrast for MRI, and treating the disease by reducing the cytokine secretion. Curcumin has been encapsulated using other strategies. Marrache et al. synthesized polymeric nanoparticles with varying sizes from 80 to $410 \mathrm{~nm}$ diameter and different surface charges, blending poly(D,L-lactic-coglycolic acid)-block (PLGA-b)-poly(ethylene glycol) (PEG)triphenylphosphonium (TPP) polymer (PLGA-b- PEG-TPP) with PLGA-COOH or PLGA-b-PEG-OH [216]. TPP is a single terminal lipophilic triphenylphosphonium (TPP) cation, which is known to cross into the mitochondrial matrix space. Targeted nanoparticles show greater uptake by the mitochondria of the treated cells that the non-targeted nanoparticles, proving that PLGA-b- PEG-TPP is necessary for the targeting action. NPs with a larger size than $200 \mathrm{~nm}$, showed a higher immune response, which makes them 
unsuitable for the application. The in vitro survival evaluation of human neuroblastoma IMR-32 cells treated with $A \beta$ showed an effective neuroprotection with the targeted curcumin-loaded nanoparticles in comparison with free curcumin or non-targeted nanoparticles.

Table 5. Targeting nanoparticles with neuroprotective, antioxidant or anti-inflammatory properties for AD treatment.

\begin{tabular}{|c|c|c|c|c|c|c|c|c|}
\hline $\begin{array}{l}\text { Type of } \\
\text { carrier }\end{array}$ & Composition & $\begin{array}{l}\text { Size } \\
(\mathrm{nm})\end{array}$ & $\begin{array}{c}\text { Route } \\
\text { administ. }\end{array}$ & Ligand BBB & $\begin{array}{c}\text { Ligand AD } \\
\text { target }\end{array}$ & Drug loaded & function & Ref. \\
\hline & $\mathrm{CH}, \mathrm{PC}$ & $180-220$ & i.n. & - & - & $\begin{array}{c}\text { Tacrine } \\
\alpha \text {-tocopherol }\end{array}$ & $\begin{array}{l}\text { Acetylcholinesterase } \\
\text { inhibitor antioxidant }\end{array}$ & [224] \\
\hline & $\begin{array}{c}\text { SPC, CH, } \\
\text { DSPE-PEG }\end{array}$ & $60-75$ & i.v. & $\begin{array}{l}\text { Peptide } \\
\text { (RMP-7) }\end{array}$ & - & NGF & Neuroprotection & [223] \\
\hline & $\begin{array}{l}\text { DSPC, CH, } \\
\text { DSPE-PEG }\end{array}$ & $180-200$ & i.v. & $\begin{array}{c}\text { Protein } \\
\text { (transferrin) }\end{array}$ & - & $\alpha$-Mangostin & Neuroprotection & {$[221]$} \\
\hline Lipo & $\begin{array}{c}\text { PC, CH-OA, } \\
\text { GLY-OA, } \\
\text { S100-COOH }\end{array}$ & $75-170$ & i.v. & $\begin{array}{c}\text { Protein } \\
\text { (lactoferrin) }\end{array}$ & - & Curcumin & Neuroprotection & [218] \\
\hline \multirow{2}{*}{ Nanogel } & PVP, AA & $65-100$ & i.p. & $\begin{array}{l}\text { Protein } \\
\text { (insulin) }\end{array}$ & - & - & Neuroprotection & {$[220]$} \\
\hline & & & & & & & & \\
\hline \multirow{5}{*}{$\begin{array}{l}\text { Polymeric } \\
\text { nanosphere }\end{array}$} & PLGA & 150 & i.v. & $\begin{array}{c}\text { Antibody } \\
(\mathrm{OX} 26 \mathrm{Mab})\end{array}$ & - & SurR9-C84A & Neuroprotection & [222] \\
\hline & PLGA & $140-170$ & oral & Polysorbate & - & Estradiol & Neuroprotection & [219] \\
\hline & PLGA & $150-200$ & in vitro & $\begin{array}{l}\text { Peptide } \\
\text { (Tet-1) }\end{array}$ & $\begin{array}{l}\text { Peptide } \\
\text { (Tet-1) }\end{array}$ & Curcumin & $\begin{array}{c}\text { Antioxidant } \\
\text { Anti-A } \beta\end{array}$ & [217] \\
\hline & PLGA-b-PEG & $80-410$ & in vitro & - & TPP & Curcumin & $\begin{array}{l}\text { Antioxidant } \\
\text { Antiamyloid }\end{array}$ & [216] \\
\hline & PBCA & 200 & in vitro & $\begin{array}{l}\text { Protein } \\
\text { (ApoE3) }\end{array}$ & - & Curcumin & $\begin{array}{c}\text { Antioxidant } \\
\text { Anti-A } \beta\end{array}$ & {$[225]$} \\
\hline & Chitosan & $140-160$ & i.v. & - & $\begin{array}{l}\text { Antibody } \\
\text { (IgG4.1) }\end{array}$ & 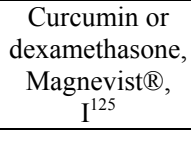 & $\begin{array}{c}\text { Antiinflammation } \\
\text { Diagnosis }\end{array}$ & [214] \\
\hline $\begin{array}{c}\text { Polymeric } \\
\text { nanocapsule }\end{array}$ & Chitosan & 240 & i.v. & $\begin{array}{l}\text { Antibody } \\
\text { (IgG4.1)* }\end{array}$ & $\begin{array}{l}\text { Antibody } \\
(\operatorname{IgG} 4.1)^{*}\end{array}$ & $\begin{array}{c}\text { CYC, } \\
\text { Magnevist }(\mathbb{2}, \\
\mathrm{I}^{125}\end{array}$ & $\begin{array}{c}\text { Antiinflammation } \\
\text { Diagnosis }\end{array}$ & {$[215]$} \\
\hline
\end{tabular}

LEGEND. Composition. CH: cholesterol. PC: phosphatidylcholine. SPC: Soybean phospholipids. DSPE-PEG: distearoyl-N-(monomethoxy polyethyleneglycol succinyl)phosphatidylethanolamine. DSPC: Distearoylphosphatidylcholine. CH-OA: cholesterol oleate. GLY-OA: glyceroltrioleate. S100- COOH: Carboxylated polyethylene glycol (100) monostearate. PVP: Poly(N-vinyl pyrrolidone). AA: Acrylic acid. PLGA: poly(lactic-co-glycolic acid). PLGA-bPEG: poly(D,L-lactic-co-glycolic acid)-block poly(ethylene glycol). PBCA: poly-n-butyl-cyanoacrylate. Routes of administration. i.n.:intranasal; i.p.: intraperitoneal. i.v.: intravenous. Ligands. RMP-7: cereport.. OX26Mab :mouse monoclonal transferrin receptor antibody. Tet-1: peptide sequence HLNILSTLWKYR. ApoE3: apolipoprotein E3. IgG4.1: anti-amyloid antibody, IgG4.1. IgG4.1*: F(ab')2 fragment of anti-amyloid antibody, IgG4.1 (pF(ab')24.1). TPP: Triphenylphosphonium (mitochondria). Drug loaded. SurR9-C84A: mutant survivin protein. CYC: cyclophosphamide. NGF: exogenous nerve growth factor.

Mathew and coworkers developed PLGA nanoparticles for the encapsulation of curcumin as well, but with a targeting moiety Tet-1 peptide [217]. This 12 amino acid peptide, that has similar binding characteristic to tetanus toxin, can interact specifically with motor neurons and is capable of retrograde delivery on the neuronal cells. The nanovehicles conserved the anti-oxidant property although they were not as potent as raw curcumin. It was shown that neither the targeted nor the non-targeted nanoparticles were toxic, but the uptake increased by multiple folds when they were targeted with Tet-1 peptide.

Besides PLGA and chitosan based nanoparticles, curcumin has also been encapsulated in nanostructured lipid carriers based on phosphatidyl choline, cholesterol oleate and glycerol trioleate) [218]. A carboxylated polyethyleneglycol monostearate was incorporated into the formulation in different ratios to provide the nanoparticles surface with negative charge to allow the ionic adsorption of lactoferrin as targeting agent to the brain. The targeted delivery capacity of the system was proved both in vitro and in vivo experiments. Ex vivo imaging experiments resulted in 2.78 times more accumulation of lactoferrin functionalized nanoparticles in the brain than of non-functionalized nanoparticles. Histopathological studies demonstrated the efficacy of the system in controlling the damage associated to AD.

Deprivation of endogenous estrogen after the menopause has been related as a risk factor for $\mathrm{AD}$ in post-menopausal women, and it is proven than women are two times more likely than men to suffer AD. Although the estrogen replacement therapy may reduce the risk of $\mathrm{AD}$, oral delivery is a non-specific route that potentiates the risk of peripheral adverse effects, such as breast cancer. Mittal et al. 
developed tween 80 coated polylactide-co-glycolide nanoparticles to deliver estradiol to the brain for oral administration [219]. Effectiveness was evaluated in an ovariectomized rat model of $\mathrm{AD}$ to mimic the postmenopausal conditions. Almost a 2-fold increase in the levels of brain estradiol was observed with oral administration of tween 80 coated nanoparticles in comparison with uncoated. Tween 80 coated nanoparticles are believed to cross the BBB by endocytosis, the absorption to apolipoprotein $\mathrm{E}$ and/or B mimics a natural low-density lipoprotein (LDL) that can interact with the LDL receptor in brain capillary endothelial cells. The coated nanoparticles successfully prevented the expression of $A \beta 42$ immunoreactivity in the hippocampus region of the brain, indicating their potential use for oral delivery.

Some studies have shown that insulin receptors are redistributed or decreased in number under $\mathrm{A} \beta$ stimulation, which relates insulin resistance and insulin action to $\mathrm{AD}$. As it has been demonstrated recently, insulin can reduce toxicity induced by $\mathrm{A} \beta$ oligomers, as it inhibits the intrinsic apoptotic pathway. Besides, its activation provides neuroprotection, since it prevents oxidative stress, mitochondrial damage and neurodegeneration, so administering it to the brain could be a possible treatment for the disease. Insulin encapsulation is the safest way of administration, as systemic delivery may produce hypoglycemia. Poly(N-vinyl pyrrolidone)-co-acrylic acid nanogels (NG) were produced and insulin was grafted onto the surface. It is demonstrated that the grafted insulin is capable of activate AKT signaling and the nanogel can be efficiently transported to across the BBB, protecting insulin from protease degradation, and overall, producing a neuroprotective effect against the damage induce by $A \beta$ [220].

Transferrin was very recently grafted onto liposomes amide coupling chemistry in order to cross the BBB. In this case, the cargo was alpha mangostin, a potential drug against $\mathrm{AD}$ due to its reported beneficial effect on the survival rate of cerebral cortical neurons against the $A \beta$ oligomer induced toxicity in rats. Remarkably high encapsulation efficiencies of $\geq 88 \%$ were observed. In vitro studies with bEnd 3 cells confirmed a preferential transport mediated by transferrin of the targeted liposomes, but also that clathrin might have participation. Consequently, in vivo studies with healthy SD rats showed higher accumulation of liposomes in the brain for the group to which transferrin grafted liposomes had been administered. Unfortunately no targeting efficiency was reported [221].

Sriramoju et al. used SurR9-C84A, a recombinant protein inhibiting apoptosis proteins, for therapy against $\mathrm{AD}$. The activity of SurR9-C84A can be apoptotic or mitotic depending on the basal levels of wild-type surviving. For the study SurR9-C84A was encapsulated in PLGA nanoparticles covalently functionalized with mouse monoclonal transferrin receptor antibody OX26. The internalization ability of the targeted nanoparticles was assessed in SK-N-SH, being successfully uptaken within $30 \mathrm{~min}$. Biodistribution studies also confirmed the enhanced brain specific permeation of anti-transferrin antibody conjugated SurR9-C84A containing nanoparticles which resulted a significant improvement against the D-Gal induced oxidative stress and in overcoming the behavioral compromises in the animal model [222].

A novel treatment for $\mathrm{AD}$ is the administration of exogenous nerve growth factor (NGF) to promote tropic responses in damaged neurons. However, NGF delivery across the BBB can be challenging upon intravenous administration. Xie et al. developed NGF loaded liposomes grafted with RMP-7, a ligand to the B2 receptor to cross the BBB [223]. RMP-7 was combined with 1,2-dioleoyl-sn-glycero-3phosphoethanolamine-n-[poly(ethyleneglycol)]-hydroxy succinamide (DSPE-PEG-NHS) to obtain DSPE-PEG-RMP7 , that was then incorporated into the liposomes. The results showed an enhanced transport of NGF across the BBB, especially when RPM-7 was incorporated in the liposome, although NGF loaded liposomes where capable of reaching the brain when they were administered together with free RPM-7. It is believed that RMP-7 and the liposomes could reach the BBB at the same time, and when the BBB was opened, the nanoparticles could be transported into the brain.

Finally, Corace et al. suggested a combined therapy for AD targeting via intranasal administration [224]. Tacrine, a traditional acetylcholinesterase inhibitor, was encapsulated in liposomes partly enriched with $\alpha$-tocopherol, which among other benefits delivered antioxidant and neuroprotective effect. The liposomal formulation enhanced the mucoadhesion, and the permeability both across phospholipid vesicle-based barrier and sheep nasal mucosa. Furthermore, the effect of the formulation on neuronal viability and intracellular ROS production was evaluated as well as their cytoprotective effect against oxidative stress.

\section{CONCLUSIONS AND PERSPECTIVES}

An increasing number of researchers are taking a nanotechnological approach to face the challenges posed for developing a therapy against AD. Nanoparticles have been used for extending the circulation time and stability of drugs already for decades.

In recent years, nanoparticles have been applied to improve the permeation of drugs through the $\mathrm{BBB}$, especially for large molecules. For this task the multivalency of nanoparticles has proven to be crucial, allowing for the functionalization of the nanoparticles with several kinds of targeting groups, that often are needed for penetrating the BBB and targeting the area of treatment. With this approach the most invasive administration routes would be avoided favoring the intravenous administration or eventually oral administration. Nevertheless, biodistribution studies still show very low targeting efficiency to the CNS and most of the drug and targeting agents are at the best lost and excreted. Yet, the low targeting efficiency is comparable to lower molecular weight systems. Moreover, the toxicity in the mid- and long-term of the nanoparticles that are to be administered against a chronic disease is still overlooked and poorly investigated. Thoroughly studies should be undertaken on this issue.

For this reason researchers are already actively investigating alternative routes of administration that allow bypassing the $\mathrm{BBB}$, being intranasal drug delivery one of the most promising ones. In this approach, nanotechnology can 
also open new opportunities, especially with the use of liposomes and mucoadhesive polymeric nanoparticles. Reports on the bioavailability after intranasal administration of encapsulated drugs improve those obtained with intravenous administration and active targeting through BBB. However it is not possible to do any fair comparison provided the diversity of approaches (encapsulated drugs, nanocarrier nature) and experimental conditions. Research on nanocarriers for treatment of $\mathrm{AD}$ following intranasal administration is unarguably increasing and is expected to undergo a great acceleration in the following years.

During the last decades, the search for a cure of $\mathrm{AD}$, also from the nanotechnological point of view, has been prominently based on amyloid cascade hypothesis, which is currently under question. At the moment $\mathrm{AD}$ is still not well understood and could be described as a multifactorial disease. For this reason combined therapies will probably be needed for a successful treatment. Multivalency places nanotechnological platforms in a good position to give support to this kind of approach. Several examples have been reported that successfully address a set of pathological aspects of $\mathrm{AD}$.

Additionally multivalency opens the opportunity to a therasnotic approach, in which therapy will be combined with diagnosis in the same platform, thus allowing less invasive monitoring of the illness progress.

Nanomedicines, although far to be used as an effective $\mathrm{AD}$ treatment, are promising candidates to overcome all the biological barriers that make AD one of the more worrisome diseases nowadays. More research, combining a better design of "smart nanomaterials" and better in vitro and in vivo model systems will help to neurologists to fight against $\mathrm{AD}$ in the near future.

\section{LIST OF ABBREVIATIONS}

If abbreviations are used in the text either they should be defined in the text where first used, or a list of abbreviations can be provided.

\section{CONFLICT OF INTEREST}

The authors confirm that this article content has no conflict of interest.

\section{ACKNOWLEDGEMENTS}

Financial support by "Fundación BBVA" and "Diputación General de Aragón" (E93) is acknowledged. L.G. and R.M.-R. thank the Spanish Ministerio de Economía y Competitividad for their contracts under the "Ramón y Cajal" subprogram (RYC-2014-15512 and RYC-201312570). S.G.-E. acknowledges "Fundación INA" for a grant. A.A. thanks European Union for financial support with a Marie Curie Fellowship (H2020-MSCA-IF-2014-657566).

\section{REFERENCES}

\section{Journal Reference}

If the number of authors exceeds six then et al. will be used after three names (the term "et al." should be in italics.)"
[1] Alzheimer's Association. 2016 Alzheimer's Disease Facts and Figures. Alzheimer's \& Dementia 2016;12(4). Page 26. Available from: http://www.alz.org/documents custom/2016-facts-and-figures.pdf Accessed October 3, 2016.

[2] Xu JQ, Murphy SL, Kochanek KD, Bastian BA. Deaths: Final data for 2013. National vital statistics reports; vol 64 no 2. Hyattsville, MD: National Center for Health Statistics. 2016. Available from: http://www.cdc.gov/nchs/data/nvsr/nvsr64/nvsr64 02.pdf $\quad$ Accessed October 3, 2016.

[3] World Health Organization. Dementia: a public health priority. Geneva: World Health Organization, 2012. ISBN 978-92-4-156445-8.

[4] Alzheimer's Disease International. World Alzheimer Report 2015. London: Alzheimer's Disease International, 2015. Available from: http://www.alz.co.uk/research/world-report

[5] Laks J, Goren A, Dueñas H, Novick D, Kahle-Wrobleski K. Caregiving for patients with Alzheimer's disease or dementia and its association with psychiatric and clinical comorbidities and other health outcomes in Brazil. Int J Geriatr Psychiatry 2016; 31(2): 176-85.

[6] Alzheimer A. Über eine eigenartige Erkrankung der Hirnrinde. Allgemeine Zeitschrift fur Psychiatrie und Psychisch-Gerichtlich Medizin 1907;64(1-2):146-148. (German)

[7] Blessed G, Tomlinson BE, Roth M. The Association Between Quantitative Measures of Dementia and of Senile Change in the Cerebral Grey Matter of Elderly Subjects. Br J Psychiatry 1968; 114(512): 797-811.

[8] Aalten P, Verhey FRJ, Boziki M, et al. Neuropsychiatric Syndromes in Dementia. Dement Geriatr Cogn Disord 2007; 24; 457-63.

[9] Zhao Q, Tan L, Wang H, Jiang T, Tan M, Tan L, et al. The prevalence of neuropsychiatric symptoms in Alzheimer's disease: Systematic review and meta-analysis. J Affect Disord [Internet]. Elsevier; 2016;190:264-71. Available from: http://dx.doi.org/10.1016/j.jad.2015.09.069

[10] Ertekin-Taner N. Genetics of Alzheimer's disease: a centennial review. Neurol Clin. 2007;25(3):611-67.

[11] Blacker D, Wilcox MA, Laird NM, Rodes L, Horvath SM, Go RCP, et al. Alpha-2 macroglobulin is genetically associated with Alzheimer disease. Nature. 1998;19:357-60.

[12] Marcello E, Gardoni F, Di Luca M. Alzheimer's disease and modern lifestyle: what is the role of stress? J Neurochem. 2015;134:795-8.

[13] Apter JT, Shastri K, Pizano K. Update on DiseaseModifying/Preventive Therapies in Alzheimer's Disease. Curr Geriatr Reports [Internet]. 2015;4(4):312-7. Available from: http://dx.doi.org/10.1007/s13670-015-0141-x

[14] Corder EH, Saunders AM, Strittmatter WJ, et al. Gene dose of apolipoprotein E type 4 allele and the risk of Alzheimer's disease in late onset families. Science 1993; 261(5123): 921-923.

[15] Dotti CG, Strooper B De. Alzheimer's dementia by circulation disorders : when trees hide the forest. Nat Cell Biol. 2009;11(2):114-6.

[16] Selkoe DJ. Alzheimer's Disease: Genes, Proteins, and Therapy. Neuron 2001;32:741-766.

[17] Ruozi B, Belletti D, Pederzoli F, Veratti P, Forni F, Vandelli MA, et al. Nanotechnology and Alzheimer's Disease: What has been Done and What to Do '. Curr Med Chem. 2014;21:4169-85. 
[18] Brunden KR, Trojanowski JQ, Lee VMY. Advances in tau-focused drug discovery for Alzheimer's disease and related tauopathies. Nat Rev Drug Discov. 2009;8:783-93.

[19] Herrup K. The case for rejecting the amyloid cascade hypothesis Nature Neuroscience 2015, 18(6), 794-99.

[20] Selkoe DJ. The molecular pathology of Alzheimer's disease. Neuron 1991, 6(4), 487-98.

[21] Hardy JA, Higgins GA. Alzheimer's disease: the amyloid cascade hypothesis. Science 1992, 256(5054), 184-185.

[22] Reitz C. Alzheimer's Disease and the Amyloid Cascade Hypothesis: A Critical Review. Int J Alzheimers Dis 2012:369808, 11 pages. Available from: https://www.hindawi.com/journals/ijad/2012/369808/

[23] Xu X. Gamma-secretase catalyzes sequential cleavages of the AbetaPP transmembrane domain. J Alzheimers Dis. 2009;16(2):211-24. Available from: $\quad$ http://content.iospress.com/articles/journal-of-alzheimersdisease/jad00957

[24] Marlow L, Cain M, Pappolla MA, Sambamurti K. $\beta$-Secretase Processing of the Alzheimer's Amyloid Protein Precursor (APP). 2003;20:233-9. Available from: http://link.springer.com/article/10.1385\%2FJMN\%3A20\%3A3\%3A233

[25] Zhang $\mathrm{Y}$, Thompson $\mathrm{R}$, Zhang $\mathrm{H}$, Xu H. APP processing in Alzheimer's disease. Brain. 2011;1-13. Available from: http://molecularbrain.biomedcentral.com/articles/10.1186/1756-6606-4-3

[26] Muller UC, Zheng H. Physiological Functions of APP Family Proteins. Cold Spring Harb Perspect Med. 2012 Feb; 2(2): a006288.

[27] Citron M. Alzheimer's disease: strategies for disease modification. Nat Rev Drug Discov [Internet]. Nature Publishing Group; 2010;9(5):387-98. Available from: http://dx.doi.org/10.1038/nrd2896

[28] Selkoe DJ, Hardy J. The amyloid hypothesis of Alzheimer's disease at 25 years. EMBO Mol Med [Internet]. 2016;8(6):1-14. Available from: http://www.ncbi.nlm.nih.gov/pubmed/27025652

[29] Yajima R, Tokutake T, Koyama A, Kasuga K, Tezuka T, Nishizawa $\mathrm{M}$, Ikeuchi T. ApoE-isoform-dependent cellular uptake of amyloid- $\beta$ is mediated by lipoprotein receptor LR11/SorLA. Biochem Biophys Res Commun. 2015 Jan 2;456(1):482-8. Available from: http://dx.doi.org/10.1016/j.bbrc.2014.11.111

[30] Namba Y, Tomonaga M, Kawasaki H, Otomo E, Ikeda K. Apolipoprotein $\mathrm{E}$ immunoreactivity in cerebral amyloid deposits and neurofibrillary tangles in Alzheimer's disease and kuru plaque amyloid in Creutzfeldt-Jakob disease. Brain Res. 1991;541:163-166.

[31] Strittmatter WJ, Weisgraber KH, Huang DY, Dong L-M, Salvesen GS, Pericak-Vance M, Schmechel D, Saunders AM, Goldgaber D, Roses AD. Binding of human apolipoprotein $E$ to synthetic amyloid $\beta$ peptide: Isoformspecific effects and implications for late-onset Alzheimer disease. Proc. Natl. Acad. Sci. USA 1993:90:8098-8102.

[32] Castellano JM, Kim J, Stewart FR, et al. Human ApoE isoforms differentially regulate brain amyloid- $\beta$ peptide clearance. Sci Transl Med. 2011; 3:89ra57.

[33] Kim J, Basak JM, Holtzman DM. The Role of Apolipoprotein E in Alzheimer's Disease. Neuron [Internet]. Elsevier Inc.; 2009;63(3):287-303. Available from: http://dx.doi.org/10.1016/j.neuron.2009.06.026
[34] Nixon RA, Cataldo AM, Mathews PM. The endosomal-lysosomal system of neurons in Alzheimer's disease pathogenesis: a review. Neurochem Res 2000;25:1161-72.

[35] Settembre C, Di Malta C, Polito VA, Garcia Arencibia M, Vetrini F, Erdin S, Erdin SU, Huynh T, Medina D, Colella P, Sardiello M, Rubinsztein DC, Ballabio A. TFEB links autophagy to lysosomal biogenesis. Science. 2011;332(6036):1429-33. Available from: http://science.sciencemag.org/content/332/6036/1429.long

[36] Xiao Q, Yan P, Ma X, Liu H, Perez R, Zhu A, et al. NeuronalTargeted TFEB Accelerates Lysosomal Degradation of APP, Reducing A $\beta$ Generation and Amyloid Plaque Pathogenesis. J Neurosci [Internet] 2015;35(35):12137-51. Available from: http://www.jneurosci.org/content/35/35/12137.long

[37] Gamblin TC. Potential structure/function relationships of predicted secondary structural elements of tau. Biochim Biophys Acta. 2005;1739:140-9.

[38] Kolarova M, García-Sierra F, Bartos A, Ricny J, Ripova D. Structure and Pathology of Tau Protein in Alzheimer Disease. Int J Alzheimers Dis. 2012;2012:Article ID 731526, 13 pages. .Available from: http://dx.doi.org/10.1155/2012/731526

[39] Wszolek ZK, Tsuboi Y, Ghetti B, Pickering-Brown S, Baba Y, Cheshire WP. Frontotemporal dementia and parkinsonism linked to chromosome 17 (FTDP-17). Orphanet J Rare Dis. 2006:1:30. Available from Available from: http://www.OJRD.com/content/1/1/30

[40] Alonso AdelC, Mederlyova A, Novak M, Grundke-Iqbal I, Iqbal K. Promotion of Hyperphosphorylation by Frontotemporal Dementia Tau Mutations. J Biol Chem. 2004 Aug 13;279(33):34873-81.

[41] Bamburg JR, Bloom GS. Cytoskeletal Pathologies of Alzheimer Disease Cell Motil Cytoskeleton. 2009 Aug;66(8):635-49. doi: $10.1002 / \mathrm{cm} .20388$

[42] Balaraman Y, Limaye AR, Levey AI, Srinivasan S. Glycogen synthase kinase $3 \beta$ and Alzheimer's disease: Pathophysiological and therapeutic significance. Cell Mol Life Sci. 2006;63(11):1226-35.

[43] Hernandez F, Avila J. Tauopathies. Cell Mol Life Sci 2007;64: $2219 \mathrm{e} 33$.

[44] Liu Y, Huang R, Jiang C. Non-viral Gene Delivery and Therapeutics Targeting to Brain. Curr Nanosci. 2011;7(1):55-70.

[45] Chen Y, Liu L. Modern methods for delivery of drugs across the blood - brain barrier. Adv Drug Deliv Rev [Internet]. Elsevier B.V.; 2012;64(7):640-65. Available from: http://dx.doi.org/10.1016/j.addr.2011.11.010

[46] Zlokovic B V. Neurovascular mechanisms of Alzheimer's neurodegeneration. TRENDS Neurosci. 2005;28(4):202-8.

[47] Deane R, Wu Z, Zlokovic BV. RAGE (yin) versus LRP (yang) balance regulates Alzheimer amyloid $\beta$-peptide clearance through transport across the blood-brain barrier. Stroke 2004;35(11 Suppl 1):2628-31.

[48] Deane R, Wu Z, Sagare A, Davis J, Yan S Du, Hamm K, et al. LRP / Amyloid $\beta$-Peptide Interaction Mediates Differential Brain Efflux of $A \beta$ Isoforms. Neuron. 2004;43:333-44.

[49] Lue LF, Walker DG, Brachova L, et al. Involvement of microglial receptor for advanced glycation endproducts (RAGE) in Alzheimer's disease: identification of a cellular activation mechanism. Provides evidence 
that $\mathrm{A} \beta$ and RAGE interaction in human microglia-mediated persistent inflammatory response in AD. Exp. Neurol 2001;171(1):29-45.

[50] Zlokovic B V. The Blood-Brain Barrier in Health and Chronic Neurodegenerative Disorders. Neuron. 2008;57:178-201.

[51] Lee G, Bendayan R. Functional expression and localization of Pglycoprotein in the central nervous system: relevance to the pathogenesis and treatment of neurological disorders. Pharm Res [Internet]. 2004;21(8):1313-30. Available from: http://link.springer.com/article/10.1023/B\%3APHAM.0000036905.82914.8

[52] Cirrito JR, Deane R, Fagan AM, Spinner ML, Parsadanian M, Finn $\mathrm{MB}$, et al. P-glycoprotein deficiency at the blood-brain barrier increases amyloid-beta deposition in an Alzheimer disease mouse model. J Clin Invest [Internet]. 2005;115(11):3285-90. Available from: http://www.pubmedcentral.nih.gov/articlerender.fcgi?artid=1257538\&tool= pmcentrez\&rendertype $=$ abstract

[53] Morris CM, Candy JM, Kerwin JM, Edwardson JA. Transferrin receptors in the normal human hippocampus and in Alzheimer's disease. NeuropatholApplNeurobiol. 1994;20(0305-1846):473-7.

[54] Ansari MA, Scheff SW. Oxidative Stress in the Progression of Alzheimer Disease in the Frontal Cortex. J. Neuropathol. Exp. Neurol.. 2010;69(2):155-67.

[55] Myung NH, Zhu X, Kruman II, Castellani RJ, Petersen RB, Siedlak SL, et al. Evidence of DNA damage in Alzheimer disease: Phosphorylation of histone H2AX in astrocytes. Age (Omaha). 2008;30(4):209-15.

[56] Zawia NH, Lahiri DK, Cardozo-Pelaez F. Epigenetics , oxidative stress, and Alzheimer disease. Free Radic Biol Med [Internet]. Elsevier Inc.; 2009;46(9):1241-9. Available from: http://dx.doi.org/10.1016/j.freeradbiomed.2009.02.006

[57] Cencioni C, Spallotta F, Martelli F, Valente S, Mai A. Oxidative Stress and Epigenetic Regulation in Ageing and Age-Related Diseases. Int J Mol Sci. 2013;17:643-63.

[58] Gella A, Durany N. Oxidative stress in Alzheimer disease. Cell Adh Migr. 2009;3(1):88-93.

[59] Sultana R, Perluigi M, Butterfield DA. Lipid peroxidation triggers neurodegeneration: A redox proteomics view into the Alzheimer disease brain. Free Radic Biol Med [Internet]. Elsevier; 2013;62:157-69. Available from: http://dx.doi.org/10.1016/j.freeradbiomed.2012.09.027

[60] Azari P, Pettigrew KD, Schapiro MB, Haxby J V, Grady CL, Pietrini $\mathrm{P}$, et al. Early Detection of Alzheimer's Disease : A Statistical Approach Using Positron Emission Tomographic Data. J Cereb Blood Flow Metab. $1993 ; 438-47$.

[61] Mastrogiacomo F, Bergeron C, Kish SJ. Brain $\alpha$-Ketoglutarate Dehydrogenase Complex Activity in Alzheimer's Disease. J Neurochem. 2007;61:2007-14.

[62] Sheu KR, Young-tai SG, Blass JP, Weksler ME. An Immunochemical Study of the Pyruvate Dehydrogenase Deficit in Alzheimer's Disease Brain. Ann Neurol. 1985;17:444-9.

[63] Di Mauro S, Schon EA. Mitochondrial Disorders in the Nervous System. Annu Rev Neurosci. 2008;31:91-123.
[64] Hirai K, Aliev G, Nunomura A, Fujioka H, Russell RL, Atwood CS, et al. Mitochondrial abnormalities in Alzheimer's disease. J Neurosci. 2001;21(9):3017-23.

[65] Baloyannis SJ. Mitochondrial alterations in Alzheimer's disease. J Alzheimers Dis. 2006;9(2):119-26.

[66] Sastre M, Klockgether T, Heneka MT. Contribution of inflammatory processes to Alzheimer's disease: Molecular mechanisms. Int J Dev Neurosci. 2006;24(2-3):167-76.

[67] Urrutia PJ, Mena NP, Núñez MT. The interplay between iron accumulation, mitochondrial dysfunction, and inflammation during the execution step of neurodegenerative disorders. Front Pharmacol. 2014;5 MAR(March):1-12.

[68] Calsolaro V, Edison P. Neuroinflammation in Alzheimer's disease: Current evidence and future directions. Alzheimers Dement [Internet]. Elsevier Inc.; 2016;12(6):719-32. Available from: http://dx.doi.org/10.1016/j.jalz.2016.02.010

[69] Heneka MT, Carson MJ, Khoury J El, Landreth GE, Brosseron F, Feinstein DL, et al. Neuroinflammation in Alzheimer's disease. Lancet Neurol. 2015;14(4):388-405.

[70] Shadfar S, Ju C, Lim HM, Neuroinflammation AÁBÁ. Involvement of inflammation in Alzheimer's disease pathogenesis and therapeutic potential of anti-inflammatory agents. Arch Pharm Res [Internet]. Pharmaceutical Society of Korea; 2015;38(12):2106-19. Available from: http://dx.doi.org/10.1007/s12272-015-0648-x

[71] $\mathrm{Xu} \mathrm{L,} \mathrm{He} \mathrm{D,} \mathrm{Bai} \mathrm{Y.} \mathrm{Microglia-Mediated} \mathrm{Inflammation} \mathrm{and}$ Neurodegenerative Disease. Mol Neurobiol [Internet]. 2015;1-7. Available from: http://dx.doi.org/10.1007/s12035-015-9593-4

[72] Nagele RG, D'Andrea MR, Lee H, Venkataraman V, Wang H-Y. Astrocytes accumulate A beta 42 and give rise to astrocytic amyloid plaques in Alzheimer disease brains. Brain Res. 2003;971:197-209.

[73] Prakash A, Dhaliwal GK, Kumar P, Majeed ABA. Brain Biometals and Alzheimer's Disease - Boon or Bane? Int $J$ Neurosci [Internet]. 2016;7454(April):1-34. Available from: http://www.tandfonline.com/doi/full/10.3109/00207454.2016.1174118

[74] Aaseth J, Alexander J, Bjørklund G, Hestad K, Dusek P, Roos PM, et al. Treatment strategies in Alzheimer's disease: a review with focus on selenium supplementation. Biometals [Internet]. Springer Netherlands; 2016;29(5):827-39. Available from: http://www.ncbi.nlm.nih.gov/pubmed/27530256

[75] Savelieff MG, Lee S, Liu Y, Lim MH. Untangling amyloid- $\beta$, tau, and metals in Alzheimer's disease. ACS Chem Biol. 2013;8(5):856-65.

[76] Jomova K, Vondrakova D, Lawson M, Valko M. Metals, oxidative stress and neurodegenerative disorders. Mol Cell Biochem. 2010;345(12):91-104.

[77] Breydo L, Uversky V. Role of metal ions in aggregation of intrinsically disordered proteins in neurodegenerative diseases. Metallomics [Internet]. 2011;3(11):1163-80. Available from: http://www.ncbi.nlm.nih.gov/pubmed/21869995\nhttp://pubs.rsc.org/en/cont ent/articlehtml $/ 2011 / \mathrm{mt} / \mathrm{c} 1 \mathrm{mt} 00106 \mathrm{j}$

[78] Bush AI, Pettingell WH, Paradis MTanzi RE. Modulation of A $\beta$ Adhesiveness and Secretase Site Cleavage by Zinc. J Biol Chem. 1994;269:12152-8. 
[79] Bush A, Pettingell WH, Multhaup G, Paradis M, Vonsattel J, Gusella $\mathrm{JF}$, et al. Rapid Induction of Alzheimer A $\beta$ Amyloid Formation by Zinc. Science. 1994;265:1464-67.

[80] Luczkowski M. "No screams and cries will convince us that white is white and black is black", an ode to the defenders of amyloid cascade hypothesis of Alzheimer's disease. Coord Chem Rev [Internet]. Elsevier B.V.; 2016;1-8. Available from: http://dx.doi.org/10.1016/j.ccr.2016.03.001

[81] Melnikova I. Therapies for Alzheimer's disease. Nat Rev. 2007;6(May 2007):341-2

[82] Coley N, Gallini A, Andrieu S. Prevention Studies in Alzheimer' s Disease: Progress Towards the Development of New Therapeutics. CNS Drugs [Internet]. Springer International Publishing; 2015;29(7):519-28. Available from: http://dx.doi.org/10.1007/s40263-015-0256-9

[83] Vassar R. BACE1 inhibitor drugs in clinical trials for Alzheimer's disease. Alzheimers Res Ther [Internet]. 2014;6(9):89. Available from: http://alzres.com/content/6/9/89

[84] Francis R, McGrath G, Zhang J, et al. aph-1 and pen-2 are required for Notch pathway signaling, gamma-secretase cleavage of betaAPP, and presenilin protein accumulation. Dev Cell. 2002;3(1):85-97.

[85] Goutte C, Tsunozaki M, Hale VA, Priess JR. APH-1 is a multipass membrane protein essential for the Notch signaling pathway in Caenorhabditis elegans embryos. Proc Natl Acad Sci U S A. 2002;99(2):775-9.

[86] Laske C. Phase 3 trials of solanezumab and bapineuzumab for Alzheimer's disease. N Engl J Med. 2014;370(15):1459.

[87] Toledo EM, Inestrosa NC. Activation of Wnt signaling by lithium and rosiglitazone reduced spatial memory impairment and neurodegeneration in brains of an APPswe/sol;PSEN1 $\Delta ; \mathrm{E} 9$ mouse model of Alzheimer\&apos;s disease. Mol Psychiatry [Internet]. Nature Publishing Group; 2009;15(3):272-85. Available from: http://www.nature.com/mp/journal/v15/n3/full/mp200972a.html

[88] Vargas JY, Fuenzalida M, Inestrosa NC. In vivo activation of Wnt signaling pathway enhances cognitive function of adult mice and reverses cognitive deficits in an Alzheimer's disease model. J Neurosci. 2014;34(6):2191-202. Available from: http://www.jneurosci.org/content/34/6/2191.full

[89] Wischik CM, Staff RT, Wischik DJ, Bentham P, Murray AD, Infirmary $\mathrm{R}$, et al. Tau Aggregation Inhibitor Therapy: An Exploratory Phase 2 Study in Mild or Moderate Alzheimer's Disease. J Alzehimer's Dis. 2015;44:705-20.

[90] Asuni AA, Boutajangout A, Quartermain D, Sigurdsson EM: Immunotherapy targeting pathological tau conformers in a tangle mouse model reduces brain pathology with associated functional improvements. J Neurosci 2007, 27:9115-29.

[91] Boutajangout A, Quartermain D, Sigurdsson EM: Immunotherapy targeting pathological tau prevents cognitive decline in a new tangle mouse model. J Neurosci 2010, 30:16559-66.

[92] Troquier L, Caillierez R, Burnouf S, et al. Targeting. Phospho-Ser422 by active Tau immunotherapy in the THYTau 22 mouse model: a suitable therapeutic approach. Curr Alzheimer Res 2012, 9:397-405.

[93] Götz J, Ittner A, Ittner LM. Tau-targeted treatment strategies in Alzheimer's disease. Br J Pharmacol. 2012;165(5):1246-59.
[94] Polito VA, Li H, Martini-Stoica H, et al. Selective clearance of aberrant tau proteins and rescue of neurotoxicity by transcription factor EB. EMBO Mol Med. 2014 Jul 28;6(9):1142-60. Available from: http://onlinelibrary.wiley.com/doi/10.15252/emmm.201303671/abstract

[95] Wang J, Tan L, Wang HF, et al. Anti-inflammatory drugs and risk of Alzheimer's disease: an updated systematic review and meta-analysis. J Alzheimers Dis. 2015;44(2):385-96. doi: 10.3233/JAD-141506

[96] Laske C, Sohrabi HR, Frost SM, López-De-Ipiña K, Garrard P, Buscema $\mathrm{M}$, et al. Innovative diagnostic tools for early detection of Alzheimer's disease. Alzheimer's Dement. 2015;11(5):561-78.

[97] Barchet TM, Amiji MM. Challenges and opportunities in CNS delivery of therapeutics for neurodegenerative diseases. Expert Opin Drug Deliv. 2009;6(3):211-25.

[98] Pardridge WM. Expert Review Drug Targeting to the Brain. Pharm Res. 2007;24(9):1733-44.

[99] Borlongan C V., Emerich DF. Facilitation of drug entry into the CNS via transient permeation of blood brain barrier: Laboratory and preliminary clinical evidence from bradykinin receptor agonist, Cereport. Brain Res Bull. 2003;60(3):297-306.

[100] Yan Q, Matheson C, Sun J, Radeke MJ, Feinstein SC, Miller J a. Distribution of intracerebral ventricularly administered neurotrophins in rat brain and its correlation with trk receptor expression. [Internet]. Vol. 127, Experimental neurology. 1994;127:23-36. Available from: http://dx.doi.org/10.1006/exnr.1994.1076

[101] Laxton AW, Stone S, Lozano AM. The neurosurgical treatment of alzheimer's disease: A review. Stereotact Funct Neurosurg. 2014;92(5):269-81.

[102] Gao H. Progress and perspectives on targeting nanoparticles for brain drug delivery. Acta Pharm Sin B [Internet]. Elsevier; 2016;6(4):268-86. Available

http://linkinghub.elsevier.com/retrieve/pii/S2211383516301186

[103] Lewis O, Woolley M, Johnson D, Rosser A, Barua NU, Bienemann AS, et al. Chronic, intermittent convection-enhanced delivery devices. J Neurosci Methods [Internet]. Elsevier B.V.; 2016;259:47-56. Available from: http://dx.doi.org/10.1016/j.jneumeth.2015.11.008

[104] Warnken ZN, Smyth HDC, Watts AB, Weitman S, Kuhn JG, Williams RO. Formulation and Device Design to Increase Nose to Brain Drug Delivery. J Drug Deliv Sci Technol [Internet]. Elsevier Ltd; 2016;35:213-22. Available from: http://linkinghub.elsevier.com/retrieve/pii/S1773224716301307

[105] Md S, Mustafa G, Baboota S, Ali J. Nanoneurotherapeutics approach intended for direct nose to brain delivery. Drug Dev Ind Pharm [Internet]. Informa Healthcare USA, Inc; 2015;41(12):1922-34. Available from: http://www.ncbi.nlm.nih.gov/pubmed/26057769

[106] Serralheiro A, Alves G, Fortuna A, Falcao A. Direct nose-to-brain delivery of lamotrigine following intranasal administration to mice. Int $\mathrm{J}$ Pharm [Internet]. Elsevier B.V.; 2015;490(1-2):39-46. Available from: http://dx.doi.org/10.1016/j.ijpharm.2015.05.021

[107] Pathan SA, Iqbal Z, Zaidi SMA, Talegaonkar S, Vohra D, Jain K, et al. CNS Drug Delivery Systems : Novel Approaches. Recent Patents Drug Deliv Formul. 2009;33:71-89.

[108] Assa F, Jafarizadeh-Malmiri H, Ajamein H, Anarjan N, Vaghari H, Sayyar Z, et al. A biotechnological perspective on the application of iron oxide nanoparticles. Nano Res. 2016;9(8):2203-25. 
[109] Bobo D, Robinson KJ, Islam J, Thurecht KJ, Corrie SR. Nanoparticle-Based Medicines: A Review of FDA-Approved Materials and Clinical Trials to Date. Pharm Res [Internet]. Pharmaceutical Research; 2016;33:2373-87. Available from: http://link.springer.com/10.1007/s11095$\underline{016-1958-5}$

[110] Mahmoodi NO, Ghavidast A, Amirmahani N. A comparative study on the nanoparticles for improved drug delivery systems. J Photochem Photobiol B Biol [Internet]. Elsevier B.V.; 2016;162:681-93. Available from: http://dx.doi.org/10.1016/j.jphotobiol.2016.07.037

[111] Das S, Carnicer-Lombarte A, Fawcett JW, Bora U. Bio-inspired nano tools for neuroscience. Prog Neurobiol [Internet]. Elsevier Ltd; 2016;142:122. Available from: http://dx.doi.org/10.1016/j.pneurobio.2016.04.008

[112] Lu A-H, Salabas EL, Schüth F. Magnetic Nanoparticles : Synthesis , Protection, Functionalization, and Application Angew Chemie Int Ed. 2007;46:1222-44.

[113] Roca AG, Costo R, Rebolledo AF, Tartaj P, Gonz T. Progress in the preparation of magnetic nanoparticles for applications in biomedicine. $\mathrm{J}$ Phys D Appl Phys. 2009;42.

[114] Mishra B, Patel BB, Tiwari S. Colloidal nanocarriers : a review on formulation technology, types and applications toward targeted drug delivery. Nanomedicine Nanotechnology, Biol Med [Internet]. Elsevier Inc.; 2010;6(1):9-24. Available from: http://dx.doi.org/10.1016/j.nano.2009.04.008

[115] Fratila RM, Rivera-Fernández S, De la Fuente JM. Shape matters: synthesis and biomedical applications of high aspect ratio magnetic nanomaterials. Nanoscale; 2015;7:8233-60.

[116] Li X, Wei J, Aifantis KE, Fan Y, Feng Q, Cui FZ, et al. Current investigations into magnetic nanoparticles for biomedical applications. J Biomed Mater Res - Part A. 2016;104(5):1285-96.

[117] Dilnawaz F, Sahoo SK. Therapeutic approaches of magnetic nanoparticles for the central nervous system. Drug Discov Today [Internet]. Elsevier Ltd; 2015;20(10):1256-64. Available from: http://dx.doi.org/10.1016/j.drudis.2015.06.008

[118] Jia H. The Influence of Extremely Low-Frequency Magnetic Field and Magnetic Nanoparticle on A $\beta 40$ Aggregation In Vitro. IEEE Trans Magn. 2015;51(11):5000805. Available from: http://ieeexplore.ieee.org/stamp/stamp.jsp?arnumber $=7114295$

[119] Salerno M, Domingo Porqueras DS. Alzheimer's disease: The use of contrast agents for magnetic resonance imaging to detect amyloid beta peptide inside the brain. Coord Chem Rev [Internet]. Elsevier B.V.; 2016; Available from: http://dx.doi.org/10.1016/j.ccr.2016.04.018

[120] Dreaden EC, Alkilany AM, Huang X, Murphy CJ, El-Sayed MA. The golden age: Gold nanoparticles for biomedicine. Chem Soc Rev 2012;41(7):2740-2779.

[121] Martinez JO, Brown BS, Nicolleta Q, Evangelopoulos M, Ferrari M, Tasciotti E. Multifunctional to multistage delivery systems : The evolution of nanoparticles for biomedical applications. Chinese Sci Bull. 2012;57(31):3961-71.

[122] Gao N, Sun H, Dong K, Ren J, Qu X. Gold-Nanoparticle-Based Multifunctional Amyloid- $\beta$ Inhibitor against Alzheimer' $s$ Disease. Chem Eur J. 2015;21:829-35.

[123] Yin T, Xie W, Sun J, Yang L, Liu J. Penetratin PeptideFunctionalized Gold Nanostars: Enhanced BBB Permeability and NIR Photothermal Treatment of Alzheimer's Disease Using Ultralow Irradiance.
ACS Appl Mater Interfaces [Internet]. 2016;8(30):19291-302. Available from: http://www.ncbi.nlm.nih.gov/pubmed/27411476

[124] Zhou Y, Dong H, Liu L, Xu M. Simple colorimetric detection of amyloid $\beta$-peptide (1-40) based on aggregation of gold nanoparticles in the presence of copper ions. Small. 2015;11(18):2144-9.

[125] Nday CM, Halevas E, Jackson GE, Salifoglou A. Quercetin encapsulation in modified silica nanoparticles : potential use against $\mathrm{Cu}$ (II) -induced oxidative stress in neurodegeneration. J Inorg Biochem [Internet] Elsevier Inc.; 2015;145:51-64. Available from: http://dx.doi.org/10.1016/j.jinorgbio.2015.01.001

[126] Gunawardena S. Nanoparticles in the Brain : A Potential Therapeutic System Targeted to an Early Defect Observed in Many Neurodegenerative Diseases. Pharm Res. 2013;30:2459-74.

[127] Allen TM, Cullis PR. Liposomal drug delivery systems: From concept to clinical applications. Adv Drug Deliv Rev [Internet]. Elsevier B.V.; 2013;65(1):36-48. Available from: http://dx.doi.org/10.1016/i.addr.2012.09.037

[128] Zhai Y, Zhai G. Advances in lipid-based colloid systems as drug carrier for topic delivery. J Control Release [Internet]. Elsevier B.V.; 2014;193:90-9. Available from: http://dx.doi.org/10.1016/j.jconrel.2014.05.054

[129] Lehner R, Wang X, Marsch S, Hunziker P. Intelligent nanomaterials for medicine : Carrier platforms and targeting strategies in the context of clinical application. Nanomedicine Nanotechnology, Biol Med [Internet]. Elsevier $\quad$ B.V.; 2013;9:742-57. Available from: http://dx.doi.org/10.1016/j.nano.2013.01.012

[130] Muralidharan P, Mallory E, Malapit M, Don Jr. H, Mansour HM. Inhalable PEGylated phospholipid nanocarriers and PEGylated therapeutics for respiratory delivery as aerosolized colloidal dispersions and dry powder inhalers. Pharmaceutics 2014;6(2):333-53.

[131] Tong-un T, Wannanon P, Wattanathorn J, Phachonpai W. Cognitiveenhancing and antioxidant activities of quercetin liposomes in animal model of Alzheimer' s disease. Online J Biol Sci. 2010;10(2):84-91.

[132] Li W, Zhou Y, Zhao N, Hao B, Wang X, Kong P. Pharmacokinetic behavior and efficiency of acetylcholinesterase inhibition in rat brain after intranasal administration of galanthamine hydrobromide loaded flexible liposomes. Environ Toxicol Pharmacol [Internet]. Elsevier B.V.; 2012;34(2):272-9. Available from: http://dx.doi.org/10.1016/i.etap.2012.04.012

[133] Mishra B, Patel BB, Tiwari S. Colloidal nanocarriers: a review on formulation technology, types and applications toward targeted drug delivery. Nanomedicine Nanotechnology, Biol Med [Internet]. Elsevier Inc.; 2010;6(1):9-24. Available from: http://dx.doi.org/10.1016/j.nano.2009.04.008

[134] Shao K, Zhang Y, Ding N, Huang S, Wu J, Li J, et al. Functionalized Nanoscale Micelles with Brain Targeting Ability and Intercellular Microenvironment Biosensitivity for Anti-Intracranial Infection Applications. Adv Healthc Mater. 2014;4(2):291-300.

[135] Hagl S, Kocher A, Schiborr C, Kolesova N, Frank J, Eckert GP. Curcumin micelles improve mitochondrial function in neuronal PC12 cells and brains of NMRI mice e Impact on bioavailability. Neurochem Int [Internet]. Elsevier Ltd; 2015;89:234-42. Available from: http://dx.doi.org/10.1016/i.neuint.2015.07.026

[136] Cacciatore I, Ciulla M, Fornasari E, Marinelli L, Di Stefano A. Solid lipid nanoparticles as a drug delivery system for the treatment of 
neurodegenerative diseases. Expert Opin Drug Deliv [Internet]. 2016;13(8):1121-31. Available from: http://www.tandfonline.com/doi/full/10.1080/17425247.2016.1178237

[137] Elsabahy M, Wooley KL. Nanomedicine themed issue. Chem Soc Rev. 2012;41(7):2545-61. Zhang H, Zhai Y, Wang J, Zhai G. New progress and prospects: The application of nanogel in drug delivery. Mater Sci Eng C [Internet]. Elsevier B.V.; 2016;60:560-8. Available from: http://dx.doi.org/10.1016/j.msec.2015.11.041

[138] Tang Z, He C, Tian H, Ding J, Hsiao BS, Chu B, et al. Polymeric Nanostructured Materials for Biomedical Applications. Prog Polym Sci [Internet]. Elsevier Ltd; 2016;60:86-128. Available from: http://linkinghub.elsevier.com/retrieve/pii/S0079670016300338

[139] Swierczewska M, Han HS, Kim K, Park JH, Lee S. Polysaccharidebased nanoparticles for theranostic nanomedicine. Adv Drug Deliv Rev [Internet]. Elsevier B.V.; 2016;99:70-84. Available from: http://dx.doi.org/10.1016/j.addr.2015.11.015

[140] Vrignaud S, Benoit J, Saulnier P. Biomaterials Strategies for the nanoencapsulation of hydrophilic molecules in polymer-based nanoparticles. Biomaterials [Internet]. Elsevier Ltd; 2011;32(33):8593-604. Available from: http://dx.doi.org/10.1016/j.biomaterials.2011.07.057

[141] Zhang H, Zhai Y, Wang J, Zhai G. New progress and prospects : The application of nanogel in drug delivery. Mater Sci Eng C [Internet]. Elsevier B.V.; 2016;60:560-8. Available from: http://dx.doi.org/10.1016/j.msec.2015.11.041

[142] Ikeda K, Okada T, Sawada S, Akiyoshi K, Matsuzaki K. Inhibition of the formation of amyloid $\beta$-protein fibrils using biocompatible nanogels as artificial chaperones. FEBS Lett. 2006;580:6587-95.

[143] Chen X, Zhi F, Jia X, Zhang X, Ambardekar R, Meng Z. Enhanced brain targeting of curcumin by intranasal administration of a thermosensitive poloxamer hydrogel. J Pharm Pharmacol. 2013;65:807-16.

[144] Elnaggar YSR, Etman SM, Abdelmonsif DA, Abdallah OY. Intranasal Piperine-Loaded Chitosan Nanoparticles as Brain-Targeted Therapy in Alzheimer's Disease: Optimization, Biological Efficacy, and Potential Toxicity. J Pharm Sci [Internet]. Elsevier Masson SAS; 2015;104(10):3544-56. Available from: http://dx.doi.org/10.1002/jps.24557

[145] Hanafy AS, Farid RM, Helmy MW, ElGamal SS. Pharmacological, toxicological and neuronal localization assessment of galantamine/chitosan complex nanoparticles in rats: future potential contribution in Alzheimer's disease management. Drug Deliv. 2016;1-12.

[146] Mizrahy S, Peer D. Polysaccharides as building blocks for nanotherapeutics. Chem Soc Rev. 2012;41:2623-40.

[147] De Koker S, Hoogenboom R, G. De Geest B. Polymeric multilayer capsules for drug delivery. Chem Soc Rev. 2012;41:2867-84.

[148] Sriramoju B, Kanwar RK, Kanwar JR. Nanomedicine Based Nanoparticles for Neurological Disorders. Curr Med Chem. 2014;21:415468.

[149] Wasiak T, Marcinkowska M, Pieszynski I, Zablocka M. Cationic phosphorus dendrimers and therapy for Alzheimer's disease. New J Chem [Internet]. Royal Society of Chemistry; 2015;39:4852-9. Available from: http://dx.doi.org/10.1039/C5NJ00309A

[150] Siafaka P, Üstündağ Okur N, Karavas E, Bikiaris D. Surface Modified Multifunctional and Stimuli Responsive Nanoparticles for Drug Targeting: Current Status and Uses. Int $\mathrm{J}$ Mol Sci [Internet].
2016;17(9):1440. Available from: http://www.mdpi.com/14220067/17/9/1440

[151] Rabanel JM, Hildgen P, Banquy X. Assessment of PEG on polymeric particles surface, a key step in drug carrier translation. J Control Release [Internet]. Elsevier B.V.; 2014;185(1):71-87. Available from: http://dx.doi.org/10.1016/j.jconrel.2014.04.017

[152] Walkey CD, Chan WCW. Understanding and controlling the interaction of nanomaterials with proteins in a physiological environment. Chem Soc Rev. 2012;41:2780-99.

[153] Moros M, Mitchell SG, Grazú V, de la Fuente, JM. The fate of nanocarriers as nanomedicines in vivo: important considerations and biological barriers to overcome. Curr Med Chem. 2013;20:2759-78.

[154] Duncan R. Polymer therapeutics as nanomedicines: new perspectives. Curr Opin Biotechnol. 2011;22:492-501.

[155] Grazú V, Moros M. Nanocarriers as nanomedicines: Design Concepts and recent Advances. In: de la Fuente JM, Grazú V, Eds. Nanobiotechnology: inorganic nanoparticles vs organic nanoparticles. $1^{\text {st }}$ ed. Amsterdam : Elsevier 2012; pp 356-58.

[156] Salatin S, Maleki Dizaj S, Khosroushahi AY. Effect of the surface modification, size, and shape on cellular uptake of nanoparticles. Cell Biol Int [Internet]. 2015 Aug [cited 2016 Sep 27];39(8):881-90. Available from: http://www.ncbi.nlm.nih.gov/pubmed/25790433

[157] Subbiah R, Veerapandian M, Yun KS. Nanoparticles: Functionalization and Multifunctional Applications in Biomedical Sciences. Curr Med Chem. 2010;7:4559-77.

[158] Fratila RM, Mitchell SG, Pino P, Grazu V, de la Fuente J. Strategies for the Biofunctionalization of Gold and Iron Oxide Nanoparticles. Langmuir. 2014;30:15057-71.

[159] Zhang C, Wan X, Zheng X, Shao X, Liu Q, Zhang Q, et al. Dualfunctional nanoparticles targeting amyloid plaques in the brains of Alzheimer's disease mice. Biomaterials [Internet]. Elsevier Ltd; 2014;35(1):456-65. Available from: http://dx.doi.org/10.1016/j.biomaterials.2013.09.063

[160] Aubin-Tam M-E, Hamad-Schifferly K. Structure and function of nanoparticle - protein conjugates. Biomed Mater. 2008;034001.

[161] Puertas S, Moros M, Polo E, del Pino P, Guisán JM, Grazú V, et al. Taking Advantage of Unspecific Interactions to Produce Highly Active Conjugates. ACS Nano. 2011;5(6):4521-8.

[162] Amin ML, Joo JY, Yi DK, An SSA. Surface modification and local orientations of surface molecules in nanotherapeutics. J Control Release [Internet]. Elsevier B.V.; 2015;207:131-42. Available from: http://dx.doi.org/10.1016/j.jconrel.2015.04.017

[163] Sapsford KE, Algar WR, Berti L, et al. Functionalizing Nanoparticles with Biological Molecules: Developing Chemistries that Facilitate Nanotechnology. Chem. Rev. 2013;113:1904-2074.

[164] Salvati E, Re F, Sesana S, Cambianica I, Sancini G, Masserini M, et al. Liposomes functionalized to overcome the blood-brain barrier and to target amyloid- $\beta$ peptide: The chemical design affects the permeability across an in vitro model. Int J Nanomedicine. 2013;8:1749-58.

[165] Loureiro JA, Gomes B, Fricker G, Cardoso I, Ribeiro CA, Gaiteiro C, et al. Dual ligand immunoliposomes for drug delivery to the brain. Colloids 
Surfaces B Biointerfaces [Internet]. Elsevier B.V.; 2015;134:213-9. Available from: http://dx.doi.org/10.1016/j.colsurfb.2015.06.067

[166] Oesterling BM, Gulati A, Joshi MD. Nanocarrier-based approaches for treatment and detection of Alzheimer's disease. J Nanosci Nanotechnol [Internet]. 2014;14(1):137-56. Available from: http://www.ncbi.nlm.nih.gov/pubmed/24730256

[167] Wilson B, Samanta MK, Santhi K, Kumar KPS, Paramakrishnan N, Suresh B. Targeted delivery of tacrine into the brain with polysorbate 80coated poly(n-butylcyanoacrylate) nanoparticles. Eur J Pharm Biopharm. 2008;70(1):75-84.

[168] Wilson B, Samanta MK, Santhi K, Kumar KPS, Paramakrishnan N, Suresh B. Poly(n-butylcyanoacrylate) nanoparticles coated with polysorbate 80 for the targeted delivery of rivastigmine into the brain to treat Alzheimer's disease. Brain Res. 2008;1200:159-68.

[169] Wilson B, Samanta MK, Santhi K, Kumar KPS, Ramasamy M, Suresh B. Significant delivery of tacrine into the brain using magnetic chitosan microparticles for treating Alzheimer's disease. J Neurosci Methods. 2009;177(2):427-33.

[170] Mourtas S, Canovi M, Zona C, Aurilia D, Niarakis A, La Ferla B, et al. Curcumin-decorated nanoliposomes with very high affinity for amyloidß1-42 peptide. Biomaterials [Internet]. Elsevier Ltd; 2011;32(6):1635-45. Available from: http://dx.doi.org/10.1016/j.biomaterials.2010.10.027

[171] Taylor M, Moore S, Mourtas S, Niarakis A, Re F, Zona C, et al. Effect of curcumin-associated and lipid ligand-functionalized nanoliposomes on aggregation of the Alzheimer's A $\beta$ peptide. Nanomedicine Nanotechnology, Biol Med [Internet]. Elsevier Inc.; 2011;7(5):541-50. Available from: http://dx.doi.org/10.1016/j.nano.2011.06.015

[172] Lazar AN, Mourtas S, Youssef I, Parizot C, Dauphin A, Delatour B, et al. Curcumin-conjugated nanoliposomes with high affinity for $\mathrm{A} \beta$ deposits: Possible applications to Alzheimer disease. Nanomedicine Nanotechnology, Biol Med [Internet]. Elsevier Inc.; 2013;9(5):712-21. Available from: http://dx.doi.org/10.1016/j.nano.2012.11.004

[173] Markoutsa E, Mourtas S, Bereczki E, Zona C, Ferla B La, Nicotra F, et al. Comparison of Various Types of Ligand Decorated Nanoliposomes for their Ability to Inhibit Amyloid Aggregation and to Reverse Amyloid Cytotoxicity. 2015;2267-76.

[174] Gobbi M, Re F, Canovi M, Beeg M, Gregori M, Sesana S, et al. Lipid-based nanoparticles with high binding affinity for amyloid- $\beta 1-42$ peptide. Biomaterials. Elsevier Ltd; 2010;31(25):6519-29.

[175] Re F, Cambianica I, Zona C, Sesana S, Gregori M, Rigolio R, et al. Functionalization of liposomes with ApoE-derived peptides at different density affects cellular uptake and drug transport across a blood-brain barrier model. Nanomedicine Nanotechnology, Biol Med [Internet]. Elsevier B.V.; 2011;7(5):551-9. Available from: http://dx.doi.org/10.1016/j.nano.2011.05.004

[176] Re F, Cambianica I, Sesana S, Salvati E, Cagnotto A, Salmona M, et al. Functionalization with ApoE-derived peptides enhances the interaction with brain capillary endothelial cells of nanoliposomes binding amyloidbeta peptide. J Biotechnol [Internet]. Elsevier B.V.; 2010;156(4):341-6. Available from: http://dx.doi.org/10.1016/j.jbiotec.2011.06.037

[177] Bana L, Minniti S, Salvati E, Sesana S, Zambelli V, Cagnotto A, et al. Liposomes bi-functionalized with phosphatidic acid and an ApoEderived peptide affect $A \beta$ aggregation features and cross the blood-brainbarrier: Implications for therapy of Alzheimer disease. Nanomedicine Nanotechnology, Biol Med [Internet]. Elsevier Inc.; 2014;10(7):1583-90. Available from: http://dx.doi.org/10.1016/j.nano.2013.12.001
[178] Balducci C, Mancini S, Minniti S, La Vitola P, Zotti M, Sancini G, et al. Multifunctional Liposomes Reduce Brain-Amyloid Burden and Ameliorate Memory Impairment in Alzheimer's Disease Mouse Models. J Neurosci [Internet]. 2014;34(42):14022-31. Available from: http://www.jneurosci.org/cgi/doi/10.1523/JNEUROSCI.0284-14.2014

[179] Nardo L, Re F, Brioschi S, Cazzaniga E, Orlando A, Minniti S, et al. Fluorimetric detection of the earliest events in amyloid $\beta$ oligomerization and its inhibition by pharmacologically active liposomes. Biochim Biophys Acta - Gen Subj [Internet]. Elsevier B.V.; 2016;1860(4):746-56. Available from: http://dx.doi.org/10.1016/j.bbagen.2016.01.003

[180] Markoutsa E, Pampalakis G, Niarakis A, Romero IA, Weksler B, Couraud PO, et al. Uptake and permeability studies of BBB-targeting immunoliposomes using the hCMEC/D3 cell line. Eur J Pharm Biopharm [Internet]. Elsevier B.V.; 2011;77(2):265-74. Available from: http://dx.doi.org/10.1016/j.ejpb.2010.11.015

[181] Markoutsa E, Papadia K, Clemente C, Flores O, Antimisiaris SG. Anti-A $\beta-\mathrm{MAb}$ and dually decorated nanoliposomes: Effect of $\mathrm{A} \beta 1-42$ peptides on interaction with hCMEC/D3 cells. Eur J Pharm Biopharm. Elsevier B.V.; 2012;81(1):49-56.

[182] Zhang C, Zheng X, Wan X, Shao X, Liu Q, Zhang Z, et al. The potential use of $\mathrm{H} 102$ peptide-loaded dual-functional nanoparticles in the treatment of Alzheimer's disease. J Control Release [Internet]. Elsevier B.V.; 2014;192:317-24. Available from: http://dx.doi.org/10.1016/j.jconrel.2014.07.050

[183] Bastus NG, Kogan MJ, Amigo R, Grillo-Bosch D, Araya E, Turiel A, et al. Gold nanoparticles for selective and remote heating of??-amyloid protein aggregates. Mater Sci Eng C. 2007;27(5-8 SPEC. ISS.):1236-40.

[184] Araya E, Olmedo I, Bastus NG, Guerrero S, Puntes VF, Giralt E, et al. Gold nanoparticles and microwave irradiation inhibit beta-amyloid amyloidogenesis. Nanoscale Res Lett. 2008;3(11):435-43.

[185] Prades R, Guerrero S, Araya E, Molina C, Salas E, Zurita E, et al. Delivery of gold nanoparticles to the brain by conjugation with a peptide that recognizes the transferrin receptor. Biomaterials. 2012;33(29):7194 205 .

[186] Song Q, Huang M, Yao L, Wang X, Gu X, Chen J, et al. Lipoproteinbased nanoparticles rescue the memory loss of mice with Alzheimer's disease by accelerating the clearance of amyloid-beta. ACS Nano. 2014;8(3):2345-59.

[187] Tanifum EA, Dasgupta I, Srivastava M, Bhavane RC, Sun L, Berridge $\mathrm{J}$, et al. Intravenous Delivery of Targeted Liposomes to Amyloid- $\beta$ Pathology in APP/PSEN1 Transgenic Mice. PLoS One. 2012;7(10), e48515.

[188] Xu C, Shi P, Li M, Ren J, Qu X. A cytotoxic amyloid oligomer selftriggered and NIR-enhanced amyloidosis therapeutic system. Nano Res. $2015 ; 8(7): 2431-44$

[189] Kumaraswamy P, Sethuraman S, Krishnan UM. Development of a dual nanocarrier system as a potential stratagem against amyloid-induced toxicity. Expert Opin Drug Deliv [Internet]. 2014;11(8):1131-47. Available from: $\quad$ http://www.scopus.com/inward/record.url?eid=2-s2.0$\underline{84904613059 \& \text { partnerID }=\text { tZOtx3y1 }}$

[190] Zheng X, Shao X, Zhang C, Tan Y, Liu Q, Wan X, et al. Intranasal H102 Peptide-Loaded Liposomes for Brain Delivery to Treat Alzheimer's Disease. Pharm Res (2015) 32:3837-3849.

[191] Hatcher H, Planalp R, Cho J, Torti FM, Torti S V. Curcumin: From ancient medicine to current clinical trials. Cell Mol Life Sci. 2008;65(11):1631-52. 
[192] Maheshwari RK, Singh AK, Gaddipati J, Srimal RC. Multiple biological activities of curcumin: A short review. Life Sci [Internet]. Elsevier B.V.; 2006;78(18):2081-7. Available from: http://dx.doi.org/10.1016/j.lfs.2005.12.007

[193] Hu S, Maiti P, Ma Q, Zuo X, Jones MR, Cole GM, et al. Clinical development of curcumin in neurodegenerative disease. Expert Rev Neurother [Internet]. Informa UK, Ltd; 2015;15(6):629-37. Available from: http://informahealthcare.com/doi/abs/10.1586/14737175.2015.1044981

[194] Banks WA, Drug delivery to the brain in Alzheimer's disease: consideration of the blood-brain barrier, Adv. Drug Deliv. Rev. Elsevier B.V.; 2012, 64, 629-639.

[195] Muntimadugu E, Dhommati R, Jain A, Challa VGS, Shaheen M, Khan W. Intranasal delivery of nanoparticle encapsulated tarenflurbil: A potential brain targeting strategy for Alzheimer's disease. Eur J Pharm Sci. 2016;92:224-34. Available from:

http://dx.doi.org/10.1016/j.ejps.2016.05.012

[196] Imbimbo BP. Why did tarenflurbil fail in alzheimer's disease? J Alzheimer's Dis. 2009;17(4):757-60.

[197] Liu Y, An S, Li J, Kuang Y, He X, Guo Y, et al. Brain-targeted codelivery of therapeutic gene and peptide by multifunctional nanoparticles in Alzheimer's disease mice. Biomaterials. 2016;80:33-45. Available from: http://dx.doi.org/10.1016/j.biomaterials.2015.11.060

[198] Alvarez-Erviti L, Seow Y, Yin H, Betts C, Lakhal S, Wood MJA. Delivery of siRNA to the mouse brain by systemic injection of targeted exosomes. Nat Biotechnol [Internet]. Nature Publishing Group; 2011;29(4):341-5. Available from: http://dx.doi.org/10.1038/nbt.1807

[199] Park TE, Singh B, Li H, Lee JY, Kang SK, Choi YJ, et al. Enhanced BBB permeability of osmotically active poly(mannitol-co-PEI) modified with rabies virus glycoprotein via selective stimulation of caveolar endocytosis for RNAi therapeutics in Alzheimer's disease. Biomaterials [Internet]. Elsevier Ltd; 2015;38:61-71. Available from: http://dx.doi.org/10.1016/j.biomaterials.2014.10.068

[200] Tamaru M, Akita H, Nakatani T, Kajimoto K, Sato Y, Hatakeyama $\mathrm{H}$, et al. Application of apolipoprotein E-modified liposomal nanoparticles as a carrier for delivering DNA and nucleic acid in the brain. Int $\mathbf{J}$ Nanomedicine [Internet]. 2014;(9):4267-76. Available from: http://hdl.handle.net/2115/57260

[201] Querfurth, HW, LaFerla FM. Alzheimer's disease. N. Engl. J. Med. $2010,362,329-344$.

[202] Orgogozo JM, Gilman S, Dartigues JF Laurent B, Puel M, Kirby LC, et al. Subacute meningoencephalitis in a subset of patients with AD after A $\beta 42$ immunization. Neurology. 2003;61(1):46-54.

[203] Carrera I, Etcheverría I, Fernández-Novoa L, Lombardi V, Cacabelos R, Vigo C. Vaccine development to treat alzheimer's disease neuropathology in APP/PS1 transgenic mice. Int $\mathrm{J}$ Alzheimers Dis. 2012;2012:Article ID 376138, 17 pages.

[204] Carrera I, Etcheverría I, Li Y, Fernández-Novoa L, Lombardi V, Vigo C, et al. Immunocytochemical Characterization of Alzheimer Disease Hallmarks in APP / PS1 Transgenic Mice Treated with a New AntiAmyloid- $\beta$ Vaccine. 2013;2013:Article ID 709145, 12 pages. Available from: http://dx.doi.org/10.1155/2013/709145

[205] Carrera I, Etcheverría I, Fernández-Novoa L, Ruggero V, Lombardi M, Lakshmana MK, et al. A Comparative Evaluation of a Novel Vaccine in APP / PS1 Mouse Models of Alzheimer's Disease. 2015;2015:Article ID 807146, 16 pages. Available from: http://dx.doi.org/10.1155/2015/807146
[206] Songjiang Z, Lixiang W. Amyloid-beta associated with chitosan nano-carrier has favorable immunogenicity and permeates the BBB. AAPS PharmSciTech [Internet]. 2009;10(3):900-5. Available from: http://www.pubmedcentral.nih.gov/articlerender.fcgi?artid=2802149\&tool= pmcentrez\&rendertype $=$ abstract

[207] Muhs A, Hickman DT, Pihlgren M, Chuard N, Giriens V, Meerschman $\mathrm{C}$, et al. Liposomal vaccines with conformation-specific amyloid peptide antigens define immune response and efficacy in APP transgenic mice. Proc Natl Acad Sci U S A. 2007;104:9810-5.

[208] Hickman DT, Lopez-Deber MP, Ndao DM, Silva AB, Nand D, Pihlgren $\mathrm{M}$, et al. Sequence-independent control of peptide conformation in liposomal vaccines for targeting protein misfolding diseases. J Biol Chem. 2011;286(16):13966-76.

[209] http://www.alzforum.org/therapeutics/aci-24 (cited $4^{\text {th }}$ October, 2016)

[210] Rafii MS. Improving Memory and Cognition in Individuals with Down Syndrome CNS Drugs. 2016. DOI 10.1007/s40263-016-0353-4

[211] Sievers SA, Karanicolas J, Chang HW, Zhao A, Jiang L, Zirafi O, et al. Structure-based design of non-natural amino-acid inhibitors of amyloid fibril formation. Nature [Internet]. 2011;475(7354):96-100. Available from: http://www.ncbi.nlm.nih.gov/pubmed/21677644\nhttp://www.pubmedcentra 1.nih.gov/articlerender.fcgi?artid=PMC4073670

[212] http://www.alzforum.org/therapeutics/aci-35 $\quad$ (cited $4^{\text {th }}$ October, 2016)

[213] Theunis C, Crespo-Biel N, Gafner V, Pihlgren M, López-Deber MP Reis $\mathrm{P}$, et al. Efficacy and safety of a liposome-based vaccine against protein Tau, assessed in Tau.P301L mice that model tauopathy. PLoS One. 2013;8(8):e72301

[214] Jaruszewski KM, Curran GL, Swaminathan SK, Rosenberg JT, Grant $\mathrm{SC}$, Ramakrishnan S, et al. Multimodal Nanoprobes to target cerebrovascular amyloid in Alzheimer's disease brain. Biomaterials [Internet]. Elsevier Ltd; 2014;35(6):1967-76. Available from http://dx.doi.org/10.1016/j.biomaterials.2013.10.075

[215] Agyare EK, Jaruszewski KM, Curran GL, Rosenberg JT, Grant SC, Lowe VJ, et al. Engineering theranostic nanovehicles capable of targeting cerebrovascular amyloid deposits. J Control Release [Internet]. Elsevier B.V.; 2014;185(1):121-9. Available from: http://dx.doi.org/10.1016/j.jconrel.2014.04.010

[216] Marrache S, Dhar S. Engineering of blended nanoparticle platform for delivery of mitochondria-acting therapeutics. Proc Natl Acad Sci U S A [Internet]. 2012;109(40):16288-93. Available from: http://www.pubmedcentral.nih.gov/articlerender.fcgi?artid=3479596\&tool= pmcentrez\&rendertype $=$ abstract

[217] Mathew A, Fukuda T, Nagaoka Y, Hasumura T, Morimoto $H$, Yoshida Y, et al. Curcumin loaded-PLGA nanoparticles conjugated with Tet-1 peptide for potential use in Alzheimer's disease. PLoS One. 2012;7(3):e32616

[218] Meng F, Asghar S, Gao S, Su Z, Song J, Huo M, et al. A novel LDLmimic nanocarrier for the targeted delivery of curcumin into the brain to treat Alzheimer's disease. Colloids Surf B Biointerfaces [Internet]. Elsevier B.V.; 2015;134:88-97. Available from: http://dx.doi.org/10.1016/j.colsurfb.2015.06.025

[219] Mittal G, Carswell H, Brett R, Currie S, Kumar MNVR Development and evaluation of polymer nanoparticles for oral delivery of estradiol to rat brain in a model of Alzheimer's pathology. J Control Release 
[Internet]. Elsevier B.V.; 2011;150(2):220-8. Available from: http://dx.doi.org/10.1016/j.jconrel.2010.11.013

[220] Picone P, Ditta LA, Sabatino MA, Militello V, San Biagio PL, Di Giacinto ML, et al. Ionizing radiation-engineered nanogels as insulin nanocarriers for the development of a new strategy for the treatment of Alzheimer's disease. Biomaterials [Internet]. Elsevier Ltd; 2016;80:179-94. Available from: http://dx.doi.org/10.1016/j.biomaterials.2015.11.057

[221] Chen ZL, Huang M, Wang XR, Fu J, Han M, Shen YQ, et al. Transferrin-modified liposome promotes $\alpha$-mangostin to penetrate the blood-brain barrier. Nanomedicine Nanotechnology, Biol Med [Internet]. Elsevier Inc.; 2015;12(2):421-30. Available from: http://dx.doi.org/10.1016/j.nano.2015.10.021

[222] Sriramoju B, Neerati P, Kanwar RK, Kanwar JR. Brain targeted PLGA nanocarriers alleviating amyloid- $\beta$ expression and preserving basal survivin in degenerating mice model. Biochim Biophys Acta - Mol Basis Dis [Internet]. Elsevier B.V.; 2015;1852(11):2423-31. Available from: http://dx.doi.org/10.1016/j.bbadis.2015.08.015
[223] Xie Y, Ye L, Zhang X, Cui W, Lou J, Nagai T, et al. Transport of nerve growth factor encapsulated into liposomes across the blood-brain barrier: In vitro and in vivo studies. J Control Release. 2005;105(1-2):10619.

[224] Corace G, Angeloni C, Malaguti M, Hrelia S, Stein PC, Brandl M, et al. Multifunctional liposomes for nasal delivery of the anti-Alzheimer drug tacrine hydrochloride. J Liposome Res [Internet]. 2014;24(4):323-35.

[225] Mulik RS, Mönkkönen J, Juvonen RO, Mahadik KR, Paradkar AR. ApoE3 Mediated Poly(butyl)Cyanoacrylate Nanoparticles Containing Curcumin: Study of Enhanced Activity of Curcumin against Beta Amyloid Induced Cytotoxicity Using In Vitro Cell Culture Model. Mol Pharm. 2010;7(3):815-25. 